\title{
Multi-objective stochastic closed-loop supply chain network design with social considerations
}

\author{
Amir Mohammad Fathollahi-Fard ${ }^{\mathrm{a}}$, Mostafa Hajiaghaei-Keshteli ${ }^{\mathrm{a}}$, Seyedali Mirjalilib*
}

${ }^{a}$ Department of Industrial Engineering, University of Science and Technology of Mazandaran, Behshahr, Iran

${ }^{b}$ Institute for Integrated and Intelligent Systems, Griffith University, Nathan, QLD 4111, Australia

* Corresponding author

E-mail addresses: amirfard@ mazust.ac.ir (Amir Mohammad Fathollahi-Fard), mostafahaji@ mazust.ac.ir (Mostafa Hajiaghaei-Keshteli), seyedali.mirjalili@griffithuni.edu.au (Seyedali Mirjalili)

Graphical abstract

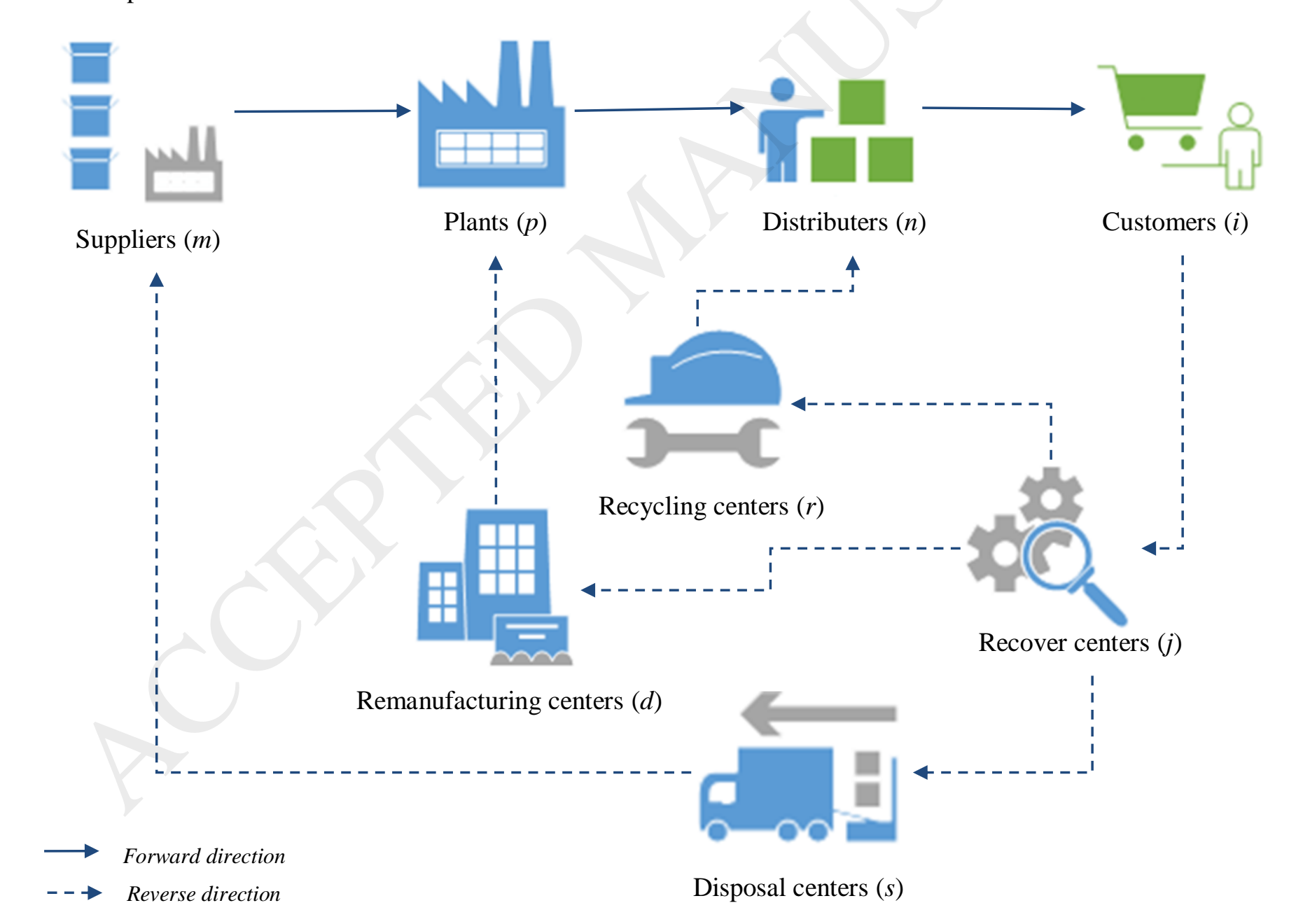

The graphical structure of a simple closed-loop supply chain network utilizing in this paper 


\title{
Highlights:
}

- Introducing a new multi-objective stochastic closed-loop supply chain network design with social considerations;

- Presenting a number of new hybrid metaheuristic algorithms to create a better interaction between the search phases;

- Comparison of developed approaches by a set of efficient evaluation metrics of Pareto optimal sets;

- Confirming the performance of proposed RDKAGA in practice;

\begin{abstract}
Nowadays, operation managers usually need efficient supply chain networks including important design factors such as economic and social considerations. The recent decade has seen a rapid development of controlling the uncertainty in supply chain configurations along with proposing novel solution approaches. By investigating the related studies, this paper shows that most of the current studies consider the economic aspects and just a few works present the two-stage stochastic programming as well as social considerations to design a closed-loop supply chain network. This motivated our attempts to consider economic and social aspects simultaneously by using the mentioned suppositions among the first studies. Another main contribution of this paper is the hybridization and tuning of a number of recent algorithms to address the problem. The results show that the proposed hybrid metaheuristic algorithms outperform the best existing techniques on the majority of case studies.
\end{abstract}

Keywords: Stochastic programming; Closed-loop supply chain; Social considerations; Metaheuristics, hybrid metaheuristic approaches.

\section{Introduction}

Nowadays, controlling and planning of supply chain systems have been motivated by both scholars and industrial practitioners to develop several decision-making models of these systems [1]. Supply Chain Management (SCM) uniforms some methods for both activities of production and distribution planning in different decision levels to achieve the chain goals efficiently [2]. Such methods are needed to be integrated the whole steps of products. These steps can be started from suppliers by procuring of raw materials and then different plants manufacture the products. Finally, transforming the products from distributer centers to customers has been done [3]. In other words, Supply Chain Network Design (SCND) has been recently developed by generating the decision-making models for the subject of SCM to uniform whole levels of supply chain network with optimization goal [4]. Generally speaking, choosing good facilities among the possible sites, determining their allocations and capacity planning of the selected ones as well as the flow of products between different levels through the supply chain network are the main concerns and decisions in SCND [5]. Besides, SCND as a key strategic issue directly influences 
on both tactical and operational activities through the entire network like inventory, transportation, and production decisions or management [6].

According to the literature of SCND, there are three classifications in this area: forward, reverse and closed-loop supply chain networks. The first case only focuses on the forward supply chain network which is started from suppliers to clients [7]. Regarding to a general supply chain network, the main decisions are adopted from manufacturers after purchasing the raw materials from suppliers [8]. Then, the products should be manufactured by a performance technology. So, these finished products are delivered to the clients with distribution planning for satisfying their demands in distribution centers [9]. The reverse logistic fully focused on the backward network by considering recovering centers i.e. from recovering centers to remanufacture, recycling and disposal centers. The flow of returned products is processed from the clients back to the recovering centers for repair is formed the core of logistic network [10]. Eventually, closed-loop network considers both mentioned types on the integrated manner. In fact, the design of the forward and reverse SCND has its own separate sub-optimal results. Therefore, their designations should be done in an integrated manner [11]. Interested readers are referred to comprehensive surveys written by Devika et al. [5] and Govindan et al. [12] for more information.

Recent studies gravitate toward environmental and social issues in SCND. What can be envisaged from the recent studies is to consider some suppositions in Social Impacts (SI) to get closer to real applications in SCND's area [10]. In order to clarify this issue, SI can be introduced generally as "the continuing commitment by business to behave ethically and contribute to the economic development while improving the quality of life of the workface and their families as well as a local community and society at large" [13]. In addition, a recent study investigated the SI in SCND and explained that the reverse activities involving of recycling and remanufacturing are known as labor intensive issues [6]. Besides, researches have indicated that these recovery activities create more job opportunities as compared to the forward activities of SCND. As pointed out by [5], European Commission found that considering the recycling, remanufacturing and generally the recovery activities yield great opportunities to generate novel distinct jobs [3].

Several endeavors have been done to plan and to optimized the SCND model that majority of them are based on the deterministic approaches via a single objective (e.g. [14]), while the real SCND models should be structured with a diverse source of uncertainty and many measures (e.g. [15]). Accordingly, Sabri and Beamon [16] mentioned that uncertainties can be the most challenging yet efficient issues in the supply chain management. Generally speaking, uncertainties can be divided into two types: operational and disruption. The operational uncertainty only considers the uncertainty in the range of parameters such as demand and operational costs etc. The disruption uncertainty considers a set of probabilistic scenarios. Each scenario describes a specific predictable situation and applies an operational uncertainty. Most of the existing works only adopt the operational uncertainty. However, this study proposes a stochastic model which can be handle the scenario with uncertainty. Regarding the stochastic 
models in the literature of SCND, there is a few works in integrating uncertainty with economic and social aspects simultaneously. Due to simplicity and low computational cost required, many papers considerably insist on the single objective form associated with clients [17]. Nevertheless, scientists do not assume these features since they make the model significantly more difficult.

The aim of this paper is to address a multi-objective stochastic programming model via four conflicting goals in contents of economic and social dimensions along with the downside risk value in a closed-loop SCND. In contrast to the majority of recent works focusing on the minimizing the cost or maximizing the profit under mixed uncertainty ([15]; [18]; [19]; [12]; [10]), this study aims to consider the SI as one of the main points in designing an efficient SCND as well as the total cost and mixed uncertainty for the parameters by proposing a two-stage stochastic programming model. To address the levels of forward and reverse directions of supply chain network, we present an example of graphical structure in the Fig. 1 to make more clear the employed closed-loop SCND for readers.

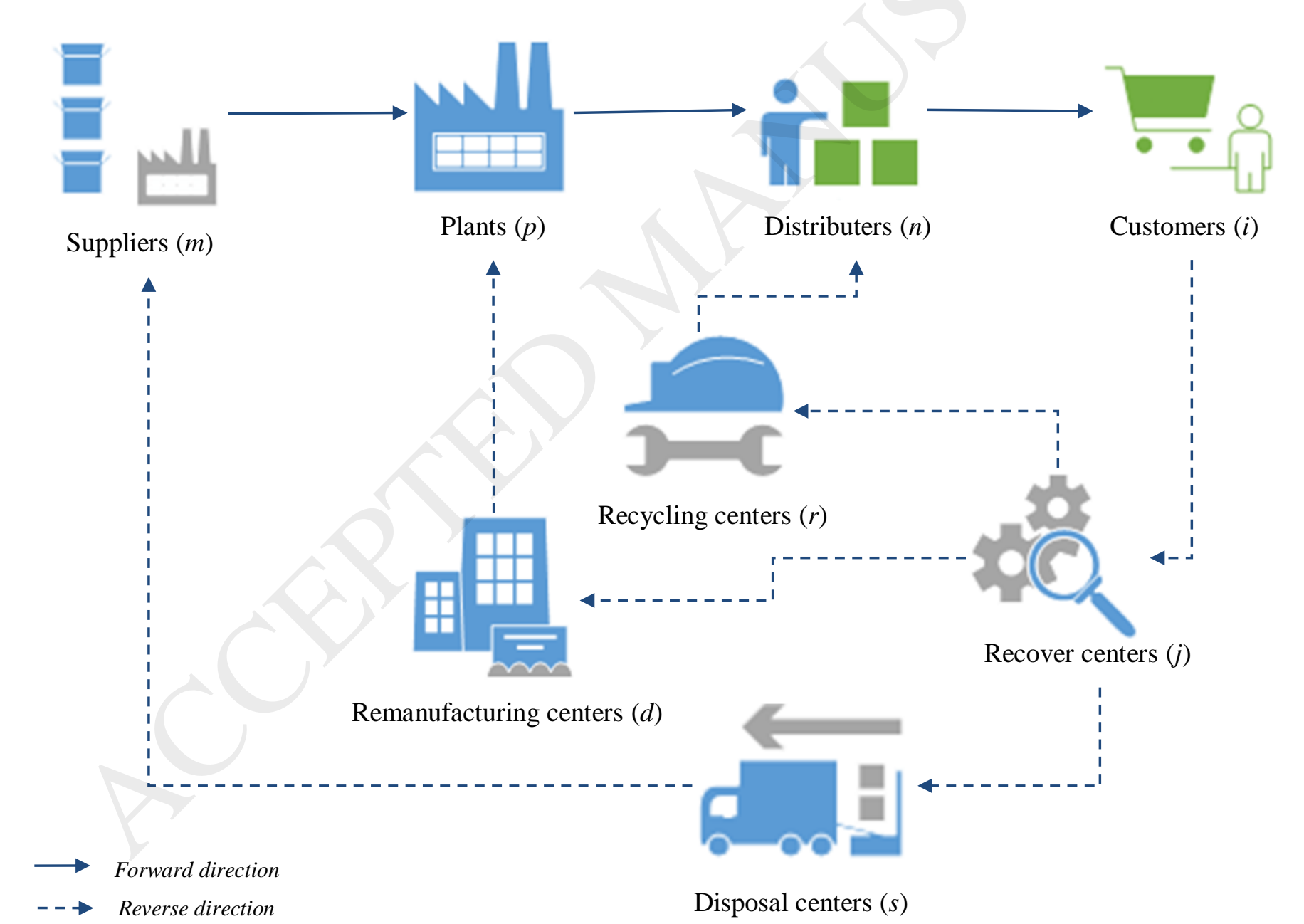

Fig. 1. The graphical structure of a simple closed-loop supply chain network utilizing in this paper 
To cope with the problem illustrated in Fig. 1, this paper not only uses recent metaheuristics but also hybridizes them to benefit from their advantages combined. In a nutshell, the main contributions of this study can be outlined as follows:

- Developing a new mathematical formulation for a multi-objective stochastic closedloop supply chain network design considering social impacts;

- Proposing four different objectives including two conflicting social impacts and downside risk as well as the total cost;

- Applying a number of recent and well-known multi-objective metaheuristic techniques: Non-dominated Sorting Genetic Algorithm (NSGA-II) [66], multiobjective of Simulated Annealing (SA) [67] and Red Deer Algorithm (RDA) [20] and also Keshtel Algorithm (KA) [21];

- Designing three novel hybrid metaheuristics by using the benefits of applied individual ones;

- Comparison of approaches by a number of performance evaluation metrics;

The rest of the paper is organized as follows. Section 2 provides the literature review around the gaps mentioned above. In Section 3, the proposed model in a two-stage stochastic programming is presented. In Section 4, the encoding and decoding representations and developed hybridization methods are explained. Consequently, experimental evaluations and computational analyses are conducted to assess the effective and efficiency of proposed metaheuristics in comparison with each other in Section 5. Finally, the main findings and future prompts of this study are presented in Section 6.

\section{Literature review}

Nowadays, collecting and treating of end-of-life (EOL) products plays a significant role in reverse and closed-loop supply chain networks. In this regard, Sasikumar and Kannan [22-24], Pokharel and Mutha [25], and also Yi et al. [26] are well-regarded review papers to classify various aspects of reverse and closed-loop SCND. Accordingly, designing reverse and closedloop supply chain networks both in industries and academic researches has been one of the interesting areas in literature in recent years [27-28].

Regarding the recent literature reviews of SCND e.g. Govindan et al. [10] and Devika et al. [5], the main published papers in two recent decades are classified by six properties in Table 2. There are including the type of supply chain network, objective functions, mathematical modeling, the stages of supply chain and logistics networks, the main outputs from decisionmaking model and solution methodology to evaluate the used model. To make easier the classifications, some notations for coding the keywords of each property are given in Table 1.

Most of models considered are varied from the simple single objective forward facility location models e.g. Jayaraman and Pirkul [14] up to complex multi-objective closed-loop models e.g. Ardalan et al. [29]. In regards to Table 2, the main similarities and findings of the papers listed are: 
- To minimize the total cost of supply chain network which is the most common objective in the surveyed models.

- To consider the benefits of closed-loop supply chain networks by assuming environmental and or social issues.

- To develop deterministic decision-making model is by proposing a Mixed Integer Linear Programming (MILP) formulation.

- As most of the SCND problems are NP-hard, numerous solution methods including heuristics and metaheuristics have been developed yet.

- Although most of the papers utilized the metaheuristic solution planning, less attention has been reported for hybrid metaheuristics among other solution methodologies using in the literature.

Due to the importance of the solution methods to select appropriate decisions in real applications of SCND, this study proposes various types of hybrid metaheuristics by considering the advantages of recent and old ones. In this regard, a number of metaheuristics has been combined with each other to design an effective and efficiency solution methods. Moreover, this study is among the first studies which assuming the total cost and downside risk in addition to social benefits. According to the Table 2, only Dehghanian and Mansour [13], Pishvaee et al. [18], Devika et al. [5], Govindan et al. [10], Ardalan et al. [29], Zhalechian et al. [30], Tahirov et al. [31], Soleimani et al. [32], Sgarbossa, and Russo [1], Arampantzi and Minis [8] and Samadi et al. [3] and also Hajiaghaei-Keshteli and Fathollahi Fard [6] have considered the social impacts in their proposed decision-making models. In contrast to the previous works, this study firstly formulates a Stochastic Mixed Integer Programming (SMIP) with considering the downside risk as an objective along with two conflicting objective functions for social considerations.

Table 1.

Proposed notation of modeling approaches.

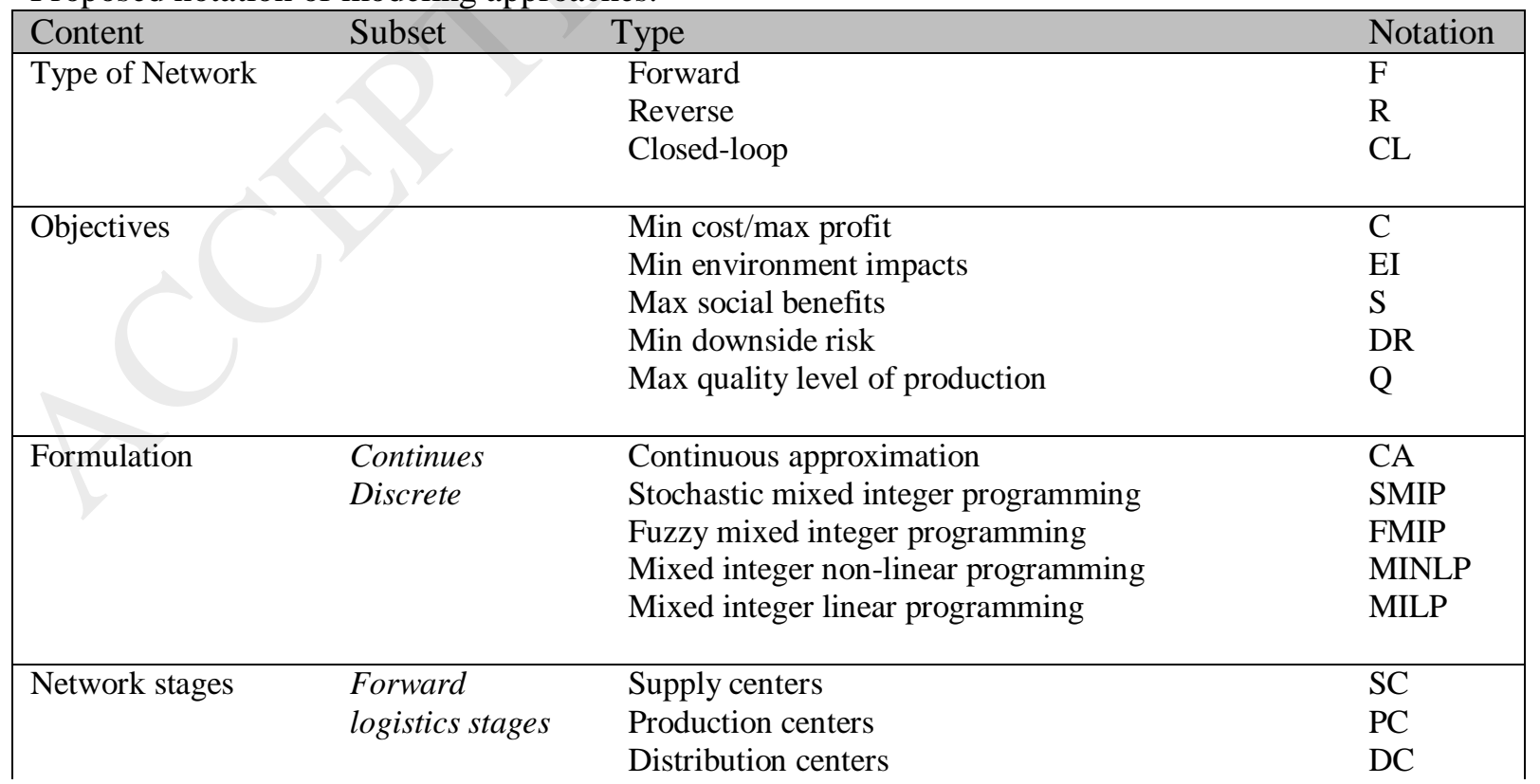




\begin{tabular}{|c|c|c|c|}
\hline & $\begin{array}{l}\text { Reverse } \\
\text { logistics stages }\end{array}$ & $\begin{array}{l}\text { Cross-docks } \\
\text { Warehouses } \\
\text { Customer zones (retail outlets) } \\
\text { Dismantlers } \\
\text { Disassembly centers } \\
\text { Redistribution centers } \\
\text { Recovering centers } \\
\text { Remanufacturing centers } \\
\text { Recycling centers } \\
\text { Disposal/incineration centers }\end{array}$ & $\begin{array}{l}\text { CD } \\
\text { WH } \\
\text { CZ } \\
\text { DSM } \\
\text { DAC } \\
\text { RDC } \\
\text { RCC } \\
\text { RMC } \\
\text { RYC } \\
\text { DPC }\end{array}$ \\
\hline Solution method & & $\begin{array}{l}\text { Exact } \\
\text { Branch and bound } \\
\text { Lagrangian relaxation-based } \\
\text { Genetic algorithm-based } \\
\text { Simulated annealing-based } \\
\text { Tabu search-based } \\
\text { Interactive fuzzy solution approach } \\
\varepsilon \text {-constraint } \\
\text { Heuristics } \\
\text { Others metaheuristics }\end{array}$ & $\begin{array}{l}\text { E } \\
\text { B\&B } \\
\text { LR } \\
\text { GA } \\
\text { SA } \\
\text { TS } \\
\text { F } \\
\text { EC } \\
\text { H } \\
\text { MH }\end{array}$ \\
\hline Outputs & & $\begin{array}{l}\text { Suppliers/orders } \\
\text { Facilities location } \\
\text { Facility capacity } \\
\text { Allocation } \\
\text { Discount } \\
\text { Production amount } \\
\text { Production assignment to production centers } \\
\text { (for multi-product problems) } \\
\text { Utilization of production centers (i.e. days } \\
\text { allocated for the production of products) } \\
\text { Production technology } \\
\text { Transportation amount } \\
\text { Transportation mode } \\
\text { Number of vehicles } \\
\text { Inventory } \\
\text { Price of products } \\
\text { technology } \\
\text { Amount of used products which are } \\
\text { processed } \\
\text { Amount of Incentive ordered (acquisition } \\
\text { price) for a used product } \\
\text { Carbon credits sold/purchased } \\
\text { Quality of production } \\
\text { Quantity of non-satisfied demand } \\
\text { Quantity of non-satisfied return of product }\end{array}$ & $\begin{array}{l}\text { S } \\
\text { L } \\
\text { FC } \\
\text { AL } \\
\text { DC } \\
\text { PQ } \\
\text { PA } \\
\text { UT } \\
\text { PT } \\
\text { TA } \\
\text { TM } \\
\text { NV } \\
\text { I } \\
\text { P } \\
\text { TT } \\
\text { US } \\
\text { INC } \\
\text { CC } \\
\text { QP } \\
\text { ND } \\
\text { NR }\end{array}$ \\
\hline
\end{tabular}

Table 2. Review of pervious related researches.

\begin{tabular}{lllllll}
\hline Author & $\begin{array}{l}\text { Type of } \\
\text { network }\end{array}$ & Objective & Modeling & Network stages & $\begin{array}{l}\text { Solution } \\
\text { method }\end{array}$ & Outputs \\
\hline $\begin{array}{l}\text { Jayaraman and } \\
\text { Pirkul [14] }\end{array}$ & F & C & MILP & SC, PC, WH, CZ & LR & L, AL, PQ, TA \\
\hline Dasci and Verter & F & C & CA & PC, CZ & E & L, AL \\
\hline
\end{tabular}




\begin{tabular}{|c|c|c|c|c|c|c|}
\hline \multicolumn{7}{|l|}{ [33] } \\
\hline $\begin{array}{l}\text { Jayaraman and } \\
\text { Ross [34] }\end{array}$ & $\mathrm{F}$ & $\mathrm{C}$ & MILP & $\mathrm{PC}, \mathrm{CD}, \mathrm{WH}$ & SA & $\mathrm{L}, \mathrm{AL}, \mathrm{TA}$ \\
\hline $\begin{array}{l}\text { Miranda and } \\
\text { Garrido [35] }\end{array}$ & $\mathrm{F}$ & $\mathrm{C}$ & MINLP & PC, WH, CZ & LR & $\mathrm{L}, \mathrm{AL}, \mathrm{TA}, \mathrm{I}$ \\
\hline Wang et al. [36] & $\mathrm{F}$ & $\mathrm{C}, \mathrm{EI}$ & MILP & $\mathrm{PC}, \mathrm{CZ}, \mathrm{SC}$ & $\mathrm{E}$ & TA \\
\hline $\begin{array}{l}\text { Georgiadis et al. } \\
\text { [37] }\end{array}$ & $\mathrm{F}$ & $\mathrm{C}$ & MILP & $\begin{array}{l}\mathrm{PC}, \mathrm{DC}, \mathrm{WH}, \\
\mathrm{CZ}\end{array}$ & B \& B & $\mathrm{L}, \mathrm{AL}, \mathrm{TA}, \mathrm{I}, \mathrm{PQ}$ \\
\hline $\begin{array}{l}\text { Pishvaee et al. } \\
{[19]}\end{array}$ & $\mathrm{F}$ & $\mathrm{C}$ & FMIP & EI, PC, DC, CZ & F & $\begin{array}{l}\mathrm{L}, \mathrm{AL}, \mathrm{PT}, \mathrm{TM}, \\
\mathrm{FC}, \mathrm{PQ}\end{array}$ \\
\hline Syarif et al. [38] & $\mathrm{F}$ & $\mathrm{C}$ & MILP & $\mathrm{SC}, \mathrm{PC}, \mathrm{DC}, \mathrm{CZ}$ & GA & L, TA, SS, PQ \\
\hline $\begin{array}{l}\text { Elhedhli and } \\
\text { Merrick [39] }\end{array}$ & $\mathrm{F}$ & C, EI & MINLP & $\mathrm{PC}, \mathrm{DC}, \mathrm{CZ}$ & LR & $\mathrm{L}, \mathrm{AL}, \mathrm{TA}$ \\
\hline $\begin{array}{l}\text { Pishvaee et al. } \\
{[18]}\end{array}$ & $\mathrm{F}$ & C, EI, S & FMIP & $\mathrm{PC}, \mathrm{DC}, \mathrm{CZ}$ & & L, TA, PT \\
\hline $\begin{array}{l}\text { Tsao and } \mathrm{Lu} \\
{[51]}\end{array}$ & F & $\mathrm{C}$ & MILP & $\mathrm{SC}, \mathrm{PC}, \mathrm{DC}, \mathrm{CZ}$ & $\mathrm{H}$ & $\mathrm{S}, \mathrm{L}, \mathrm{DC}$ \\
\hline $\begin{array}{l}\text { Babazadeh et al. } \\
\text { [7] }\end{array}$ & $\mathrm{F}$ & $\mathrm{C}, \mathrm{EI}$ & MINLP & $\mathrm{CIC}, \mathrm{WH}, \mathrm{CZ}$ & E & $\begin{array}{l}\text { I, AL, FC, TM, } \\
\text { PA }\end{array}$ \\
\hline $\begin{array}{l}\text { Ardalan et al. } \\
\text { [29] }\end{array}$ & $\mathrm{F}$ & $\mathrm{C}, \mathrm{S}$ & MILP & $\begin{array}{l}\text { SC, DC, PC, } \\
\text { CIC, WH }\end{array}$ & LR & $\mathrm{L}, \mathrm{AL}, \mathrm{PA}$ \\
\hline $\begin{array}{l}\text { Listes and } \\
\text { Dekker [40] }\end{array}$ & $\mathrm{R}$ & $\mathrm{C}$ & SMIP & $\mathrm{CZ}, \mathrm{RYC}$ & $\mathrm{E}$ & $\mathrm{L}, \mathrm{TA}$ \\
\hline $\begin{array}{l}\text { Fonseca et al. } \\
\text { [41] }\end{array}$ & $\mathrm{R}$ & $\mathrm{C}, \mathrm{EI}$ & SMIP & $\mathrm{CZ}, \mathrm{RCC}, \mathrm{DPC}$ & E & L, TA, TT \\
\hline $\begin{array}{l}\text { Kannan et al. } \\
\text { [27] }\end{array}$ & $\mathrm{R}$ & $\mathrm{C}, \mathrm{EI}$ & MILP & $\mathrm{CZ}, \mathrm{RCC}, \mathrm{DPC}$ & E & $\mathrm{L}, \mathrm{TA}$ \\
\hline $\begin{array}{l}\text { Dehghanian and } \\
\text { Mansour [13] }\end{array}$ & $\mathrm{R}$ & C, EI, S & MILP & CIC, RYC, DPC & GA & $\mathrm{L}, \mathrm{TA}, \mathrm{FC}, \mathrm{TT}$ \\
\hline $\begin{array}{l}\text { Cruz-Rivera and } \\
\text { Ertel [42] }\end{array}$ & $\mathrm{R}$ & $\mathrm{C}$ & MILP & $\mathrm{CZ}, \mathrm{RCC}$ & E & $\mathrm{L}, \mathrm{AL}, \mathrm{TA}$ \\
\hline $\begin{array}{l}\text { Govindan et al. } \\
{[10]}\end{array}$ & $\mathrm{R}$ & C, EI, S & FMIP & $\begin{array}{l}\text { CIC, RYC, } \\
\text { DPC, RMC, } \\
\text { RDC }\end{array}$ & MH & $\begin{array}{l}\text { L. TA, FC, TT, } \\
\text { US }\end{array}$ \\
\hline Yi et al. [26] & $\mathrm{R}$ & $\mathrm{C}, \mathrm{EI}$ & MINLP & $\begin{array}{l}\text { SC, CZ, RMC, } \\
\text { CIC, DC, DPC, } \\
\text { DAC, RDC }\end{array}$ & GA & $\mathrm{L}, \mathrm{AL}, \mathrm{TA}, \mathrm{FC}$ \\
\hline $\begin{array}{l}\text { Fleischmann } e t \\
\text { al. [43] }\end{array}$ & CL & $\mathrm{C}$ & MILP L & $\begin{array}{l}\text { PC, WH, CZ, } \\
\text { CIC, RMC, DPC }\end{array}$ & $\mathrm{E}$ & $\mathrm{AL}$ \\
\hline $\begin{array}{l}\text { Demirel and } \\
\text { Gökçen [44] }\end{array}$ & $\mathrm{CL}$ & $\mathrm{C}$ & MILP & $\begin{array}{l}\text { PC, DC, CZ, } \\
\text { CIC, DAC }\end{array}$ & GA & $\mathrm{L}, \mathrm{PQ}, \mathrm{TA}$ \\
\hline $\begin{array}{l}\text { Pishvaee et al. } \\
{[15]}\end{array}$ & CL & $\mathrm{C}, \mathrm{EI}$ & FMIP & $\begin{array}{l}\text { PC, CZ, CIC, } \\
\text { RCC, RCC, } \\
\text { DPC }\end{array}$ & $\mathrm{F}$ & L, TA, PQ, US \\
\hline $\begin{array}{l}\text { Chaabane } \text { et al. } \\
{[45]}\end{array}$ & CL & $\mathrm{C}, \mathrm{EI}$ & MILP & $\begin{array}{l}\text { SC, PC, DC, CZ, } \\
\text { RYC }\end{array}$ & E & $\begin{array}{l}\text { L, PQ, I, PT, } \\
\text { TM, CR }\end{array}$ \\
\hline $\begin{array}{l}\text { Wang and Hsu } \\
\text { [46] }\end{array}$ & CL & $\mathrm{C}$ & MILP & $\begin{array}{l}\text { SC, PC, DC, CZ, } \\
\text { DSM, RMC, } \\
\text { RDC, DPC }\end{array}$ & GA & $\mathrm{L}, \mathrm{PQ}, \mathrm{TA}$ \\
\hline $\begin{array}{l}\text { Ramezani et al. } \\
\text { [47] }\end{array}$ & CL & $\mathrm{C}, \mathrm{Q}, \mathrm{DR}$ & SMIP & $\begin{array}{l}\text { SC, PC, DC, } \\
\text { RCC, DMC }\end{array}$ & $\mathrm{EC}$ & $\begin{array}{l}\text { S, L, PQ, PA, } \\
\text { TA, QP }\end{array}$ \\
\hline Devika et al. [5] & $\mathrm{CL}$ & C, EI, S & MILP & $\begin{array}{l}\text { SC, PC, DC, CZ, } \\
\text { CIC, RDC, } \\
\text { RCC, RMC, } \\
\text { RYC, DPC }\end{array}$ & MH & $\begin{array}{l}\text { S, L, AL, PQ, } \\
\text { PT, TA, US }\end{array}$ \\
\hline
\end{tabular}




\begin{tabular}{|c|c|c|c|c|c|c|}
\hline $\begin{array}{l}\text { Soleimani and } \\
\text { Kannan [48] }\end{array}$ & CL & $\mathrm{C}$ & MINLP & $\begin{array}{l}\text { SC, PC, CZ, } \\
\text { WH, DC, RMC, } \\
\text { RCC }\end{array}$ & $\mathrm{E}, \mathrm{MH}$ & $\begin{array}{l}\text { FC, TA, UT, I, } \\
\text { US }\end{array}$ \\
\hline $\begin{array}{l}\text { Tahirov et al. } \\
\text { [31] }\end{array}$ & CL & C, EI, S & MILP & $\begin{array}{l}\text { SC, PC, DC, CZ, } \\
\text { CIC, RDC, } \\
\text { RCC, RMC, } \\
\text { RYC, }\end{array}$ & $\mathrm{E}$ & $\begin{array}{l}\mathrm{L}, \mathrm{AL}, \mathrm{PA}, \mathrm{CC} \text {, } \\
\mathrm{TT}, \mathrm{US}, \mathrm{INC}\end{array}$ \\
\hline $\begin{array}{l}\text { Zohal and } \\
\text { Soleimani [49] }\end{array}$ & CL & $\mathrm{C}, \mathrm{EI}$ & MILP & $\begin{array}{l}\mathrm{DC}, \mathrm{CZ}, \mathrm{SC}, \\
\mathrm{RYC}\end{array}$ & MH & $\begin{array}{l}\mathrm{L}, \mathrm{AL}, \mathrm{US}, \mathrm{CC}, \\
\text { TA }\end{array}$ \\
\hline $\begin{array}{l}\text { Schultmann et } \\
\text { al. [50] }\end{array}$ & CL & $\mathrm{C}$ & MILP & $\begin{array}{l}\text { SC, WH, CZ, } \\
\text { RMC, CIC }\end{array}$ & TS & $\mathrm{L}, \mathrm{AL}, \mathrm{TA}$ \\
\hline $\begin{array}{l}\text { Zhalechian et al. } \\
\text { [30] }\end{array}$ & CL & C, EI, S & MILP & $\begin{array}{l}\text { SC, WH, CZ, } \\
\text { RMC, CIC, DC, } \\
\text { DPC, DAC, } \\
\text { RDC }\end{array}$ & GA & $\begin{array}{l}\text { L, AL, TA, I, } \\
\text { NV, FC }\end{array}$ \\
\hline $\begin{array}{l}\text { Fathollahi Fard } \\
\text { et al. [4] }\end{array}$ & CL & $\mathrm{C}, \mathrm{DR}$ & SMIP & $\begin{array}{l}\text { SC, PC, DC, CZ, } \\
\text { CIC, RDC, } \\
\text { RCC, RMC, } \\
\text { RYC, DPC }\end{array}$ & $\mathrm{MH}$ & $\begin{array}{l}\text { S, L, AL, PQ, } \\
\text { PT, TA, US }\end{array}$ \\
\hline $\begin{array}{l}\text { Soleimani et al. } \\
\text { [32] }\end{array}$ & CL & $\mathrm{C}, \mathrm{EI}, \mathrm{S}$ & FMIP & $\begin{array}{l}\text { SC, PC, DC, CZ, } \\
\text { CIC, RDC, } \\
\text { RCC, RMC, } \\
\text { RYC, DPC }\end{array}$ & GA & $\begin{array}{l}\text { S, L, AL, PT, } \\
\text { TA, US }\end{array}$ \\
\hline $\begin{array}{l}\text { Sgarbossa, and } \\
\text { Russo [1] }\end{array}$ & CL & C, EI, S & MILP & $\begin{array}{l}\text { SC, PC, CZ, } \\
\text { WH, DC, RMC, } \\
\text { RCC }\end{array}$ & $\mathrm{E}$ & $\begin{array}{l}\text { FC, TA, UT, I, } \\
\text { US }\end{array}$ \\
\hline $\begin{array}{l}\text { Arampantiz and } \\
\text { Minis [8] }\end{array}$ & CL & C, EI, S & MILP & $\begin{array}{l}\text { SC, PC, DC, CZ, } \\
\text { CIC, RDC, } \\
\text { RCC, RMC, } \\
\text { RYC, DPC }\end{array}$ & $\mathrm{EC}$ & $\begin{array}{l}\text { S, L, AL, PQ, } \\
\text { PT, TA, US }\end{array}$ \\
\hline $\begin{array}{l}\text { Fathollahi Fard } \\
\text { and Hajaghaei- } \\
\text { Keshteli [2] }\end{array}$ & CL & $\mathrm{C}$ & MILP & $\mathrm{PC}, \mathrm{DC}, \mathrm{RCC}$ & $\mathrm{H}, \mathrm{MH}$ & $\mathrm{L}, \mathrm{FC}, \mathrm{AL}, \mathrm{PQ}$ \\
\hline Samadi et al. [3] & CL & C, EI, S & MILP & $\begin{array}{l}\text { SC, PC, DC, CZ, } \\
\text { CIC, RDC, } \\
\text { RCC, RMC, } \\
\text { RYC, DPC }\end{array}$ & $\mathrm{H}, \mathrm{GA}$ & $\begin{array}{l}\text { S, L, AL, PQ, } \\
\text { PT, TA, US }\end{array}$ \\
\hline $\begin{array}{l}\text { Hajaghaei- } \\
\text { Keshteli and } \\
\text { Fathollahi Fard } \\
{[6]}\end{array}$ & CL & C, EI, S & MINLP & $\begin{array}{l}\text { SC, PC, DC, CZ, } \\
\text { CIC, RDC, } \\
\text { RCC, RMC, } \\
\text { RYC, DPC }\end{array}$ & $\mathrm{H}, \mathrm{MH}$ & $\begin{array}{l}\text { S, L, AL, PQ, } \\
\text { PT, TA, US, DC }\end{array}$ \\
\hline This study & CL & $\mathrm{C}, \mathrm{S}, \mathrm{S}, \mathrm{DR}$ & SMIP & $\begin{array}{l}\text { SC, PC, DC, CZ, } \\
\text { RDC, RCC, } \\
\text { RMC, RYC, } \\
\text { DPC }\end{array}$ & $\mathrm{MH}$ & $\begin{array}{l}\text { S, L, AL, PQ, } \\
\text { PT, TA, US }\end{array}$ \\
\hline
\end{tabular}

This paper can be considered as another Closed-loop SCND (CLSC)'s work in this area. As mentioned earlier, CLSC is a recent and interesting term in the literature to integrate forward and reverse network design. This term avoids the sub-optimality arising in separated modeling of both forward and reverse networks [52]. Perhaps, Fleischmann et al. [43] was one of the first studies to suggest a decision-making model to design a CLSC. The aim of their work was to show that RL and CLSC operations often can be coordinated efficiently into existing forward 
flows of SCND. Later, by proposing a real case study in German, Schultmann et al. [50] considered EOL vehicle operation for their RL model. Thus, their problem was an NP-hard one. Tabu search (TS) was employed to solve their model. They suggested their TS can be combined with an exploration-based metaheuristic to enhance the efficiency of algorithm. In a recent study, Fathollahi Fard and Hajiaghaei-Keshteli [2] recently by proposing a tri-level decision-making model considered the forward and reverse flows in their supply chain network, simultaneously. They applied a glass industry as an application of their model through a case study in Iran. To tackle their NP-hard model, they introduced a nested approach utilizing metaheuristics. So, Water Wave Optimization (WWO) and Keshtel Algorithm (KA) were examined in their study. The main suggestion for the future works of their work was to hybridizing the recent metaheuristics e.g. WWO and KA to generate more powerful methods. Also, Samadi et al. [3] for a sustainable CLSC showed that hybridizing the recent metaheuristic by single-solution heuristics are more efficient than the individual metaheuristic. So, these valuable suggestions and results motivate us to develop three novel hybrid metaheuristics for a proposed CLSC problem.

There are only a few studies that used a stochastic programming for developing a SCND model (Pishvaee et al. [15], Ramezani et al. [47], Fathollahi Fard et al. [4]). To get closer to reality, a set of probabilistic scenarios should be considered. Then, according to each scenario cost and its profit, the decision maker determines the most suitable decision as the output of the considered the decision-making model. Additionally, this study opens a new direction in this research area. In this regard, only Ramezani et al. [47] considered the network quality and downside risk as one of the objective functions to be optimized. Additionally, Fatholahi Fard et al. [4] recently considered downside risk and total cost of objective functions to formulate a stochastic CLSC. This paper uses a metaheuristic approach to solve a Stochastic Mixed Integer Programming (SMIP) model in a closed-loop SCND for the first time in this area. In order to address the new concept in this zone, this work presents a multi-objective, multi-echelon, multiple types of production technology in the logistic network design problem.

One might ask the differences between this paper and the existing works in the literature. Firstly, the social impacts of sustainability are quantified as a distinct objective beside the total costs. In addition, the authors tried to develop an uncertainty model which has different SIs alongside economical aspects in a simple SMIP problem.

Secondly, the forward and reverse logistics are coordinated by a general type of ClosedLoop Supply Chain (CLSC) model. While Dehghanian and Mansour [13] and Pishvaee et al. [18] modeled forward and reverse supply chain networks, respectively, our mathematical formulation explored a closed-loop SCND and have three different goals.

Finally, we consider the downside risk as an objective function to control the model for generating robust solution in against of uncertainty. According to the risk management, solutions should be robust and must be satisfied in conflicting objectives considered by decision makers' preferences. It shows the uncertainty of the social impacts precisely in the study. Although most of the papers in SCND have only one objective to be minimized or maximized e.g. Jayaraman 
and Pirkul [14] and Ardalan et al. [29], this paper optimizes four conflicting objective functions simultaneously. For this reason, the stochastic multi-objective programming is utilized.

Generally speaking, the SCND is an NP-hard problem [53]; [54]; [38]. Thus, novel and strong approaches in metaheuristics are proposed to find Pareto-optimal solutions. The Red Deer Algorithm (RDA) [20] and Keshtel Algorithm (KA) [21] are utilized to solve the proposed closed-loop SCND problem as the recent developed optimizers. In addition, two state of art multi-objective optimizers called Non-dominated Sorting Genetic Algorithm (NSGA-II) [66] and multi-objective of Simulated Annealing (SA) [67] are employed, as well. By considering the advantages and disadvantages of algorithms, three hybrid methods synthesizing three algorithms are also utilized to tackle such NP-hard problem. For solving problems with a small number of variables used in this work, the $\varepsilon$-constraint method is used to control the satisfying of the metaheuristics' results.

\section{Problem description}

This paper considers a multi-level CLSC including suppliers, plants, distributors and customers in a forward supply chain. Also, recovering centers, recycling centers, remanufacturing centers and disposal centers are formed a reverse supply chain in an integrated manner as seen in Fig. 1. Manufacturers supply the raw material from suppliers. After that, the manufactured products are distributed in markets by distributers. Then, recover centers collect a part of used products from customers. The recovery centers divide these collected products in three levels. Regarding the quality of them, a set of used products which have a higher quality are recycled by recycling centers and then transformed into distributers to distribute in their markets. Another group of used products may need to remanufacture by remanufacturing centers and then transformed into plants to consider them as a set of new manufactured products. The rest of used products are transformed into disposal centers to make them as the raw material producing by suppliers. This study aims to assess the economic and social dimensions of this CLSC presented under uncertainty.

In terms of economic dimension of proposed CLSC, the formulation aims to minimize the total cost of supply chain network including the cost of establishing the facilities, processing cost, transportation cost and purchasing cost. Accordingly, the proposed formulation determines the location of facilities and the right amount of products or used products or raw materials to consider the allocation between facilities. Whole of them aims to consider the total cost of CLSC which should be minimized.

One of main real suppositions of proposed model is the social considerations. Generally, the two main social dimensions which have been studied in several studies from the literature are the job opportunity and work injuries dimensions. To estimate these impacts, there are different frameworks in the literature [1]; [5]; [6]; [18]. One of the great researches in this regard refers to Pishvaee et al., [18]. They comprised different social guidelines. Their framework was a social life cycle assessment of products introduced by Beno it and Mazijn [55] and social 
responsibility-ISO 26000 [56]. Regarding this social life cycle assessment, the life cycle stages of CLSC as follows:

- Manufacturing processing along with its different technologies;

- Location and capacities of establishment facilities;

- Distributing and collecting of manufactured products, used products and raw materials;

The proposed CLSC has been formulated by considering SA8000 guideline [57]. Accordingly, the job opportunities and workers' safety have been considered to asses to social impacts of CLSC proposed. The job opportunities not only cover the labor practices but also consider the community involvement and development. Regarding the second factor, the workers' safety indicates the human rights and fair operating practices. However, both factors should be estimated in two periods including establishment and utilization. Note that there is no available software or database to estimate the social impacts. Therefore, the external experts have been employed to estimate the weights and amount of each parameter in this study.

Another main real assumption of this study is to handle a set of probabilistic scenarios with the uncertainty in a number of key parameters for a CLSC configuration. To control this uncertainty, the downside risk has been considered to achieve a robust solution for the proposed model. In the following, the assumptions and proposed formulation with details have been illustrated.

\subsection{Assumptions}

As mentioned earlier, the CLSC model investigated in this study is a multi-objective, multiechelon, multi-type of production technology and considering the operational uncertainties in a closed-loop configuration which is challenging and requires more computational resources to check than both the forward and reverse network, simultaneously. The problem developed mainly focuses on the treatment process by taking into account three types of facilities called treatment centers in the reverse network: remanufacturing, recycling, and disposal. The proposed SMIP model is founded on the following suppositions in this research area [58]; [38]; [46]; [59]; [5]; [3]; [6]:

1. The demand of each customer must be met.

2. The number of facilities and their potential sites in each echelon is predefined.

3. No flow exists between the facilities of the same echelon.

4. As a special supposition in CLSC suggested by Van Der Laan et al. [60], it is assumed that the number of the EOL products returned to the recovering centers is a fraction of the clients' demands.

5. The rate of purchasing the production, manufacturing costs, assigning cost of costumers to distribution centers, clients' demands and their return rates are uncertain. They are described by a set of scenarios. Also, the return rates to recover centers are directly depended on the customer's demand.

6. The other costs i.e., fixed costs and transportation costs are predefined. 


\subsection{Formulation}

As stated above, the main structure of the proposed CLSC is depicted in Fig. 1. Generally speaking, this problem aims to determine the location decisions and amount of products between different levels from suppliers to manufacturers. The allocation of distribution centers to manufacturers, and also the assignment of customers to distribution centers and recover centers as well as the flow of materials should be decided in a two-stage stochastic programming as well.

Table 3. Index of formulation

\begin{tabular}{|ll|}
\hline Indices & \\
\hline$m$ & Index of suppliers: $m \in\{1,2, \ldots, M\}$ \\
$p$ & Index of potential plant: $p \in\{1,2, \ldots, P\}$ \\
$n$ & Index of potential distribution centers: $n \in\{1,2, \ldots, N\}$ \\
$i$ & Index of customer zones: $i \in\{1,2, \ldots, I\}$ \\
$d$ & Index of potential remanufacturing centers: $d \in\{1,2, \ldots, D\}$ \\
$r$ & Index of potential recycling centers: $r \in\{1,2, \ldots, R\}$ \\
$j$ & Index of potential recovering centers: $j \in\{1,2, \ldots J\}$ \\
$s$ & Index of potential disposal centers: $s \in\{1,2, \ldots, S\}$ \\
$t$ & Index of production technologies: $t \in\{1,2, \ldots, T\}$ \\
$c$ & Index of scenario $c \in\{1,2, \ldots, C\}$ \\
$e, e$, & Index of echelons: $e, e^{\prime} \in\{m, p, n, i, d, r, s\}$ \\
$f_{e}, f_{e}$, & Index of facilities in echelon $e: f_{e}, f_{e}^{\prime} \in\left\{1, \ldots, F_{e}\right\}$ \\
\hline
\end{tabular}

Table 4. Model's parameters

\begin{tabular}{|ll|}
\hline Parameters & Cost of purchasing raw material from supplier $m$ over scenario $c$ \\
\hline$p c_{m}^{c}$ & Fixed opening cost of facility $f_{e} \mid e \in\{d, m, n, p, r, s, j\}$ \\
$f c_{f_{e}}$ & Fixed establishing cost of plant center $p$ with technology $t$ \\
$f c_{p t}$ & Manufacturing cost of each unit product at plant center $p$ with technology $t$ over scenario c \\
$m c_{p t}^{c}$ & Per unit handling cost at facility $f_{e} \mid e \in\{d, m, n, p, r, s, j\}$ \\
$v c_{f_{e}}$ & Transportation cost per unit by considering discount from facility $f_{e}$ to facility $f^{\prime}{ }_{e}$, corresponding to \\
$t c_{f_{e} f^{\prime}{ }^{\prime}}$ & $X_{f_{e} f^{\prime} e^{\prime}}$ \\
$a c_{n i}^{c}$ & Per unit cost of assigning customer zone $i$ to distribution center $n$ over scenario $c$ \\
$f j_{p t}$ & The number of fixed job opportunities (i.e. job opportunities which are independent of production capacity like \\
$f j_{f e}$ & managerial positions) created by establishing plant center $p$ with technology $t$ \\
$v o_{p t}$ & The number of fixed job opportunities created by establishing facility $f_{e} \mid e \in\{d, m, n, p, r, s, j\}$ \\
$v o_{f e}$ & The number of variable job opportunities (i.e. job opportunities which vary by production capacity like \\
$f l_{p t}$ & manufacturing line workers) created through manufacturing at center $p$ with technology $t$ \\
$f l_{f}$ & The number of variable job opportunities created through working of facility $f_{e} \mid e \in\{d, m, n, p, r, s, j\}$ \\
$v l_{p t}$ & The lost days cost from work's damages during the establishment of technology $t$ at plant center $p$. \\
$v l_{f e}$ & The lost days cost from work's damages during the establishment of facility $f_{e} \mid e \in\{d, m, n, p, r, s, j\}$ \\
$p_{p t} \mid$ & The lost of days caused work's damages during the manufacturing at plant center $p$ with technology $t$. \\
$p_{f e}$ & The lost of days caused work's damages during the handling of products at facility $f_{e} \mid e \in\{d, m, n, p, r, s, j\}$ \\
$m a x$ & Capacity of plant center $p$ with technology $t$ \\
$d_{i}^{c}$ & Capacity of facility $f_{e} \mid e \in\{d, m, n, p, r, s, j\}$ \\
$b_{p t}$ & Maximum desired number of established sites in echelon $e \in\{d, m, n, p, r, s, j\}$. \\
$\propto_{i}$ & Demand of customer zone $i$ over scenario $c$ \\
& The fraction of broken products manufactured by technology $t$ at plant center $p$ \\
& The fraction of used products returned from customer zone $i$.
\end{tabular}




\begin{tabular}{|ll}
$\gamma_{S}, \gamma_{d}$ and $\gamma_{r}$ & The fraction of products shipped from a disposal and remanufacturing and recycling center to used products, \\
& respectively. \\
$s c_{S}, s c_{d}$ and $s c_{r}$ & Per unit monetary saving resulted from using disposal, remanufactured and recycled EOL products, respectively. \\
$p b_{c}$ & Occurrence probability of scenario c where $\sum_{c=1}^{C} p b_{c}=1$ \\
$\varphi$ & A minimum quantity for expected profit instead of all scenario c.
\end{tabular}

Table 5. The decision variables and objectives of formulation

\begin{tabular}{|ll|}
\hline Variables & \\
\hline Continues variables: & \\
$X_{f_{e} f^{\prime} e^{\prime}}^{c}$ & Flow of products from facility $f_{e}$ to facility $f_{e}$, over scenario $c$ \\
$H_{p t}^{c}$ & Amount of products manufactured with technology $t$ at plant center $p$ over scenario $c$ \\
$V_{c \varphi}$ & The deviation between the scenario cost value and target profit $\varphi$ \\
\hline Binary variables: & 1 if facility $f_{e} \mid \mathrm{e}\{d, m, n, p, r, s, j\}$ is to be established, 0 otherwise \\
$Y_{f_{e}}$ & 1 if plant $p$ is to be established with technology t, 0 otherwise. \\
$Y_{p t}$ & 1 if customer zone $i$ is assigned to distribution center $n$ over scenario c, 0 otherwise \\
$Z_{n i}^{c}$ & 1 if customer zone $i$ is assigned to recover center $j$ over scenario c, 0 otherwise \\
$Z_{i j}^{c}$ & \\
& \\
\hline Objective functions: & Expected total cost \\
$E($ Cost $)$ & Expected job opportunities of social \\
$E(J o b)$ & Expected work damages \\
$E(W o r k)$ & Downside risk of total cost \\
$D R i s k_{\varphi}$ &
\end{tabular}

Overall, Tables 3, 4 and 5, illustrate the indices, parameters and decision variables of the proposed model, respectively.

Here, the formulations of the CLSC proposed are presented. These formulations are developed by extending the pervious works (mainly on Hajaghaei-Keshteli and Fathollahi Fard $[6])$.

$$
\begin{aligned}
\min E(\text { Cost })= & \min \left(\sum _ { c = 1 } ^ { C } p b _ { c } \left(\sum_{p=1}^{P} \sum_{t=1}^{T} f c_{p t} \cdot Y_{p t}+\sum_{e=1}^{E} \sum_{f=1}^{F} f c_{f_{e}} \cdot Y_{f_{e}}+\sum_{m=1}^{M} \sum_{p=1}^{P} p c_{m}^{c} . X_{m p}^{c}\right.\right. \\
& +\sum_{p=1}^{P} \sum_{t=1}^{T} m c_{p t}^{c} \cdot H_{p t}^{c}+\sum_{e=1}^{E} \sum_{e^{\prime}=1}^{E} \sum_{f=1}^{F} \sum_{f^{\prime}=1}^{F} t c_{f_{e} f^{\prime} e^{\prime}} \cdot X_{f_{e} f^{\prime} e^{\prime}}^{c} \\
& +\sum_{i=1}^{I} \sum_{n=1}^{N} Z_{n i}^{c} \cdot a c_{n i}^{c} \cdot d_{i}^{c}+\sum_{i=1}^{J} \sum_{j=1}^{J} Z_{i j}^{c} \cdot v c_{j} \cdot \propto_{i} \cdot d_{i}^{c}-s c_{s}\left(\sum_{p=1}^{P} \sum_{n=1}^{N} X_{p n}^{c}\right) \\
& \left.\left.-s c_{r}\left(\sum_{r=1}^{R} \sum_{n=1}^{N} X_{r n}^{c}\right)-s c_{d}\left(\sum_{e=1}^{E} \sum_{f=1}^{F} \sum_{j=1}^{J} \gamma_{e} X_{j f_{e}}^{c}\right)\right)\right)
\end{aligned}
$$

Equation (1) represents the economical aspects of supply chain network to minimize the total cost of system. The remaining terms are multiplied by the corresponding probability of its 
scenario. The first term is the fixed cost of opening manufacturers according to its selected technology. The second term is the fixed costs of establishment for other facilities. The third to seventh summations are affiliated with purchasing, manufacturing, handling, transportation, assignment costs. The eights and tenth terms represent the saving resulting from the disposal, remanufacturing and recycling of returned products. These terms specify the profit of CLSC configuration in our model. The social objectives regarding the job opportunities and work damages are presented as the following equations separately.

$$
\begin{aligned}
\max E(\mathrm{Job})= & \max \left(\sum _ { c = 1 } ^ { C } p b _ { c } \left[\sum_{p=1}^{P} \sum_{t=1}^{T} f j_{p t} \cdot Y_{p t}+\sum_{e=1}^{E} \sum_{f=1}^{F} f j_{f_{e}} \cdot Y_{f_{e}}\right.\right. \\
& +\sum_{p=1}^{P} \sum_{t=1}^{T} v o_{p t} . H_{p t}^{c} / p_{p t}+\sum_{n=1}^{N} \sum_{p=1}^{P} v o_{n} X_{p n}^{c} / p_{n} \\
& \left.\left.+\sum_{j=1}^{J} \sum_{i=1}^{I} v o_{j} . Z_{i j}^{c} \cdot \propto_{i} . d_{i}^{c}+\sum_{e=1}^{E} \sum_{f=1}^{F} \sum_{j=1}^{J} v o_{f_{e}} X_{j f_{e}}^{c} / p_{f_{e}}\right]\right)
\end{aligned}
$$

Equation (2) reveals the social aspects regarding the job opportunities to be maximized. Like the first objective, the remaining terms are multiplied by the corresponding probability of its scenario. The first term depending on the type of technology remains the fixed job opportunities for manufacturers. The second term shows the formulation of fixed job opportunities for other facilities as well. The third to sixth terms represent the variable job opportunities related to the amount of manufactured, distributed and sold products as well as other activities in facilities depending on the flow of products, accordingly.

$$
\begin{aligned}
\min E(\text { Work }) & =\min \left(\sum _ { c = 1 } ^ { C } p b _ { c } \left[\sum_{p=1}^{P} \sum_{t=1}^{T} f l_{p t} \cdot Y_{p t}+\sum_{e=1}^{E} \sum_{f=1}^{F} f l_{f_{e}} \cdot Y_{f_{e}}\right.\right. \\
& +\sum_{p=1}^{P} \sum_{t=1}^{T} v l_{p t} \cdot H_{p t}^{c} / p_{p t}+\sum_{n=1}^{N} \sum_{p=1}^{P} v l_{n} X_{p n}^{c} / p_{n} \\
& \left.\left.+\sum_{j=1}^{J} \sum_{i=1}^{I} v l_{j} . Z_{i j}^{c} \cdot \propto_{i} \cdot d_{i}^{c}+\sum_{e=1}^{E} \sum_{f=1}^{F} \sum_{j=1}^{J} v l_{f_{e}} X_{j f_{e}}^{c} / p_{f_{e}}\right]\right)
\end{aligned}
$$

In addition, the impact of work's damages is considered in terms of Equation (3) to be minimized. Regarding the scenario-based properties of formulation, the remaining terms are multiplied by the corresponding probability of its scenario. The first to fifth terms stand for the work's damages which are caused either during the establishment of facilities or during the manufacturing and handling of products.

Notably, the downside risk objective as the fourth objective function of the model will be illustrated after presenting constraints of model as follows: 
As depicted in Fig. 1, Equations (4) to (9) ensure that the flow of products and correlation of decision variables to each other are maintained. For instance, Equation (4) guarantees that the amount of manufactured products should be equaled to the amount of distributed products in markets.

$$
\begin{aligned}
& \sum_{m=1}^{M} X_{m p}^{c}=\sum_{n=1}^{N} X_{p n}^{c} \quad \forall c, p \\
& \sum_{p=1}^{P} X_{p n}^{c}=\sum_{i=1}^{I} Z_{n i}^{c} \cdot d_{i}^{c} \quad \forall c, n \\
& \sum_{f_{e}=1}^{F_{e}} X_{j f_{e}}^{c}=\sum_{i=1}^{I} \alpha_{i} \cdot d_{i}^{c} \cdot Z_{i j}^{c} \quad \forall c, j, \quad e \in\{d, r, s\} \\
& \sum_{m=1}^{M} X_{s m}^{c}=\left(1-\gamma_{s}\right) \sum_{j=1}^{J} X_{j s}^{c} \quad \forall c, s \\
& \sum_{p=1}^{P} X_{d p}^{c}=\left(1-\gamma_{d}\right) \sum_{j=1}^{J} X_{j d}^{c} \quad \forall c, d \\
& \sum_{n=1}^{N} X_{r n}^{c}=\left(1-\gamma_{r}\right) \sum_{j=1}^{J} X_{j r}^{c} \quad \forall c, r
\end{aligned}
$$

Equation (10) represents the amount of products which should be manufactured by each plant center:

$$
\sum_{t=1}^{T} H_{p t}^{c}=\sum_{m=1}^{M} X_{m p}^{c} \quad \forall c, p
$$

Only one technology is considered for each potential site of established plant.

$$
\sum_{t=1}^{T} Y_{p t}=1 \quad \forall p
$$

For each customer, only one distribution center and recover center should be considered:

$$
\sum_{n=1}^{N} Z_{n i}^{c}=\sum_{j=1}^{J} Z_{i j}^{c}=1 \quad \forall c, i
$$


As mentioned in the assumption, the capacity of facilities has been limited in this study. Equation (13) shows the capacity constraints of suppliers:

$$
\sum_{m=1}^{M} X_{m p}^{c} \leq p_{m} \quad \forall c, p
$$

Similar to above formula, Equation (14) represents that manufacturer can manufacture the products only when it is opened and it has an idle capacity:

$$
\sum_{c=1}^{C} H_{p t}^{c} \leq p_{p t} . Y_{p t} \quad \forall p, t
$$

Generally, a facility is allowed to process the products only when the respective facility is operating and has enough capacity:

$$
\begin{aligned}
& \sum_{p=1}^{P} X_{p n}^{c} \leq p_{n} \cdot Y_{n} \quad \forall c, k \\
& \sum_{i=1}^{I} \propto_{i} \cdot d_{i}^{c} \cdot Z_{i j}^{c} \leq p_{j} . Y_{j} \quad \forall c, j \\
& \sum_{j=1}^{J} X_{j f_{e}}^{c} \leq p_{f_{e}} \cdot Y_{f_{e}} \quad \forall e \in\{d, r, s\}
\end{aligned}
$$

The budget of CLSC configuration is limited to allow that only some facilities in each echelon can be opened.

$$
\begin{aligned}
& \sum_{\substack{p=1 \\
F_{e}}}^{P} \sum_{t=1}^{T} Y_{p t} \leq \max _{p} \\
& \sum_{f_{e}=1}^{F_{e}} Y_{f_{e}} \leq \max _{e} \quad \forall e \in\{d, m, n, p, r, s\}
\end{aligned}
$$

Finally, binary and positive variables are guaranteed in stage one:

$$
\begin{aligned}
& Y_{p t}, Y_{f_{e}}, Z_{n i}^{c}, Z_{i j}^{c} \in\{0,1\} \\
& X_{f_{e} f_{e}}^{c}, H_{p t}^{c} \geq 0
\end{aligned}
$$


To control the uncertainty with unfavorable scenarios, the risk management is employed which helps the Decision Maker (DM) when it develops the stochastic programming. An efficient way to manage the risk and uncertainty programming model is to add a risk metric leading to a multi-objective optimization model where the total cost, the social impacts and the risk measure are three objective functions to be optimized. The downside risk can be formulated as follows:

$$
\begin{aligned}
& \operatorname{DRisk}_{\varphi}=E\left(V_{c \varphi}\right) \\
& \text { where } V_{c \varphi}=\left\{\begin{array}{c}
\operatorname{Cost}^{c}-\varphi \text { if } \operatorname{Cost}^{c}>\varphi \\
0 \text { otherwise }
\end{array} \forall c\right\}
\end{aligned}
$$

$V_{c \varphi}$ is a positive variable that measures deviation between the scenario cost value $\left(\operatorname{Cost}^{c}\right)$ with a target $\varphi$. Downside risk $\left(D_{R i s k_{\varphi}}\right)$ is defined as the expected value of the positive variable $V_{c \varphi}$. Since the CLSC model is designed under uncertainty with probabilistic scenario, the risk associated with considered CLSC's activities should be evaluated by downside risk. This metric to measure the risk can help the DM in its decisions about the CLSC. To coordinate this metric within the mathematical formulation, a set of constraints defined by Equations (24), (25) and (26) should be added as second stage of developed model which were formulated by equations (1)-(21).

$$
\begin{aligned}
& \min \operatorname{DRisk}_{\varphi}=\min \left(\sum_{c=1}^{C} p b_{c} V_{c \varphi}\right) \\
& V_{c \varphi} \geq \operatorname{Cost}^{c}-\varphi, \forall c \\
& V_{c \varphi} \geq 0, \forall c
\end{aligned}
$$

\section{Proposed solution}

As mentioned earlier, the proposed model is developed in a two-stage stochastic programming. In stage one, the expected value of the total cost and social impacts with two conflicting goals are computed. Then, for each cost of scenario in the first objective, the downside risk is calculated in order to be optimized. So, there are four conflicting goals in this study. As mentioned before, this problem is known as NP-hard. Addressing the NP-hard problems requires effective methods to find the best optimal solution successfully [61]. As pointed out by Mirjalili et al. [62], the No Free Lunch (NFL) theory [63] indicates that there is no algorithm to solve all optimization problems. Therefore, the current algorithms might need modifications, tunings, or hybridizations to solve a set of specific problems [64].

We present and use two powerful recent metaheuristics. These methods have been introduced recently and proved to be beneficial when solving optimization problems (e.g. [65]; [2]; [3]). From Table 2, most of papers in SCND used two successful methods (i.e. GA-based and SA-based algorithms). So, researchers also utilize these well-known methods to compare with the new proposed ones. Here, we utilize NSGA-II and multi-objective of SA to evaluate the recent presented ones. In this work, three new hybridization methods are developed from both 
groups in order to enrich the algorithms efficiently and aggregate their advantages. The hybridized algorithms are based on the incorporating three metaheuristics in the same time. Note that the $\varepsilon$-constraint method is utilized to control the satisfying the results of metaheuristics.

Notably, due to page limitation, the description of multi-objective optimization has been illustrated in online supplement F1. Also, our individual metaheuristics including NSGA-II, multi-objective of SA and KA and also RDA have been addressed in online supplement F2, F3, F4 and F5, respectively. The illustration of $\varepsilon$-constraint method has been transformed into online supplement F6 as well. In the following subsections, the encoding and decoding presentations along with three proposed novel metaheuristics are detailed to solve the problem proposed.

\subsection{Encoding scheme}

In order to use metaheuristic approaches, a two-stage technique called Random-Key $(R K)$ is employed to solve developed mathematical formulation. This paper utilizes a two-stage technique called Random-Key $(R K)$ to solve the developed discrete problem. Researchers have used this technique repeatedly during last two decades e.g. Golshahi-Roudbaneh et al. [68]; Fathollahi Fard and Hajaghaei-Keshteli [2] and Samadi et al. [3]. This technique assists users to use any continuous and binary metaheuristics to solving a mathematical formulation model with various variables and constraints [2]. In $R K$, two main steps are existed. Firstly, a solution is generated randomly and converted into a feasible discrete solution by a procedure [69]. In this problem, the solutions are defined in three different sub-solutions. The illustration of encoding sub-solutions is depicted in Fig. 2. A matrix with size $|q|$ elements that are uniformly distributed over 0 to 1 is constructed (Fig. 2(a)). This sub-solution is transformed into binary variables indexation $\left(Q_{\operatorname{Max}}=3\right)$ the selection of distribution centers, recover centers, remanufacturing centers and recycling centers and also disposal $\left(\mathrm{Q}_{2}, \mathrm{Q}_{4}\right.$, and $\mathrm{Q}_{5}$ in the given example). Furthermore, conforming to Fig. 2(b), the type of technology is determined for each plant. Eventually, Fig. 2(c) determines the flow of products. In the other words, a random matrix is formed with number of rows equals the number of non-zero element obtained ( 3 in the given example) and number of columns equal to destination facilities ( 4 in the given example). The columns of the second matrix are then normalized to specify how distributers and other facilities distribute their supply.

\begin{tabular}{|c|c|c|c|c|}
\hline$Q_{1}$ & $Q_{2}$ & $Q_{3}$ & $Q_{4}$ & $Q_{5}$ \\
\hline 0.34 & 0.57 & 0.25 & 0.68 & 0.92 \\
\hline \multicolumn{5}{|c|}{$Q_{\operatorname{Max}}=3$} \\
\hline 0 & 1 & 0 & 1 & 1 \\
\hline
\end{tabular}

Facilities selection sub-solution (a)

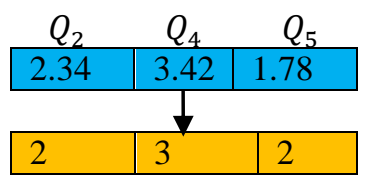

Technology selection (b)

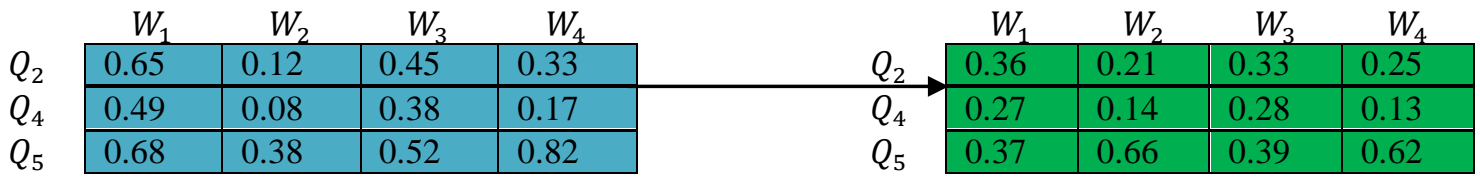

\section{Shipment from plants to distribution centers (c)}


Fig. 2. The graphical illustration of structure solution with three parts: (a) Facilities selection sub-solution; (b) Technology levels selection; (c) Flow of products sub-solution;

\subsection{RDSAGA}

Another main contribution of this paper is to propose three new hybrid metaheuristic approaches. In this regard, a powerful recent algorithm is employed as the main actor and the others help it to search carefully the feasible space. In this section, RDA illustrated in online supplement F5 is used in the core loop and both SA and GA which are stated in online supplement F2 and F3, respectively, improve the local search. As discussed earlier, RDA has three phases: roaring, fighting and mating. Instead of roaring process, the SA mechanism is utilized to amend the exploitation properties. Actually in RDA, the mating behavior is to enhance the exploratory behavior. Although it seems that the mentioned process is very good at performing the diversification phase, it is too long and complex. In this regard, the crossover operator in GA is obtained to do the exploration and reform the mating process. For each commander, a hind is selected by the roulette wheel selection in order to mate. Due to clarifying the proposed method, Fig. 3 presents the pseudo-code of algorithm. This algorithm is compared to their own general methods and also RDSA to probe this idea.

Initialize the Red Deers population.

Calculate the fitness and sort them and form the hinds $\left(N_{\text {hind }}\right)$ and male RDs $\left(N_{\text {male }}\right)$.

Generate the Pareto frontiers of solutions.

$\mathrm{T}_{1}=$ clock;

while $(t<$ maximum time of simulation)

for each male RD

$\mathrm{sub}=0$;

while (sub< maximum number of sub-iteration)

Create a neighbor of this solution.

if the function value (at least of all) of the new solution is better than prior

Replace the old solution by new solution.

else

Compute $\delta, \delta=\left|f_{\text {old }}-f_{\text {new }}\right|$.

if $\mathrm{rand}<\exp (-\delta / T)$

Replace the new solution

endif

$\mathrm{sub}=\mathrm{sub}+1$;

endwhile

endfor

Update $T$.

Sort the males and also form the stags and the commanders.

for each male commander

Select a hind by roulette wheel selection.

Mate (Crossover) male commander with the selected hind.

end for

for each stag

Select a hind randomly.

Mate (Crossover) stag with the selected hind. 


\section{end for}

Select the next generation via roulette wheel selection.

Update the Pareto frontiers.

Update the best set of solutions.

$\mathrm{T}_{2}=$ clock;

$\mathrm{t}=$ etime $\left(\mathrm{T}_{2}, \mathrm{~T}_{1}\right)$;

end while

return the best set of Pareto optimal solutions

Fig. 3. The pseudo-code of RDSAGA

\subsection{KAGASA}

As explained in the KA from online supplement F4, this algorithm utilizes a strong exploitation mechanism. Also, in exploration phase, the algorithm uses two different procedures; moving some Keshtels and replacing the other Keshtels by new random ones. Moving the Keshtels over the feasible area to find virgin zones is a good idea to cover whole space. But, this operator is improved by SA to search intelligently. Besides, replacing the Keshtels by new random ones, although keeps the randomized nature of this algorithm, the evolutionary concepts used in GA can employed for this step. We select two different Keshtels as parents by the roulette wheel and make new solutions or offspring by crossover operator and replace with their parents in the next generation. This idea is examined to solve the problem in comparison of their original algorithms and also KAGA. The pseudo-code of algorithm is specified in Fig. 4.

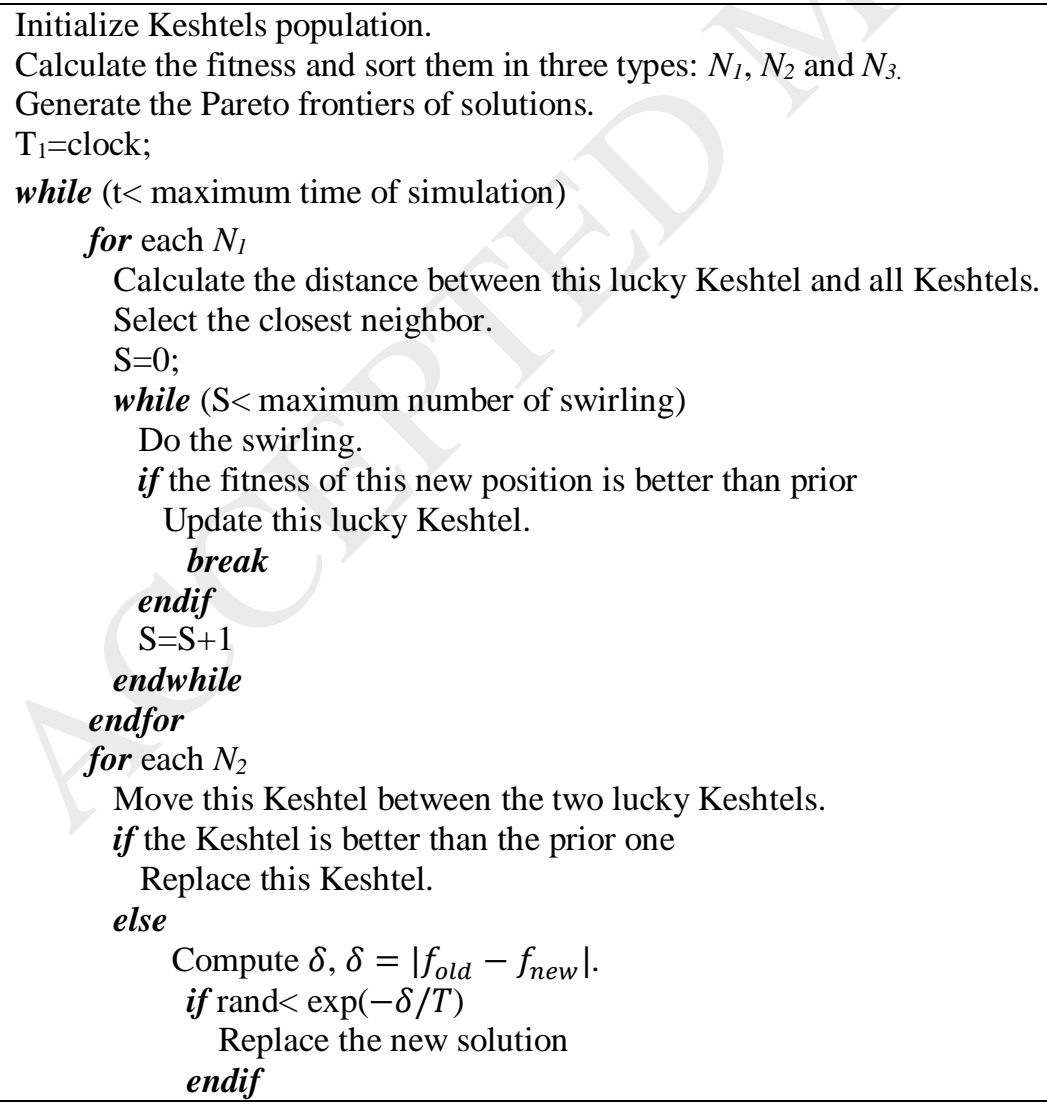




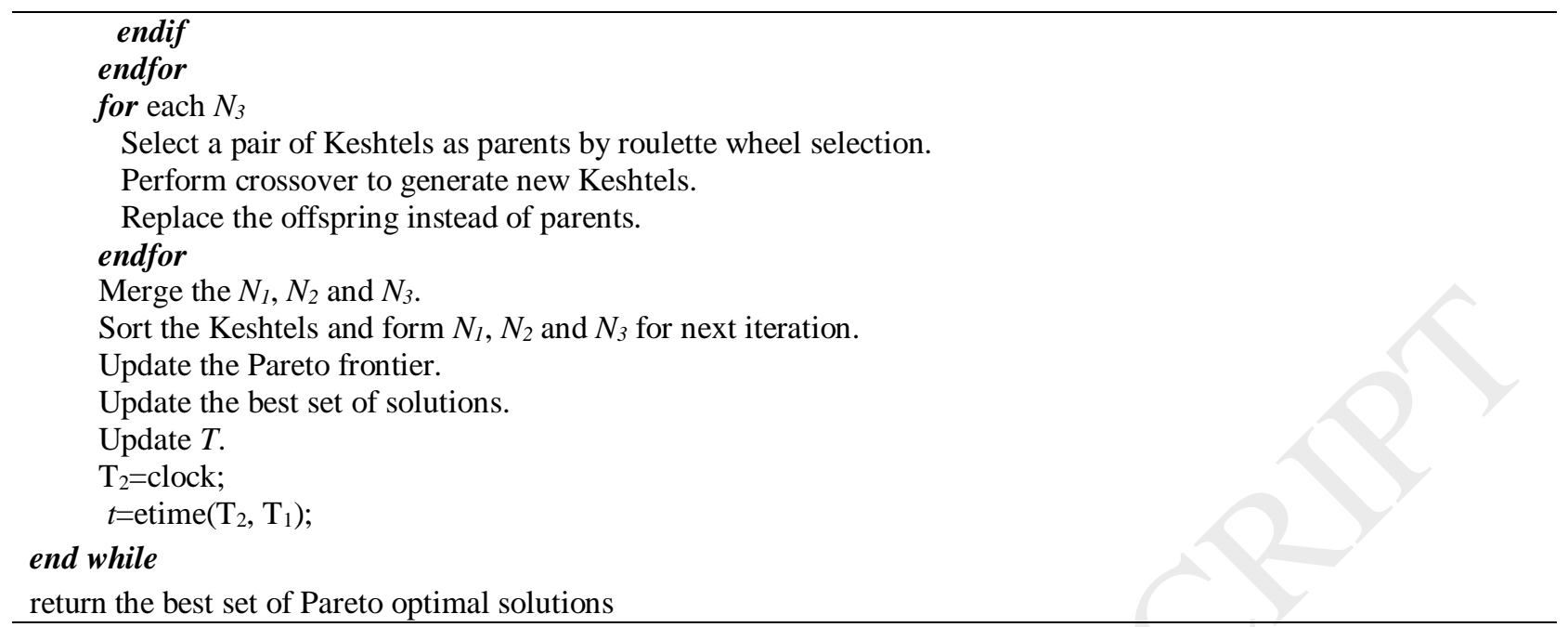

Fig. 4. The pseudo-code of KAGASA

\subsection{RDKAGA}

As mentioned earlier, KA benefits from a high exploitative behaviour. It seems that the swirling process can be done instead of two processes including of roaring and fighting in RDA. In this way, for each male, the closest neighbor is specified and the swirling action is done. Due to mating process, like RDSAGA, the GA mechanism is developed. In brief, KA is specified the intensification action and GA is measured the diversification phase. This opinion is employed to examine the proposed method with their original methods and also RDKA. To probe the proposed RDKAGA, the pseudo-code is presented in Fig. 5.

Initialize the Red Deers population.

Calculate the fitness and sort them and form the hinds $\left(N_{\text {hind }}\right)$ and male RDs $\left(N_{\text {male }}\right)$.

Generate the Pareto frontiers of solutions.

$\mathrm{T}_{1}=$ clock;

while $(t<$ maximum time of simulation)

for each male RD

Calculate the distance between this male and all males.

Select the closest neighbor.

$\mathrm{S}=0$;

while $(\mathrm{S}<$ maximum number of swirling)

Do the swirling.

if the fitness of this new position is better than prior

Update this lucky male.

break

endif

$\mathrm{S}=\mathrm{S}+1$

endwhile

endfor

Sort the males and also form the stags and the commanders.

for each male commander

Select a hind by roulette wheel selection.

Mate (Crossover) male commander with the selected hind.

end for 


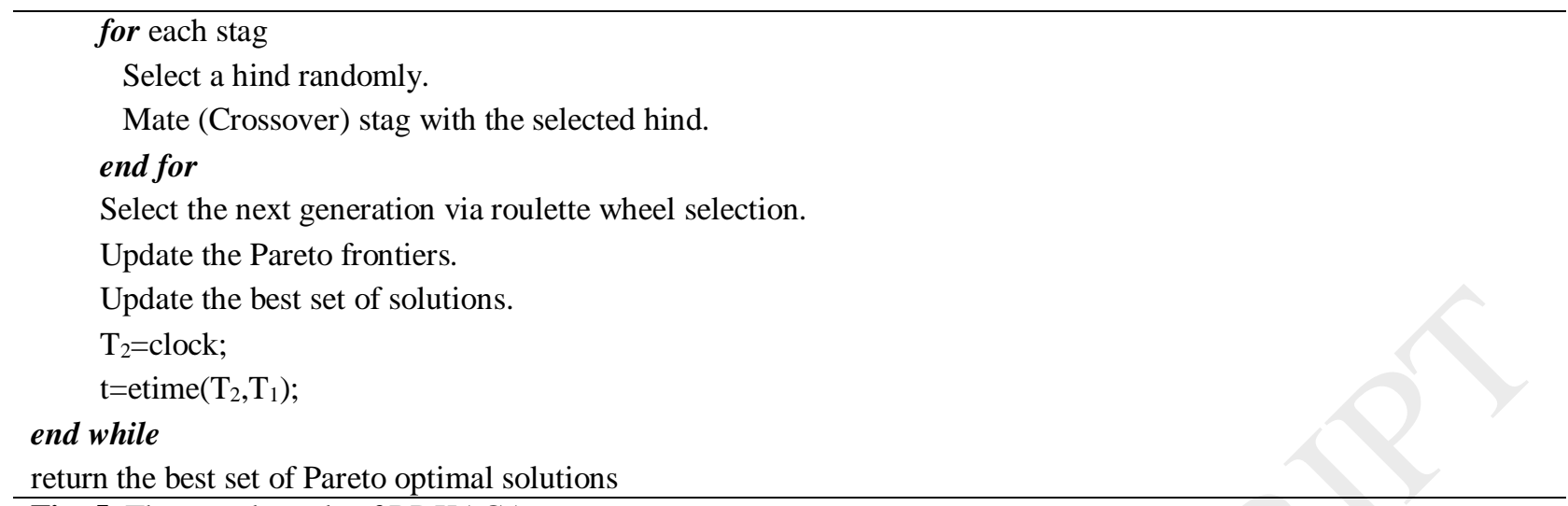

Fig. 5. The pseudo-code of RDKAGA

\section{Experimental results}

In this section, firstly, the test problem according to the novelty of developed formulation has been generated. Then, by proposing five assessment metrics regarding the population of Pareto optimal sets, the algorithms will be tuned. Consequently, statistical analyses in different criteria are performed as well as some sensitivity analyses are discussed to assess the risk model.

\subsection{Data generation}

In order to analyze the efficiency and performance of algorithms, a set of test problems are generated. The number of potential places in each echelon directly indicates the complexity of the problem [69]. Here, the problems are divided into three classes (i.e. small, medium and large). In each level, eight random problems are generated. In this regard, 24 test problems are examined. In each test problem, the 10 scenarios are defined. The details of the test problems are shown in Table 6, 7 and 8. To have a fair comparison, the searching time for algorithms in each test problem is defined by considering the size of problems as seen in Table 6. Indeed, by increasing the size of problem, the searching time of metaheuristics is updated as well.

Table 6.

The level, number and size of problems

\begin{tabular}{|lllll|}
\hline $\begin{array}{l}\text { Problem } \\
\text { levels }\end{array}$ & $\begin{array}{l}\text { Problem } \\
\text { numbers }\end{array}$ & $\begin{array}{l}\text { Number of } \\
\text { scenarios }(\mathrm{C})\end{array}$ & Problem size $(M, P, T, N, I, J, D, R, S)$ & $\begin{array}{l}\text { Searching time } \\
(\text { Sec })\end{array}$ \\
\hline Small & P1 & 10 & $(7,5,2,10,9,10,3,2,2)$ & 100 \\
& P2 & 10 & $(11,7,2,10,12,10,5,5,3)$ & 120 \\
& P3 & 10 & $(15,9,2,12,15,12,7,6,4)$ & 130 \\
& P4 & 10 & $(19,11,3,14,18,14,9,8,5)$ & 130 \\
& P5 & 10 & $(23,13,3,16,21,16,11,10,6)$ & 140 \\
& P6 & 10 & $(27,15,3,18,24,18,13,10,7)$ & 140 \\
& P7 & 10 & $(31,17,4,20,27,20,15,12,8)$ & 150 \\
& P8 & 10 & $(35,19,4,22,30,22,17,12,9)$ & 160 \\
& & & & \\
& P9 & 10 & $(55,29,7,31,51,31,19,18,16)$ & 160
\end{tabular}




\begin{tabular}{|lllll|} 
& P13 & 10 & $(71,37,8,39,63,39,27,22,20)$ & 180 \\
& P14 & 10 & $(75,39,8,41,66,41,29,24,21)$ & 200 \\
& P15 & 10 & $(79,41,9,43,69,43,31,24,22)$ & 220 \\
& P16 & 10 & $(83,43,9,45,72,45,33,26,23)$ & 220 \\
\hline Large & & & \\
& P17 & 10 & $(103,53,11,57,107,57,35,34,28)$ & 240 \\
& P18 & 10 & $(107,55,11,59,111,59,36,35,29)$ & 250 \\
& P19 & 10 & $(111,57,11,61,115,61,37,37,30)$ & 260 \\
P20 & 10 & $(115,59,12,63,119,63,38,39,31)$ & 270 \\
P21 & 10 & $(119,61,12,65,123,65,39,40,32)$ & 280 \\
& P22 & 10 & $(123,63,12,67,127,67,40,42,33)$ & 280 \\
P23 & 10 & $(127,65,13,69,131,69,41,42,34)$ & 290 \\
P24 & 10 & $(131,67,13,71,135,71,42,43,35)$ & 300 \\
\hline
\end{tabular}

Table 7.

Parameters and their surfaces.

\begin{tabular}{|ll|}
\hline Parameters & Surfaces \\
\hline$v c_{d}, v c_{m}, v c_{n}, v c_{r}, v c_{s}, v c_{j}, v c_{p}$ & $\sim U(1,5)$ \\
$t c_{f f}$ & $\sim U(1,6)$ \\
$b_{p t}$ & $\sim U(0.01,0.03)$ \\
$\propto_{i}$ & $\sim U(0.3,0.7)$ \\
$f j_{p t}, f j_{f}$ & $\sim U(5,10)$ \\
$v o_{p t}, v o_{f}$ & $\sim U(0.02,0.06)$ \\
$v l_{p t}, v l_{f}$ & $\sim U(0.1,1)$ \\
$f l_{p t}, f l_{f}$ & $\sim U(10,1000)$ \\
$\gamma_{d}, \gamma_{j}, \gamma_{r}$ & $\sim U(0,0.3)$ \\
\hline
\end{tabular}

Table 8. Parameters and their surface Parameters Set of scenarios

\begin{tabular}{|c|c|c|c|c|c|c|c|c|c|c|}
\hline & $\mathrm{c}=1$ & $\mathrm{c}=2$ & $c=3$ & $\mathrm{c}=4$ & $\mathrm{c}=5$ & $c=6$ & $\mathrm{c}=7$ & $\mathrm{c}=8$ & $\mathrm{c}=9$ & $c=10$ \\
\hline$p c_{m}^{c}, m c_{p t}^{c}$ & $\sim U(5,10)$ & $\sim U(7,12)$ & $\sim U(10,15)$ & $\sim U(12,17)$ & $\sim U(15,20)$ & $\sim U(17,22)$ & $\sim U(20,25)$ & $\sim U(22,27)$ & $\sim U(25,30)$ & $\sim U(27,32)$ \\
\hline$a c_{n i}^{c}$ & $\sim U(0.5,3)$ & $\sim U(1.5,4.5)$ & $\sim U(2.5,5.5)$ & $\sim U(3.5,6.5)$ & $\sim U(4.5,7.5)$ & $\sim U(5.5,8.5)$ & $\sim U(6.5,9.5)$ & $\sim U(7.5,10.5)$ & $\sim U(8.5,11.5)$ & $\sim U(9.5,12.5)$ \\
\hline${ }_{d} c$ & $\begin{array}{l}\sim N(100, \\
20)\end{array}$ & $\begin{array}{l}\sim N(100, \\
20)\end{array}$ & $\begin{array}{l}\sim N(120, \\
20)\end{array}$ & $\begin{array}{l}\sim N(140, \\
20)\end{array}$ & $\begin{array}{l}\sim N(160, \\
20)\end{array}$ & $\begin{array}{l}\sim N(180, \\
20)\end{array}$ & $\begin{array}{l}\sim N(200, \\
20)\end{array}$ & $\sim N(220,20)$ & $\sim N(240,20)$ & $\sim N(260,20)$ \\
\hline
\end{tabular}

In addition, a half of potential number of units is considered according to their maximum desired numbers. The fixed opening costs of facilities are approximated as follows:

$f c_{f}^{\text {mean }}=\frac{\propto \times \max _{f}}{F} \times \frac{\sum_{f=1}^{F} \sum_{f^{\prime}=1}^{F} t c_{f f^{\prime}}}{F \times F^{\prime}}, \forall f=\{j, d, m, n, p, r, s\}$

$f c_{f}^{\text {min }}=\left[(1-\delta) \times f c_{f}^{\text {mean }}\right]$ and $f c_{f}^{\text {max }}=\left[(1+\delta) \times f c_{f}^{\text {mean }}\right], \forall f=\{j, d, m, n, p, r, s\}$

$f c_{f}=U\left(f c_{f}^{\min }, f c_{f}^{\max }\right)$

where $\propto \sim U(35,45)$ and $\delta \sim U(0,0.1)$. In addition, the capacities of facilities are estimated as follows: 
$p_{f}^{\text {mean }}=\frac{\gamma \times(1+\beta)}{\max _{f}}, \forall f=\{j, d, m, n, p, r, s\}$

$p_{f}^{\text {min }}=\left[(1-\delta) \times p_{f}^{\text {mean }}\right]$ and $p_{f}^{\text {max }}=\left[(1+\delta) \times p_{f}^{\text {mean }}\right], \forall f=\{j, d, m, n, p, r, s\}$

$p_{f}=U\left(p_{f}^{\min }, p_{f}^{\max }\right), \forall f=\{j, d, m, n, p, r, s\}$

where $\gamma$ is the summation of demands which is limited by lower hand echelon, and also $\beta$ and $\delta$ are coefficients distributed as $U(0,0.1)$. Furthermore, $s c_{s}, s c_{d}$ and $s c_{r}$ are approximated as the average total of cost of purchasing, manufacturing, handling a product which is taken back to the respective stage in the forward chain. Finally, the value of target $\varphi$ is depended on the size of problem and estimated with the expected cost value.

\subsection{Evaluation metrics}

In order to solve the proposed problem, five metrics are presented. These metrics aim to evaluate the quality of Pareto optimal solutions (i.e. Diversification Metric (DM) [12], Spread of Non-dominance Solution (SNS) [70], Data Envelopment Analysis (DEA) [71] and Percentage of Domination (POD) [72] and also Hypervolume (HV) [73]). The higher value of these metrics brings the better solution quality. The characteristics of metric are explained simultaneously in Table 9. These parameters are presented in recent researches. So, we refer the readers interested to study more about the formulations and illustrations of these assessment metrics to [70-75] and Govindan et al. [12] as well.

Table 9. Metrics used to measure the quality of Pareto optimal solutions

\begin{tabular}{|ll|}
\hline Metrics & Definition \\
\hline Diversification Metric (DM) & Measures the spread of non-dominated solution set. \\
\hline Spread of Non-dominated Solution (SNS) & Measures the diversity of solutions. \\
\hline Percentage of Domination (POD) & $\begin{array}{l}\text { Measures the ability of an algorithm to dominate the solutions of other } \\
\text { algorithms. }\end{array}$ \\
\hline Data Envelopment Analysis (DEA) & Determines the efficiency of solutions. \\
\hline Hypervolume (HV) & Measures the size of portion of objective space \\
\hline
\end{tabular}

\subsection{Parameters setting}

When a metaheuristic is used, it is necessary to tune its parameters [49]; [75]. RSM introduced by Box and Wilson [76] is employed in this paper. In this method, each factor $\left(X_{i}\right)$ which is measured at two levels that can be coded as -1 to 1 the low level $\left(x_{l}\right)$ and high level $\left(x_{h}\right)$ of each variable, respectively [77]. The following equation shows the independent variables which are used in our study:

$$
x_{i}=\frac{2 X_{i}-x_{h}-x_{l}}{x_{h}-x_{l}}, i=\{1,2, \ldots, K\}
$$


where $K$ is the number of variables. The response surface when variables are assumed measurable can be declared as $\mathrm{y}=f_{\left(x_{1}, x_{2}, \ldots, x_{n}\right)}$. And the goal is to optimize response variables. In this way, we define $y$ which is utilized to describe the variation in response variables, as follows:

$$
y=\beta_{0}+\sum_{j=1}^{k} \beta_{j} x_{j}+\sum_{j=1}^{k} \sum_{i<j}^{k} \beta_{i j} x_{i} x_{j}+\sum_{j=1}^{k} \beta_{j j} x_{j j}^{2}+\varepsilon
$$

where $\beta_{0}, \beta_{j}, \beta_{i j}$ and $\beta_{j j}$ are the constant of the linear coefficient, the interaction coefficient $\left(\beta_{i j}\right)$, and the quadratic coefficient $\left(\beta_{j j}\right)$, respectively. Note that Equation (34) should be assumed while there is curvature in the system. The factors and their levels as well as the number of experiments are shown in Table 10. In this table, the lower limit and upper limit are written on left and write, respectively.

Table 10. Algorithms and Factor levels with the number of experiments.

\begin{tabular}{|c|c|c|c|c|c|c|c|c|}
\hline Algorithm & Facto & and the & levels & & & & & $\begin{array}{l}\text { Number of experiments; } \\
\text { Total Number }=\left(n_{f}, n_{a x} \text {, }\right.\end{array}$ \\
\hline RDA & $\begin{array}{l}\text { nPop } \\
(100, \\
200)\end{array}$ & $\begin{array}{l}N_{\text {male }} \\
(15, \\
40)\end{array}$ & $\begin{array}{l}P_{\propto} \\
(0.6 \\
0.9)\end{array}$ & $\begin{array}{r}P_{\beta} \\
(0.4 \\
0.7)\end{array}$ & $\begin{array}{r}P_{\gamma} \\
(0.5 \\
0.8)\end{array}$ & & & $48=\left(2^{5}, 10,6\right)$ \\
\hline KA & $\begin{array}{l}\text { nPop } \\
(100, \\
200)\end{array}$ & $\begin{array}{l}P_{N 1} \\
(0.2 \\
0.5)\end{array}$ & $\begin{array}{l}P_{N 2} \\
(0.1 \\
0.4)\end{array}$ & $\begin{array}{l}N_{\text {Swirl }} \\
(2,10)\end{array}$ & & & & $30=\left(2^{4}, 8,6\right)$ \\
\hline NSGA-II & $\begin{array}{l}\text { nPop } \\
(100, \\
200)\end{array}$ & $\begin{array}{r}P_{C} \\
(0.5 \\
0.8) \\
\end{array}$ & $\begin{array}{l}P_{M} \\
(0.02 \\
0.1) \\
\end{array}$ & & & & & $20=\left(2^{3}, 6,6\right)$ \\
\hline SA & $\begin{array}{l}\text { SubIt } \\
(20, \\
50)\end{array}$ & $\begin{array}{l}\text { T0 } \\
(500 \\
1000) \\
\end{array}$ & $\begin{array}{r}R_{\propto} \\
(0.99 \\
0.999) \\
\end{array}$ & & & & & $20=\left(2^{3}, 6,6\right)$ \\
\hline RDSA & $\begin{array}{l}\text { nPop } \\
(100, \\
200)\end{array}$ & $\begin{array}{l}N_{\text {male }} \\
(15, \\
40)\end{array}$ & $\begin{array}{r}P_{\propto} \\
(0.6 \\
0.9) \\
\end{array}$ & $\begin{array}{r}P_{\beta} \\
(0.4 \\
0.7) \\
\end{array}$ & $\begin{array}{r}P_{\gamma} \\
(0.5, \\
0.8) \\
\end{array}$ & $\begin{array}{l}\text { T0 } \\
(500, \\
1000) \\
\end{array}$ & $\begin{array}{c}R_{\propto} \\
(0.99 \\
0.999) \\
\end{array}$ & $\begin{array}{l}70=(50,14,6) \\
\text { Min Run Ress } \\
\text { V }\end{array}$ \\
\hline KAGA & $\begin{array}{l}\text { nPop } \\
(100, \\
200)\end{array}$ & $\begin{array}{l}P_{N 1} \\
(0.2 \\
0.5)\end{array}$ & $\begin{array}{l}P_{N 2} \\
(0.1, \\
0.4)\end{array}$ & $\begin{array}{l}N_{\text {Swirl }} \\
(2,10)\end{array}$ & & & & $30=\left(2^{4}, 8,6\right)$ \\
\hline RDKA & $\begin{array}{l}\text { nPop } \\
(100, \\
200)\end{array}$ & $\begin{array}{l}N_{\text {male }} \\
(15, \\
40)\end{array}$ & $\begin{array}{l}P_{\alpha} \\
(0.6 \\
0.9)\end{array}$ & $\begin{array}{r}P_{\beta} \\
(0.4 \\
0.7)\end{array}$ & $\begin{array}{l}N_{\text {Swirl }} \\
(2, \\
10)\end{array}$ & & & $48=\left(2^{5}, 10,6\right)$ \\
\hline RDSAGA & $\begin{array}{l}\text { nPop } \\
(100, \\
200)\end{array}$ & $\begin{array}{l}N_{\text {male }} \\
(15, \\
40)\end{array}$ & $\begin{array}{r}P_{\gamma} \\
(0.5 \\
0.8)\end{array}$ & $\begin{array}{l}\text { T0 } \\
(500, \\
1000)\end{array}$ & $\begin{array}{c}R_{\propto} \\
(0.99 \\
0.999)\end{array}$ & & & $48=\left(2^{5}, 10,6\right)$ \\
\hline KAGASA & $\begin{array}{l}\text { nPop } \\
(100, \\
200)\end{array}$ & $\begin{array}{l}\quad P_{N 1} \\
(0.2 \\
0.5)\end{array}$ & $\begin{array}{l}P_{N 2} \\
(0.1 \\
0.4)\end{array}$ & $\begin{array}{l}N_{\text {Swirl }} \\
(2,10)\end{array}$ & $\begin{array}{l}\text { T0 } \\
(500, \\
1000)\end{array}$ & $\begin{array}{c}R_{\propto} \\
(0.99 \\
0.999)\end{array}$ & & $\begin{array}{l}60=(42,12,6) \\
\text { Min Run Ress } \\
\text { V }\end{array}$ \\
\hline RDKAGA & $\begin{array}{l}\text { nPop } \\
(100, \\
200)\end{array}$ & $\begin{array}{l}N_{\text {male }} \\
(15, \\
40)\end{array}$ & $\begin{array}{l}N_{\text {Swirl }} \\
(2,10)\end{array}$ & & & & & $20=\left(2^{3}, 6,6\right)$ \\
\hline
\end{tabular}


Since some performance evaluation metrics are utilized together to make quantitative comparisons in multi-objective metaheuristics, such methods will be tuned by a medium problem (i.e. P13) to set the input value of factors based on the represented evaluation metrics as illustrated in Table 9 simultaneously, which leads to desired response in multi-objective decision making (MODM). In this way, Derringer and Suich [78] presented a utility function according to Eq. (35) and (36) to optimize the multiple responses for minimizing and maximizing functions, as following equations:

$$
\begin{array}{ll}
d_{i}\left(y_{i}\right)=\left(\frac{h_{i}-y_{i}}{h_{i}-l_{i}}\right)^{s}, & l_{i}<y_{i}<h_{i} \\
d_{i}\left(y_{i}\right)=\left(\frac{y_{i}-l_{i}}{h_{i}-l_{i}}\right)^{s}, & l_{i}<y_{i}<h_{i}
\end{array}
$$

Where response functions in form of minimum $y_{i}$ are transformed to a utility function $d_{i}\left(y_{i}\right)$. The parameters $l_{i}$ and $h_{i}$ are lower and upper bounds, respectively. The variable $s$ measures the severity of $d_{i}\left(y_{i}\right)$ by which the shape of the desirability can be arrayed for each goal by severity value. Severity is utilized to put emphasis on the lower/upper bounds. If $s=1$, $d_{i}\left(y_{i}\right)$ will array from 0 to 1 in a linear fashion. When $s$ is between 0.1 and 1 , less emphasis is placed on the goal. Conversely, when $s$ is between 1 and 10, the more emphasis is on the goal function. Hence, the parameters $s$ is set to 1, 1, 2, 3 and 4 for DM, DEA, SNS, POD and HV, due to their importance, respectively [79]. Accordingly, desirability is estimated through the following equation, where $m$ is the number of objectives:

$$
D=\sqrt[m]{d_{1}\left(y_{1}\right) \times d_{2}\left(y_{2}\right) \times \ldots \times d_{m}\left(y_{m}\right)}
$$

Also, it is obvious the higher value of $D$ brings the better capability for algorithms. The tuned values for parameters, $R$-squared $\left(R^{2}\right)$ and desirability $(D)$, are approximated as displayed in Table 11. Note that $R^{2}$ is a statistical measure of how close the data are fitted to regression line. It is a percentage of the response variable variation that is explained by a linear model [80]. It is always between 0 and $100 \%$. In general, the higher the $R^{2}$, the better the model fits the data [81].

Table 11. Final values of Parameters of algorithms, R-squared $\left(\mathrm{R}^{2}\right)$ and Desirability (D).

\begin{tabular}{|l|l|l|lllll|l|}
\hline \multirow{2}{*}{$\begin{array}{l}\text { Num. of } \\
\text { algorithms }\end{array}$} & \multirow{2}{*}{ Algorithm } & \multirow{2}{*}{ Tuned parameters } & \multicolumn{2}{|l}{$\mathrm{R}^{2}(\%)$} & \multirow{2}{*}{$\mathrm{D}$} \\
\cline { 4 - 6 } Alg.1 & RDA & $\begin{array}{l}\text { nPop }=148 ; N_{\text {male }}=28 ; \\
P_{\alpha}=0.85 ; P_{\beta}=0.52 ; P_{\gamma}=0.77\end{array}$ & 58 & 62 & 64 & 73 & 78 & 0.6855 \\
\hline Alg.2 & KA & $\begin{array}{l}\text { nPop }=123 ; P_{N 1}=0.34 ; \\
P_{N 2}=0.38 ; N_{\text {Swirl }}=6\end{array}$ & 56 & 68 & 62 & 68 & 80 & 0.6823 \\
\hline Alg.3 & NSGA-II & nPop=168; $P_{C}=0.75 ; P_{M}=0.05$ & 52 & 74 & 58 & 56 & 72 & 0.6523 \\
\hline Alg.4 & SA & SubIt=43; T0=920; $R_{\alpha}=0.992$ & 34 & 66 & 69 & 51 & 68 & 0.6412 \\
\hline Alg.5 & RDSA & $\begin{array}{l}\text { nPop }=158 ; N_{\text {male }}=32 ; P_{\alpha}=0.75 ; P_{\beta}=0.56 ; \\
P_{\gamma}=0.72 ; \mathrm{T} 0=766 ; R_{\alpha}=0.995\end{array}$ & 68 & 64 & 72 & 69 & 76 & 0.6643 \\
\hline
\end{tabular}




\begin{tabular}{|l|l|l|lllll|l|}
\hline Alg.6 & KAGA & $\begin{array}{l}\text { nPop=134; } P_{N 1}=0.38 ; \\
P_{N 2}=0.31 ; N_{\text {Swirl }}=4\end{array}$ & 76 & 68 & 74 & 72 & 80 & 0.7163 \\
\hline Alg.7 & RDKA & $\begin{array}{l}\text { nPop=161; } N_{\text {male }}=33 ; \\
P_{\alpha}=0.70, P_{\beta}=0.56 ; N_{\text {Swirl }}=5\end{array}$ & 72 & 66 & 69 & 74 & 82 & 0.7429 \\
\hline Alg.8 & RDSAGA & $\begin{array}{l}\text { nPop=181; } N_{\text {male }}=34 ; P_{\gamma}=0.71 ; \mathrm{T} 0=812 ; \\
R_{\alpha}=0.996\end{array}$ & 66 & 64 & 68 & 71 & 88 & 0.6948 \\
\hline Alg.9 & KAGASA & $\begin{array}{l}\text { nPop=163; } P_{N 1}=0.33 ; \\
P_{N 2}=0.32 ; N_{\text {Swirl }}=6 ; \text { T0=766; } R_{\alpha}=0.995\end{array}$ & 59 & 68 & 74 & 73 & 86 & 0.7765 \\
\hline Alg.10 & RDKAGA & nPop=177; $N_{\text {male }}=35 ; N_{\text {Swirl }}=5$ & 68 & 72 & 76 & 78 & 84 & 0.7853 \\
\hline
\end{tabular}

\subsection{Comparing the effectiveness and efficiency among metaheuristics}

This sub-section aims to investigate the effectiveness and efficiency of proposed methods. Each algorithm is performed in all test problems for thirty times, and the best outputs are saved. First of all, the proposed evaluation metrics are calculated as given in Table 12, 13 and 14. It should be mentioned that the $\varepsilon$-constraint method $(\varepsilon$-c) explained in online supplement F6 has been utilized only in the small sizes. Due to the difficulty of problem proposed when solving the large-scale instances, the employed exact method i.e. the $\varepsilon$-constraint method cannot be utilized accordingly. Note that the runtime of exact method in P8 is $6034 \mathrm{~s}$, while the stop condition of metaheuristics is $140 \mathrm{~s}$. This experiment can support the level of difficulty of problem proposed when the size increases.

Due to nature randomization of metaheuristics, the obtained results for each problem are converted to Relative Percentage Deviation $(R P D)$ to be reliable. The $R P D$ is employed by this formulation:

$R P D=\frac{\mid A \lg _{\text {sol }}-\text { Best }_{\text {sol }} \mid}{\text { Best }_{\text {sol }}}$

where $\mathrm{Alg}_{\text {sol }}$ is the output of algorithm and Best ${ }_{\text {sol }}$ is the best value ever found in size of problem. It should be noted that the lower value for $R P D$ is preferred.

Table 12. The evaluation metrics to algorithms performance for small size of test problems.

\begin{tabular}{|c|c|c|c|c|c|c|c|c|c|}
\hline & \multicolumn{8}{|c|}{ Small sizes } \\
\hline & & P1 & $\mathrm{P} 2$ & P3 & P4 & P5 & P6 & P7 & P8 \\
\hline \multirow{11}{*}{$\mathrm{DM}$} & Alg.1 & 17566 & 16773 & 19745 & 12766 & 14529 & 24402 & 27193 & 31293 \\
\hline & Alg. 2 & 16297 & 17304 & 20283 & 11354 & 13407 & 25108 & 26204 & 29634 \\
\hline & Alg.3 & 15633 & 16443 & 17452 & 8443 & 10865 & 22375 & 25071 & 26026 \\
\hline & Alg.4 & 16072 & 17822 & 19985 & 9251 & 12944 & 21032 & 24883 & 25511 \\
\hline & Alg. 5 & 16592 & 17008 & 18397 & 10788 & 13530 & 26253 & 22357 & 32456 \\
\hline & Alg.6 & 17343 & 17281 & 19553 & 12926 & 14615 & 25485 & 23574 & 28613 \\
\hline & Alg.7 & 18127 & 17533 & 18396 & 11534 & 15203 & 24512 & 25105 & 27287 \\
\hline & Alg.8 & 17891 & 18709 & 18727 & 12872 & 13571 & 25463 & 28466 & 28189 \\
\hline & Alg.9 & 16854 & 19402 & 19458 & 11655 & 14834 & 26912 & 25564 & 29823 \\
\hline & Alg. 10 & 17379 & 19725 & 20017 & 12095 & 15064 & 25237 & 27397 & 32192 \\
\hline & $\varepsilon-\mathrm{c}$ & 16544 & 19833 & 21132 & 13007 & 15118 & 27018 & 28592 & 31588 \\
\hline \multirow{3}{*}{ SNS } & Alg.1 & 3496 & 5092 & 4408 & 2318 & 3922 & 1572 & 7843 & 4921 \\
\hline & Alg. 2 & 3478 & 4253 & 3896 & 2227 & 3757 & 1572 & 8166 & 4469 \\
\hline & Alg. 3 & 3656 & 4462 & 2637 & 1456 & 2511 & 465 & 4241 & 3231 \\
\hline
\end{tabular}




\begin{tabular}{|c|c|c|c|c|c|c|c|c|c|}
\hline & Alg.4 & 2835 & 4375 & 2226 & 1575 & 2654 & 344 & 5596 & 3684 \\
\hline & Alg. 5 & 3017 & 4636 & 4316 & 2452 & 3789 & 799 & 8825 & 4565 \\
\hline & Alg.6 & 4903 & 4597 & 3654 & 2783 & 3874 & 823 & 8354 & 4372 \\
\hline & Alg.7 & 4782 & 4820 & 3965 & 2783 & 3316 & 945 & 7633 & 4739 \\
\hline & Alg. 8 & 4569 & 5718 & 4821 & 2632 & 3635 & 1753 & 8862 & 5494 \\
\hline & Alg.9 & 5347 & 5026 & 4573 & 2091 & 3856 & 1248 & 8441 & 5671 \\
\hline & Alg.10 & 5121 & 5935 & 4142 & 2989 & 3856 & 1917 & 8778 & 5846 \\
\hline & $\varepsilon-\mathrm{c}$ & 5423 & 5811 & 4633 & 3011 & 3514 & 1822 & 8914 & 5211 \\
\hline \multirow{11}{*}{ DEA } & Alg.1 & 0.14 & 0.20 & 0.19 & 0.17 & 0.16 & 0.23 & 0.22 & 0.24 \\
\hline & Alg. 2 & 0.16 & 0.19 & 0.23 & 0.24 & 0.17 & 0.19 & 0.21 & 0.23 \\
\hline & Alg. 3 & 0.12 & 0.15 & 0.09 & 0.11 & 0.10 & 0.14 & 0.11 & 0.14 \\
\hline & Alg.4 & 0.13 & 0.17 & 0.13 & 0.15 & 0.16 & 0.09 & 0.11 & 0.12 \\
\hline & Alg. 5 & 0.26 & 0.24 & 0.23 & 0.19 & 0.22 & 0.23 & 0.21 & 0.22 \\
\hline & Alg.6 & 0.25 & 0.22 & 0.22 & 0.25 & 0.23 & 0.28 & 0.24 & 0.27 \\
\hline & Alg.7 & 0.23 & 0.25 & 0.27 & 0.28 & 0.25 & 0.27 & 0.33 & 0.25 \\
\hline & Alg. 8 & 0.22 & 0.24 & 0.23 & 0.29 & 0.28 & 0.29 & 0.26 & 0.29 \\
\hline & Alg.9 & 0.24 & 0.26 & 0.25 & 0.30 & 0.24 & 0.26 & 0.29 & 0.22 \\
\hline & Alg.10 & 0.26 & 0.24 & 0.27 & 0.31 & 0.29 & 0.25 & 0.33 & 0.25 \\
\hline & $\varepsilon-c$ & 0.28 & 0.29 & 0.28 & 0.26 & 0.31 & 0.28 & 0.27 & 0.28 \\
\hline \multirow{11}{*}{ POD } & Alg.1 & 0.18 & 0.20 & 0.16 & 0.18 & 0.14 & 0.27 & 0.14 & 0.27 \\
\hline & Alg. 2 & 0.24 & 0.23 & 0.21 & 0.24 & 0.28 & 0.22 & 0.18 & 0.18 \\
\hline & Alg. 3 & 0.15 & 0.16 & 0.12 & 0.16 & 0.16 & 0.15 & 0.12 & 0.14 \\
\hline & Alg.4 & 0.16 & 0.19 & 0.14 & 0.12 & 0.16 & 0.12 & 0.12 & 0.16 \\
\hline & Alg.5 & 0.24 & 0.24 & 0.18 & 0.21 & 0.14 & 0.22 & 0.19 & 0.17 \\
\hline & Alg.6 & 0.23 & 0.28 & 0.22 & 0.22 & 0.19 & 0.23 & 0.22 & 0.19 \\
\hline & Alg.7 & 0.25 & 0.27 & 0.24 & 0.28 & 0.22 & 0.25 & 0.26 & 0.22 \\
\hline & Alg. 8 & 0.26 & 0.32 & 0.23 & 0.29 & 0.21 & 0.27 & 0.28 & 0.25 \\
\hline & Alg.9 & 0.25 & 0.24 & 0.27 & 0.28 & 0.23 & 0.27 & 0.27 & 0.22 \\
\hline & Alg. 10 & 0.27 & 0.25 & 0.31 & 0.27 & 0.24 & 0.26 & 0.28 & 0.26 \\
\hline & $\varepsilon-\mathrm{c}$ & 0.28 & 0.29 & 0.26 & 0.25 & 0.26 & 0.27 & 0.25 & 0.29 \\
\hline \multirow{11}{*}{$\mathrm{HV}$} & Alg.1 & $2.43 \mathrm{E}+11$ & $4.63 \mathrm{E}+11$ & $2.87 \mathrm{E}+11$ & $4.83 \mathrm{E}+11$ & $5.84 \mathrm{E}+12$ & $5.22 \mathrm{E}+11$ & $3.92 \mathrm{E}+12$ & $5.87 \mathrm{E}+12$ \\
\hline & Alg. 2 & $6.89 \mathrm{E}+10$ & $2.81 \mathrm{E}+11$ & $5.94 \mathrm{E}+11$ & $5.16 \mathrm{E}+11$ & $4.27 \mathrm{E}+12$ & $4.91 \mathrm{E}+11$ & $4.18 \mathrm{E}+12$ & $4.65 \mathrm{E}+12$ \\
\hline & Alg. 3 & $4.38 \mathrm{E}+10$ & $7.84 \mathrm{E}+10$ & $1.86 \mathrm{E}+11$ & $2.81 \mathrm{E}+11$ & $3.17 \mathrm{E}+11$ & $3.17 \mathrm{E}+10$ & $2.33 \mathrm{E}+11$ & $3.24 \mathrm{E}+11$ \\
\hline & Alg.4 & $1.86 \mathrm{E}+10$ & $4.12 \mathrm{E}+10$ & $2.87 \mathrm{E}+10$ & $3.89 \mathrm{E}+11$ & $2.86 \mathrm{E}+11$ & $6.82 \mathrm{E}+10$ & $1.95 \mathrm{E}+11$ & $3.52 \mathrm{E}+11$ \\
\hline & Alg. 5 & $5.68 \mathrm{E}+10$ & $3.82 \mathrm{E}+11$ & $3.74 \mathrm{E}+12$ & $4.68 \mathrm{E}+12$ & $3.65 \mathrm{E}+12$ & $3.89 \mathrm{E}+11$ & $2.75 \mathrm{E}+12$ & $4.71 \mathrm{E}+12$ \\
\hline & Alg.6 & $3.82 \mathrm{E}+10$ & $7.92 \mathrm{E}+11$ & $7.92 \mathrm{E}+12$ & $7.64 \mathrm{E}+12$ & $3.81 \mathrm{E}+12$ & $7.11 \mathrm{E}+11$ & $3.58 \mathrm{E}+12$ & $5.67 \mathrm{E}+12$ \\
\hline & Alg.7 & $7.19 \mathrm{E}+11$ & $5.18 \mathrm{E}+11$ & $4.28 \mathrm{E}+12$ & $5.38 \mathrm{E}+12$ & $5.82 \mathrm{E}+12$ & $2.86 \mathrm{E}+11$ & $4.71 E+12$ & $6.85 \mathrm{E}+12$ \\
\hline & Alg. 8 & $1.66 \mathrm{E}+12$ & $8.14 \mathrm{E}+11$ & $5.18 \mathrm{E}+12$ & $7.85 \mathrm{E}+12$ & $4.91 E+12$ & $6.94 \mathrm{E}+12$ & $5.16 \mathrm{E}+12$ & $6.22 \mathrm{E}+12$ \\
\hline & Alg.9 & $5.92 \mathrm{E}+11$ & $2.51 \mathrm{E}+11$ & $2.89 \mathrm{E}+12$ & $7.39 \mathrm{E}+12$ & $5.22 \mathrm{E}+12$ & $3.82 \mathrm{E}+12$ & $6.82 \mathrm{E}+12$ & $7.84 \mathrm{E}+12$ \\
\hline & Alg.10 & $6.43 E+12$ & $1.46 \mathrm{E}+12$ & $3.71 \mathrm{E}+12$ & $7.68 \mathrm{E}+12$ & $6.81 E+12$ & $8.24 \mathrm{E}+12$ & $5.76 \mathrm{E}+12$ & $7.91 \mathrm{E}+12$ \\
\hline & $\varepsilon-\mathrm{c}$ & $4.33 E+09$ & $4.71 E+08$ & $2.88 \mathrm{E}+09$ & $3.17 \mathrm{E}+10$ & $2.13 \mathrm{E}+10$ & $2.67 \mathrm{E}+10$ & $3.15 E+11$ & $2.35 \mathrm{E}+10$ \\
\hline
\end{tabular}

Table 13. The evaluation metrics to algorithms performance for medium size of test problems.

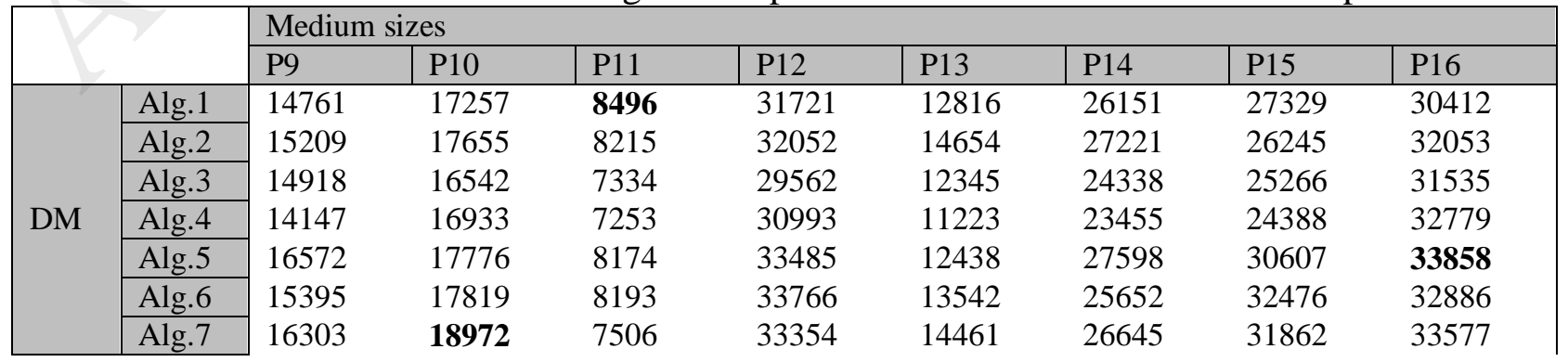




\begin{tabular}{|c|c|c|c|c|c|c|c|c|c|}
\hline & Alg. 8 & 16682 & 17643 & 7783 & 33437 & 15716 & 27852 & 28645 & 33554 \\
\hline & Alg.9 & 16264 & 18074 & 7961 & 34228 & 14344 & 28044 & 29023 & 33193 \\
\hline & Alg.10 & 16923 & 18407 & 7842 & 33115 & 15873 & 28955 & 32761 & 33602 \\
\hline & Alg.1 & 2611 & 6518 & 7718 & 5792 & 2573 & 1429 & 5263 & 5825 \\
\hline & Alg. 2 & 2582 & 6292 & 7139 & 5273 & 2728 & 1554 & 5654 & 5841 \\
\hline & Alg. 3 & 1774 & 5637 & 6372 & 4459 & 1454 & 764 & 4346 & 4948 \\
\hline & Alg.4 & 1865 & 4554 & 6956 & 4746 & 1527 & 582 & 4828 & 4592 \\
\hline SNC & Alg. 5 & 2746 & 5438 & 7247 & 6514 & 3153 & 1764 & 5491 & 5574 \\
\hline SNS & Alg.6 & 2627 & 6581 & 7483 & 6222 & 2515 & 1337 & 5513 & 5668 \\
\hline & Alg.7 & 2838 & 6825 & 7603 & 6435 & 2722 & 1629 & 6633 & 5233 \\
\hline & Alg. 8 & 3259 & 6641 & 7536 & 5762 & 3276 & 1501 & 5985 & 5771 \\
\hline & Alg. 9 & 3270 & 6764 & 7865 & 6371 & 3345 & 1786 & 6389 & 5956 \\
\hline & Alg.10 & 3193 & 6939 & 7718 & 5843 & 3439 & 1855 & 5802 & 5988 \\
\hline & Alg.1 & 0.20 & 0.24 & 0.25 & 0.22 & 0.23 & 0.24 & 0.21 & 0.19 \\
\hline & Alg. 2 & 0.22 & 0.23 & 0.22 & 0.24 & 0.25 & 0.24 & 0.20 & 0.21 \\
\hline & Alg. 3 & 0.16 & 0.14 & 0.16 & 0.12 & 0.14 & 0.18 & 0.22 & 0.18 \\
\hline & Alg. 4 & 0.14 & 0.16 & 0.12 & 0.08 & 0.10 & 0.09 & 0.15 & 0.14 \\
\hline $\mathrm{DF}$ & Alg. 5 & 0.18 & 0.22 & 0.16 & 0.18 & 0.24 & 0.28 & 0.26 & 0.32 \\
\hline DEA & Alg.6 & 0.22 & 0.25 & 0.22 & 0.19 & 0.23 & 0.18 & 0.28 & 0.25 \\
\hline & Alg.7 & 0.23 & 0.23 & 0.27 & 0.22 & 0.27 & 0.28 & 0.32 & 0.29 \\
\hline & Alg. 8 & 0.27 & 0.28 & 0.29 & 0.27 & 0.31 & 0.32 & 0.35 & 0.30 \\
\hline & Alg. 9 & 0.27 & 0.26 & 0.27 & 0.25 & 0.28 & 0.32 & 0.33 & 0.32 \\
\hline & Alg.10 & 0.26 & 0.29 & 0.31 & 0.32 & 0.35 & 0.26 & 0.31 & 0.28 \\
\hline & Alg.1 & 0.14 & 0.20 & 0.18 & 0.17 & 0.16 & 0.18 & 0.19 & 0.22 \\
\hline & Alg. 2 & 0.19 & 0.24 & 0.19 & 0.16 & 0.23 & 0.26 & 0.18 & 0.17 \\
\hline & Alg. 3 & 0.08 & 0.12 & 0.14 & 0.16 & 0.07 & 0.12 & 0.14 & 0.12 \\
\hline & Alg. 4 & 0.12 & 0.14 & 0.08 & 0.10 & 0.14 & 0.12 & 0.12 & 0.14 \\
\hline $\mathrm{POD}$ & Alg.5 & 0.16 & 0.17 & 0.18 & 0.19 & 0.23 & 0.17 & 0.19 & 0.18 \\
\hline PUD & Alg.6 & 0.18 & 0.19 & 0.21 & 0.23 & 0.28 & 0.21 & 0.24 & 0.22 \\
\hline & Alg.7 & 0.22 & 0.23 & 0.20 & 0.24 & 0.25 & 0.23 & 0.22 & 0.29 \\
\hline & Alg.8 & 0.28 & 0.26 & 0.25 & 0.29 & 0.26 & 0.27 & 0.31 & 0.32 \\
\hline & Alg.9 & 0.32 & 0.25 & 0.27 & 0.29 & 0.31 & 0.26 & 0.23 & 0.25 \\
\hline & Alg.10 & 0.27 & 0.26 & 0.28 & 0.27 & 0.32 & 0.28 & 0.29 & 0.32 \\
\hline & Alg.1 & $4.62 \mathrm{E}+11$ & $5.87 \mathrm{E}+11$ & $7.96 \mathrm{E}+11$ & $1.34 \mathrm{E}+12$ & $2.66 \mathrm{E}+12$ & $5.43 \mathrm{E}+12$ & $6.71 \mathrm{E}+12$ & $7.18 \mathrm{E}+12$ \\
\hline & Alg. 2 & $3.87 \mathrm{E}+11$ & $4.11 \mathrm{E}+11$ & $4.75 \mathrm{E}+11$ & $5.83 \mathrm{E}+11$ & $8.12 \mathrm{E}+11$ & $3.89 \mathrm{E}+12$ & $2.87 \mathrm{E}+12$ & $4.88 \mathrm{E}+12$ \\
\hline & Alg.3 & $2.78 \mathrm{E}+10$ & $3.67 \mathrm{E}+10$ & $6.74 \mathrm{E}+10$ & $6.89 \mathrm{E}+10$ & $8.31 \mathrm{E}+10$ & $5.48 \mathrm{E}+11$ & $7.19 \mathrm{E}+11$ & $8.23 E+11$ \\
\hline & Alg.4 & $1.89 \mathrm{E}+10$ & $4.76 \mathrm{E}+10$ & $5.86 \mathrm{E}+10$ & $6.17 \mathrm{E}+10$ & $8.19 \mathrm{E}+10$ & $1.24 \mathrm{E}+11$ & $1.86 \mathrm{E}+11$ & $2.03 \mathrm{E}+11$ \\
\hline HV & Alg.5 & $5.82 \mathrm{E}+11$ & $7.48 \mathrm{E}+11$ & $8.19 \mathrm{E}+11$ & $1.64 \mathrm{E}+12$ & $2.85 \mathrm{E}+12$ & $1.89 \mathrm{E}+12$ & $3.86 \mathrm{E}+12$ & $5.82 \mathrm{E}+12$ \\
\hline HV & Alg.6 & $4.91 \mathrm{E}+11$ & $7.84 \mathrm{E}+11$ & $6.25 \mathrm{E}+11$ & $7.81 \mathrm{E}+11$ & $6.48 \mathrm{E}+11$ & $9.23 \mathrm{E}+11$ & $5.74 \mathrm{E}+12$ & $7.12 \mathrm{E}+12$ \\
\hline & Alg.7 & $5.72 \mathrm{E}+11$ & $4.71 \mathrm{E}+11$ & $6.33 \mathrm{E}+11$ & $7.92 \mathrm{E}+11$ & $1.56 \mathrm{E}+12$ & $6.82 \mathrm{E}+12$ & $5.34 \mathrm{E}+12$ & $4.98 \mathrm{E}+12$ \\
\hline & Alg. 8 & $6.81 \mathrm{E}+12$ & $5.74 \mathrm{E}+12$ & $7.81 E+12$ & $3.62 E+13$ & $4.83 \mathrm{E}+13$ & $2.87 \mathrm{E}+13$ & $6.85 E+13$ & $5.91 \mathrm{E}+13$ \\
\hline & Alg.9 & $7.12 \mathrm{E}+12$ & $8.49 \mathrm{E}+12$ & $1.47 \mathrm{E}+13$ & $1.88 \mathrm{E}+13$ & $2.53 E+13$ & $2.77 \mathrm{E}+13$ & $5.83 \mathrm{E}+13$ & $4.91 \mathrm{E}+13$ \\
\hline & Alg.10 & $7.43 E+12$ & $6.85 E+12$ & $9.36 \mathrm{E}+12$ & $2.54 \mathrm{E}+13$ & $5.78 E+13$ & $4.82 \mathrm{E}+13$ & $7.85 E+13$ & $6.33 E+13$ \\
\hline
\end{tabular}

Table 14. The evaluation metrics to algorithms performance for large size of test problems.

\begin{tabular}{|c|c|c|c|c|c|c|c|c|c|}
\hline & \multicolumn{8}{|c|}{ Large sizes } \\
\hline & & P17 & P18 & P19 & P20 & P21 & P22 & P23 & P24 \\
\hline \multirow{5}{*}{ DM } & Alg.1 & 5242 & 9914 & 13475 & 10653 & 15613 & 24107 & 34582 & 25839 \\
\hline & Alg. 2 & 5662 & 9846 & 13344 & 10579 & 14525 & 25718 & 35445 & 26672 \\
\hline & Alg.3 & 4575 & 8835 & 12523 & 9865 & 12446 & 23423 & 32272 & 23481 \\
\hline & Alg.4 & 4414 & 7553 & 13977 & 8445 & 15775 & 24664 & 33655 & 23562 \\
\hline & Alg. 5 & 6831 & 10628 & 14212 & 10882 & 17482 & 25353 & 35167 & 24374 \\
\hline
\end{tabular}




\begin{tabular}{|c|c|c|c|c|c|c|c|c|c|}
\hline & Alg. 6 & 6376 & 10164 & 14543 & 12035 & 16303 & 25882 & 34733 & 25629 \\
\hline & Alg.7 & 6941 & 11485 & 14458 & 10426 & 15354 & 25269 & 36534 & 27291 \\
\hline & Alg. 8 & 5257 & 10566 & 14627 & 11154 & 16831 & 26718 & 35867 & 25886 \\
\hline & Alg.9 & 6378 & 10302 & 14869 & 11863 & 17873 & 26323 & 35326 & 28193 \\
\hline & Alg.10 & 5998 & 10227 & 14771 & 12119 & 18082 & 26594 & 36709 & 29827 \\
\hline \multirow{10}{*}{ SNS } & Alg.1 & 5365 & 4892 & 1329 & 1803 & 6237 & 4828 & 3627 & 5438 \\
\hline & Alg. 2 & 5248 & 4665 & 1543 & 1524 & 6471 & 4657 & 3564 & 4347 \\
\hline & Alg. 3 & 4791 & 3781 & 567 & 1635 & 5659 & 4743 & 2755 & 4468 \\
\hline & Alg.4 & 4604 & 3537 & 769 & 1356 & 5873 & 4591 & 2393 & 4283 \\
\hline & Alg.5 & 5852 & 4329 & 954 & 1612 & 7429 & 5774 & 3802 & 4772 \\
\hline & Alg.6 & 6448 & 4564 & 1471 & 1788 & 7306 & 4337 & 3217 & 5112 \\
\hline & Alg.7 & 6373 & 4115 & 1536 & 1359 & 6682 & 5662 & 4937 & 5634 \\
\hline & Alg. 8 & 5761 & 4877 & 1847 & 1780 & 7256 & 5559 & 3168 & 5764 \\
\hline & Alg. 9 & 6448 & 4682 & 1692 & 1579 & 6764 & 5303 & 3349 & 5634 \\
\hline & Alg.10 & 6329 & 4755 & 1773 & 1956 & 7183 & 5461 & 4566 & 5882 \\
\hline \multirow{10}{*}{ DEA } & Alg.1 & 0.12 & 0.14 & 0.20 & 0.16 & 0.18 & 0.24 & 0.22 & 0.26 \\
\hline & Alg.2 & 0.18 & 0.16 & 0.16 & 0.22 & 0.26 & 0.19 & 0.26 & 0.28 \\
\hline & Alg.3 & 0.14 & 0.08 & 0.08 & 0.12 & 0.14 & 0.18 & 0.12 & 0.10 \\
\hline & Alg.4 & 0.08 & 0.12 & 0.14 & 0.16 & 0.12 & 0.10 & 0.16 & 0.08 \\
\hline & Alg.5 & 0.16 & 0.18 & 0.18 & 0.20 & 0.20 & 0.18 & 0.22 & 0.22 \\
\hline & Alg.6 & 0.22 & 0.22 & 0.24 & 0.26 & 0.18 & 0.24 & 0.26 & 0.28 \\
\hline & Alg.7 & 0.32 & 0.28 & 0.28 & 0.26 & 0.24 & 0.18 & 0.22 & 0.29 \\
\hline & Alg.8 & 0.22 & 0.26 & 0.26 & 0.24 & 0.22 & 0.20 & 0.20 & 0.28 \\
\hline & Alg.9 & 0.28 & 0.31 & 0.28 & 0.18 & 0.22 & 0.28 & 0.24 & 0.26 \\
\hline & Alg.10 & 0.22 & 0.28 & 0.32 & 0.26 & 0.29 & 0.22 & 0.26 & 0.30 \\
\hline \multirow{10}{*}{ POD } & Alg.1 & 0.26 & 0.22 & 0.24 & 0.28 & 0.26 & 0.22 & 0.28 & 0.32 \\
\hline & Alg.2 & 0.27 & 0.24 & 0.20 & 0.26 & 0.27 & 0.22 & 0.24 & 0.27 \\
\hline & Alg.3 & 0.24 & 0.22 & 0.28 & 0.22 & 0.19 & 0.14 & 0.12 & 0.16 \\
\hline & Alg.4 & 0.17 & 0.14 & 0.18 & 0.24 & 0.20 & 0.26 & 0.22 & 0.12 \\
\hline & Alg.5 & 0.25 & 0.24 & 0.26 & 0.22 & 0.26 & 0.24 & 0.26 & 0.28 \\
\hline & Alg.6 & 0.26 & 0.24 & 0.28 & 0.32 & 0.26 & 0.28 & 0.22 & 0.25 \\
\hline & Alg.7 & 0.32 & 0.31 & 0.34 & 0.28 & 0.27 & 0.29 & 0.24 & 0.28 \\
\hline & Alg.8 & 0.27 & 0.28 & 0.26 & 0.26 & 0.24 & 0.28 & 0.24 & 0.26 \\
\hline & Alg.9 & 0.22 & 0.27 & 0.29 & 0.27 & 0.28 & 0.25 & 0.28 & 0.29 \\
\hline & Alg. 10 & 0.32 & 0.35 & 0.28 & 0.29 & 0.24 & 0.33 & 0.31 & 0.28 \\
\hline \multirow{10}{*}{$\mathrm{HV}$} & Alg.1 & $5.89 \mathrm{E}+12$ & $4.83 \mathrm{E}+12$ & $6.72 \mathrm{E}+12$ & $5.91 \mathrm{E}+12$ & $8.13 E+12$ & $9.22 \mathrm{E}+12$ & $2.75 E+13$ & $2.89 \mathrm{E}+13$ \\
\hline & Alg.2 & $4.54 \mathrm{E}+12$ & $5.73 E+12$ & $4.16 \mathrm{E}+12$ & $4.82 \mathrm{E}+12$ & $5.44 \mathrm{E}+12$ & $7.81 E+12$ & $7.22 \mathrm{E}+12$ & $8.19 \mathrm{E}+12$ \\
\hline & Alg. 3 & $8.97 \mathrm{E}+11$ & $7.43 \mathrm{E}+11$ & $8.91 E+11$ & $1.09 \mathrm{E}+12$ & $1.78 \mathrm{E}+12$ & $1.85 \mathrm{E}+12$ & $4.23 \mathrm{E}+12$ & $5.66 \mathrm{E}+12$ \\
\hline & Alg.4 & $2.72 \mathrm{E}+11$ & $3.72 \mathrm{E}+11$ & $4.17 \mathrm{E}+11$ & $5.91 \mathrm{E}+11$ & $4.89 \mathrm{E}+11$ & $6.28 \mathrm{E}+11$ & $5.18 \mathrm{E}+11$ & $8.15 E+11$ \\
\hline & Alg. 5 & $5.88 \mathrm{E}+12$ & $2.16 \mathrm{E}+12$ & $3.86 \mathrm{E}+12$ & $5.18 \mathrm{E}+12$ & $7.46 \mathrm{E}+12$ & $1.45 E+13$ & $2.81 E+13$ & $4.33 \mathrm{E}+13$ \\
\hline & Alg.6 & $7.34 \mathrm{E}+12$ & $8.25 \mathrm{E}+12$ & $9.11 \mathrm{E}+12$ & $2.73 \mathrm{E}+12$ & $2.65 \mathrm{E}+12$ & $5.48 \mathrm{E}+12$ & $4.98 \mathrm{E}+12$ & $2.18 \mathrm{E}+12$ \\
\hline & Alg.7 & $4.79 \mathrm{E}+12$ & $2.64 \mathrm{E}+12$ & $3.56 \mathrm{E}+12$ & $5.87 \mathrm{E}+12$ & $7.65 E+12$ & $1.34 \mathrm{E}+13$ & $1.89 \mathrm{E}+13$ & $2.55 E+13$ \\
\hline & Alg.8 & $5.82 \mathrm{E}+13$ & $7.88 E+13$ & $6.71 E+13$ & $7.23 \mathrm{E}+13$ & $6.19 \mathrm{E}+13$ & $8.24 \mathrm{E}+13$ & $7.61 E+13$ & $9.25 E+13$ \\
\hline & Alg.9 & $4.03 \mathrm{E}+13$ & $5.12 \mathrm{E}+13$ & $4.29 \mathrm{E}+13$ & $6.12 \mathrm{E}+13$ & $8.44 \mathrm{E}+13$ & $1.08 \mathrm{E}+14$ & $2.65 \mathrm{E}+14$ & $6.88 \mathrm{E}+14$ \\
\hline & Alg.10 & $6.85 E+13$ & $7.84 \mathrm{E}+13$ & $8.55 \mathrm{E}+13$ & $1.86 \mathrm{E}+14$ & $3.21 \mathrm{E}+14$ & $7.85 \mathrm{E}+14$ & $8.12 E+14$ & $6.99 \mathrm{E}+14$ \\
\hline
\end{tabular}




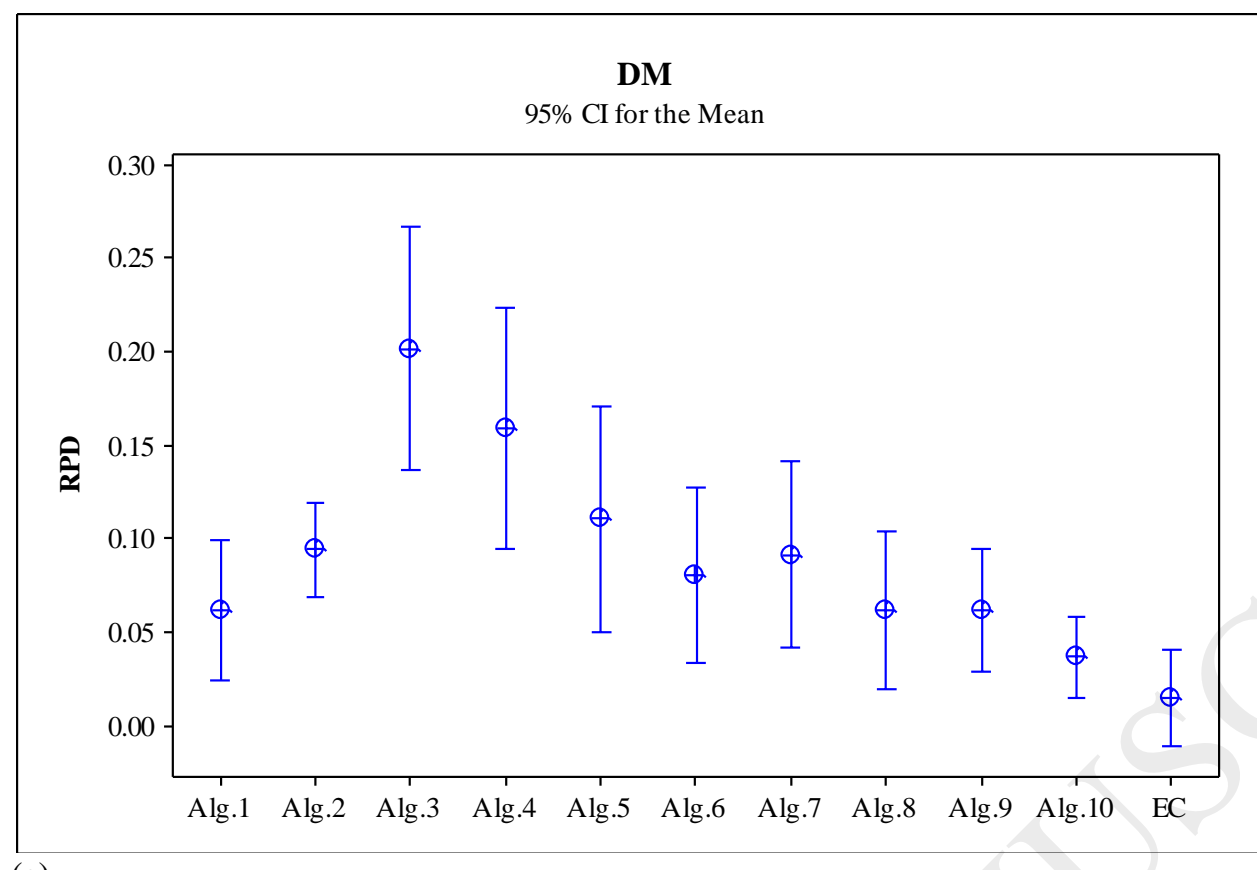

(a)

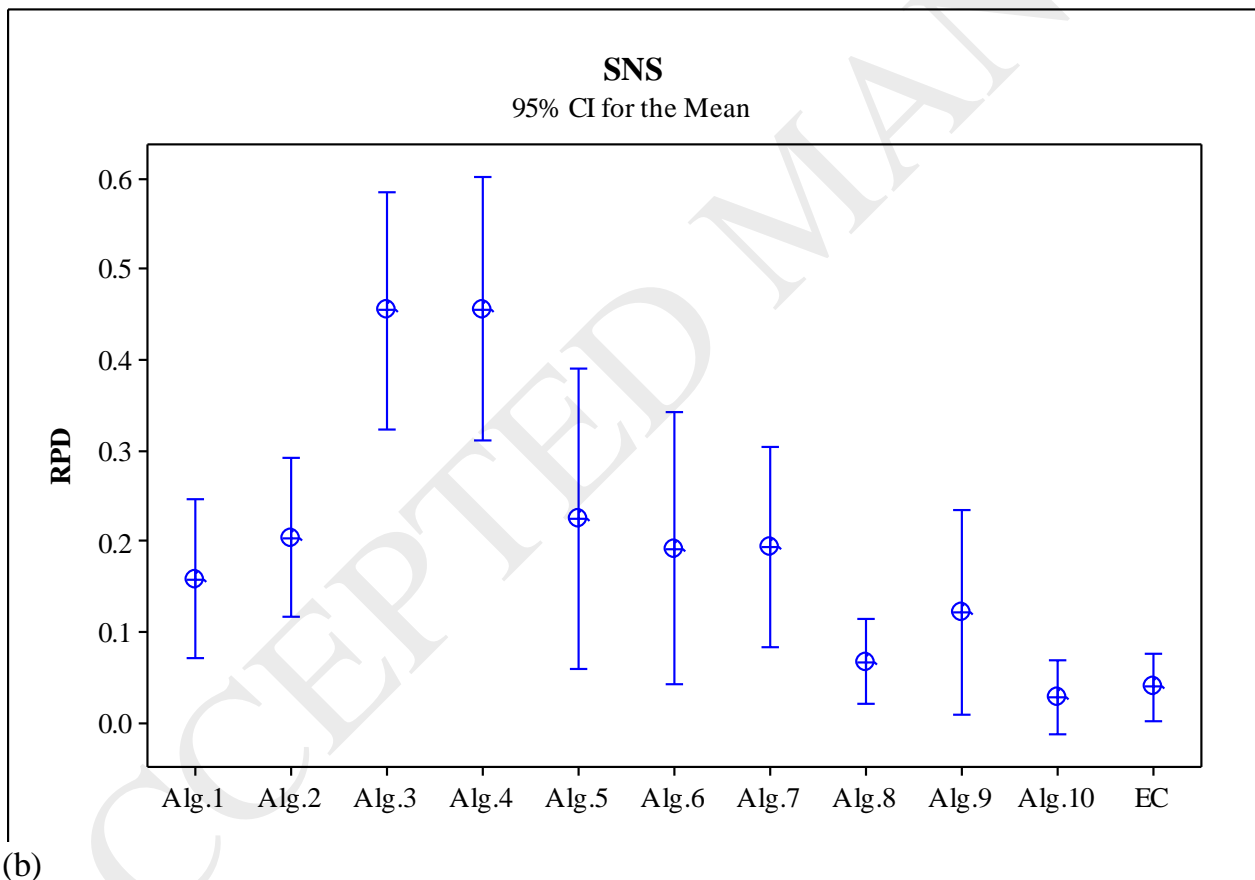




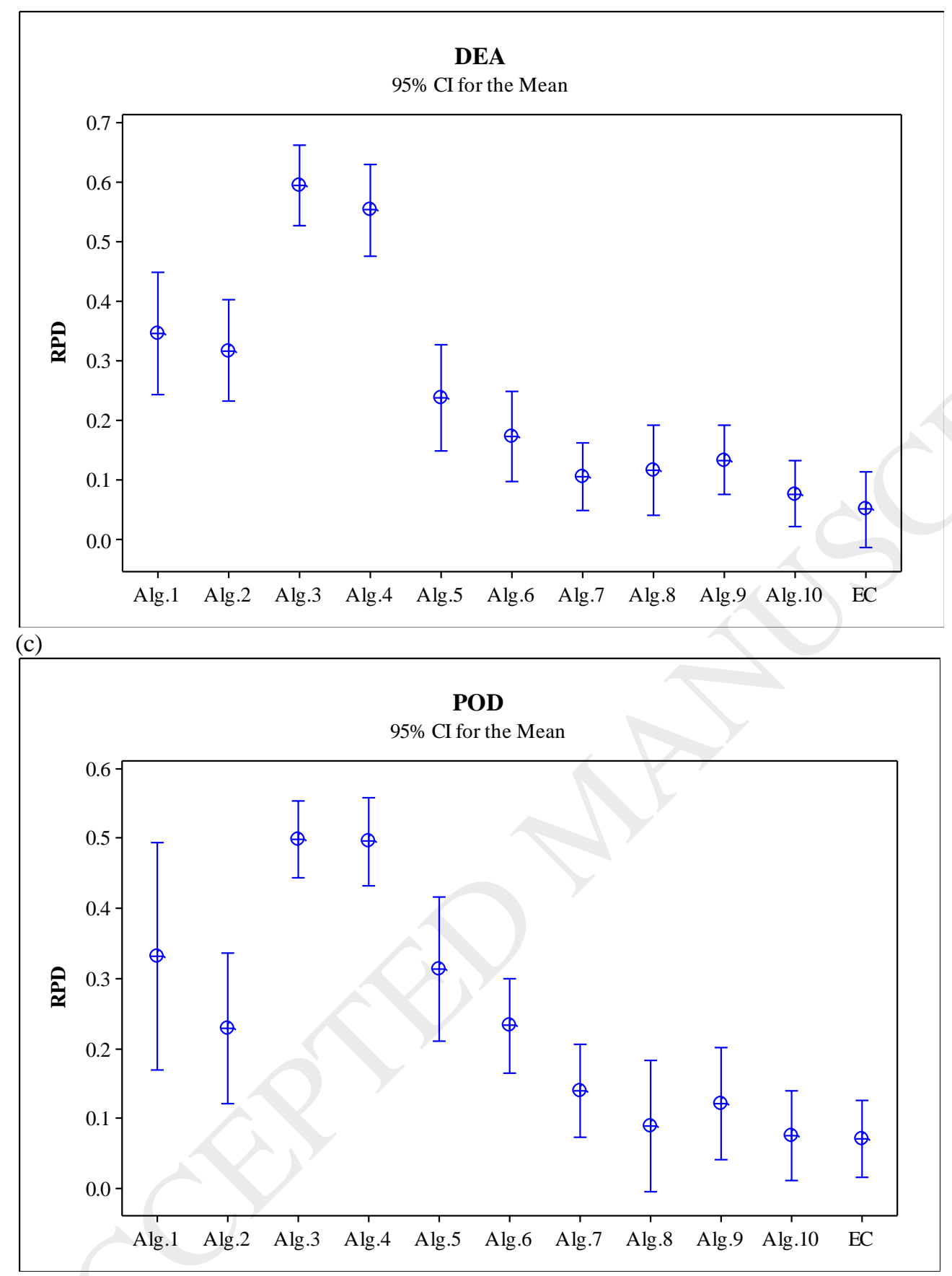

(d) 


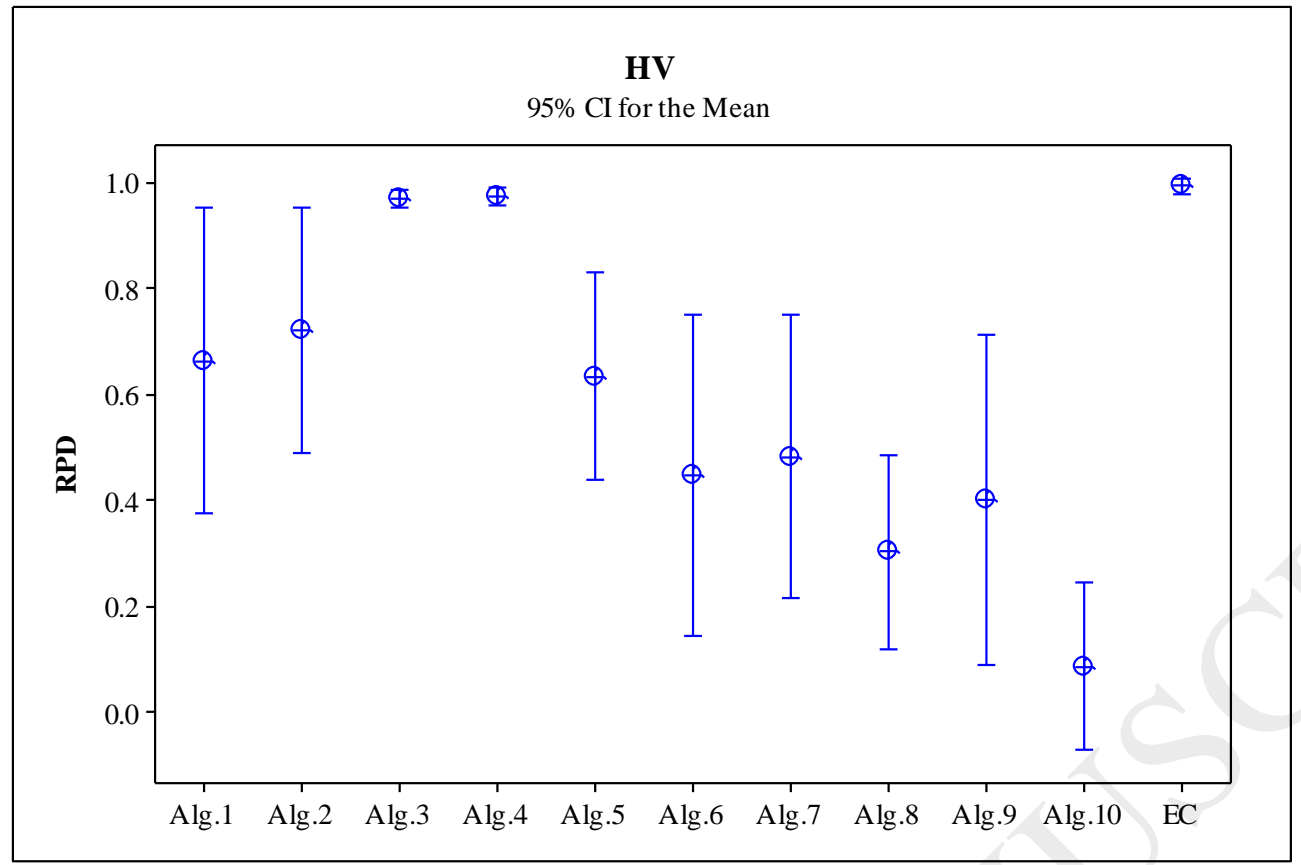

(e)

Fig. 6. Means plot and LSD intervals to specify RPD for evaluation parameter in small sizes of test problem (i.e. (a) for DM, (b) for SNS, (c) for DEA, (d) for POD and (e) for HV).

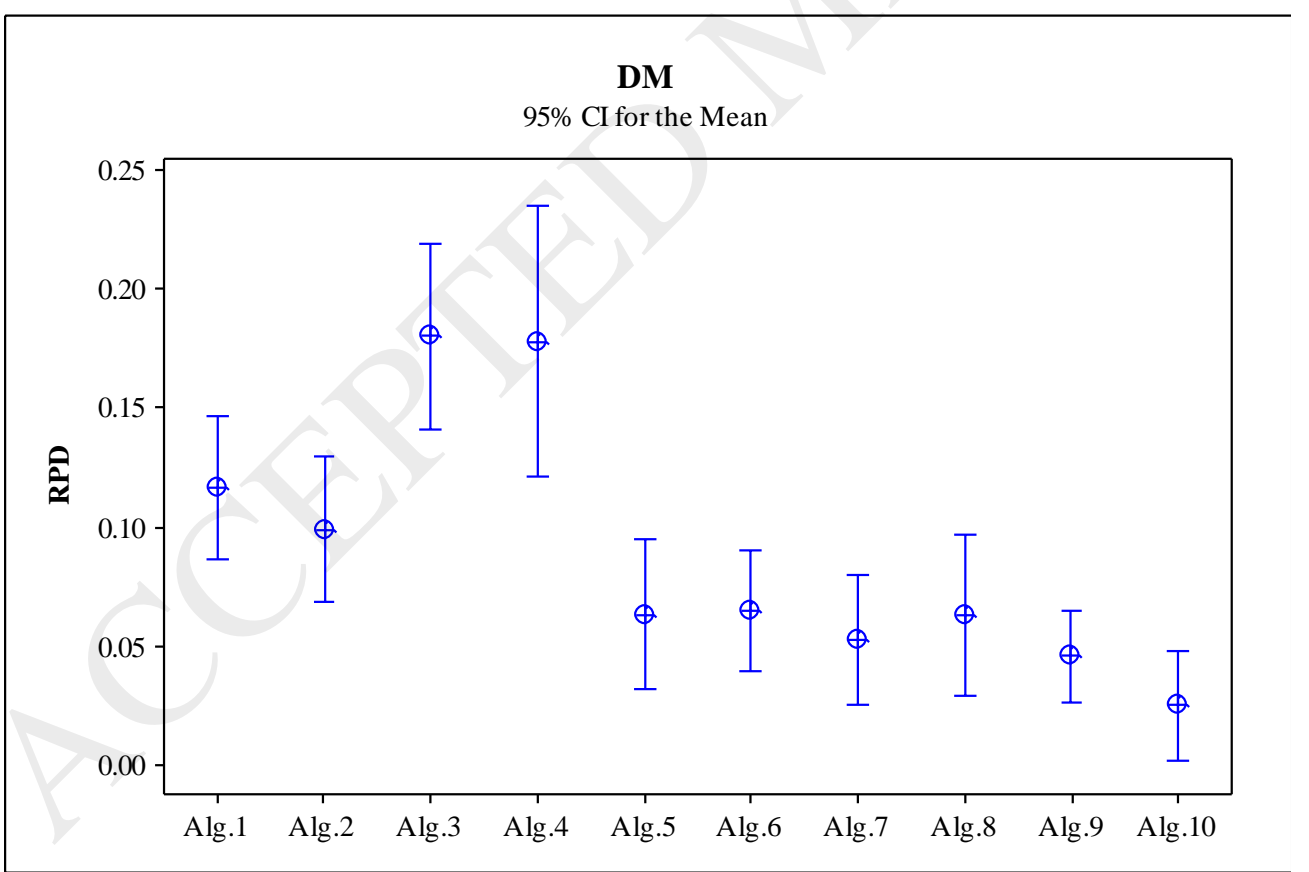

(a) 


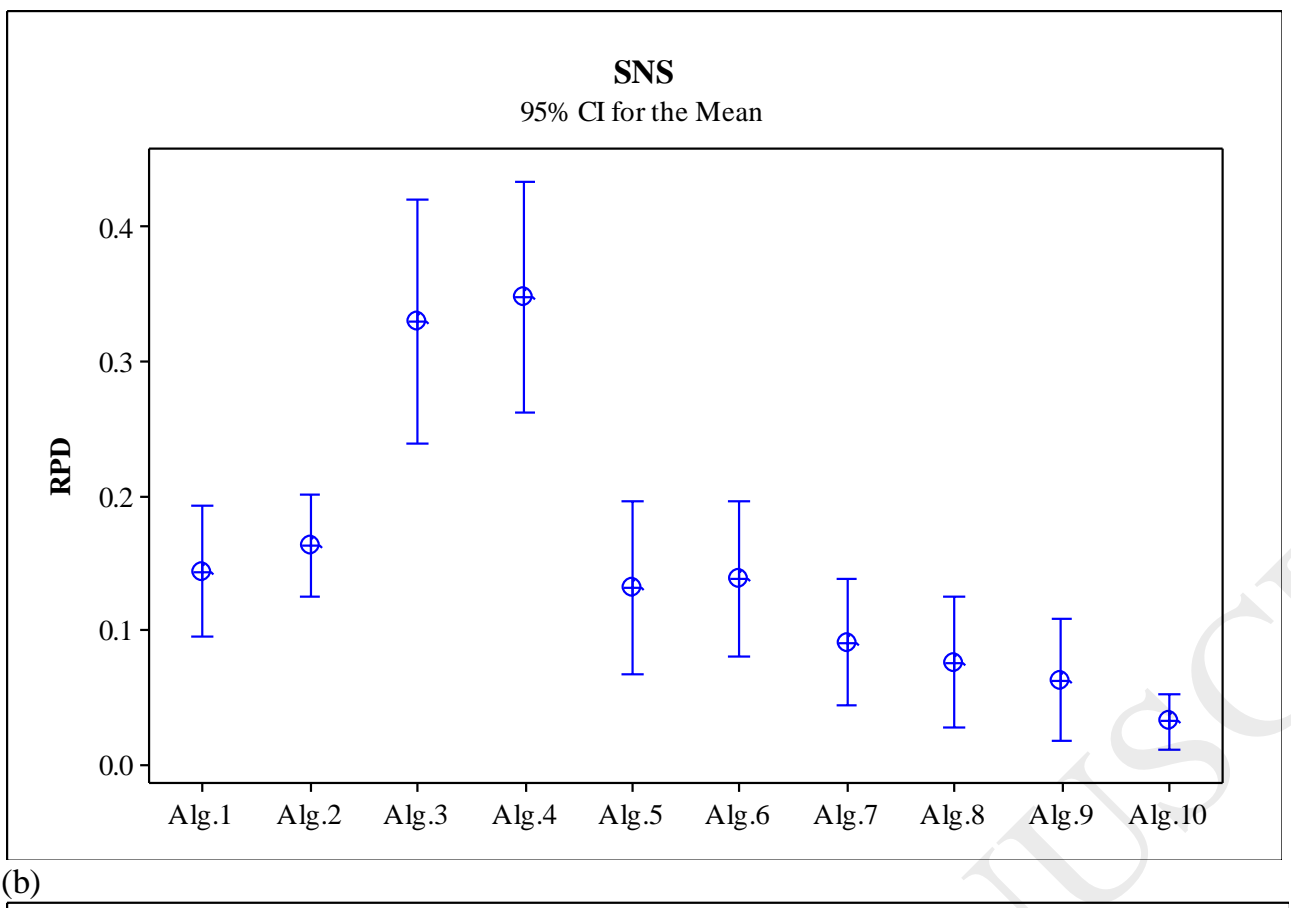

(b)

\section{DEA}

95\% CI for the Mean

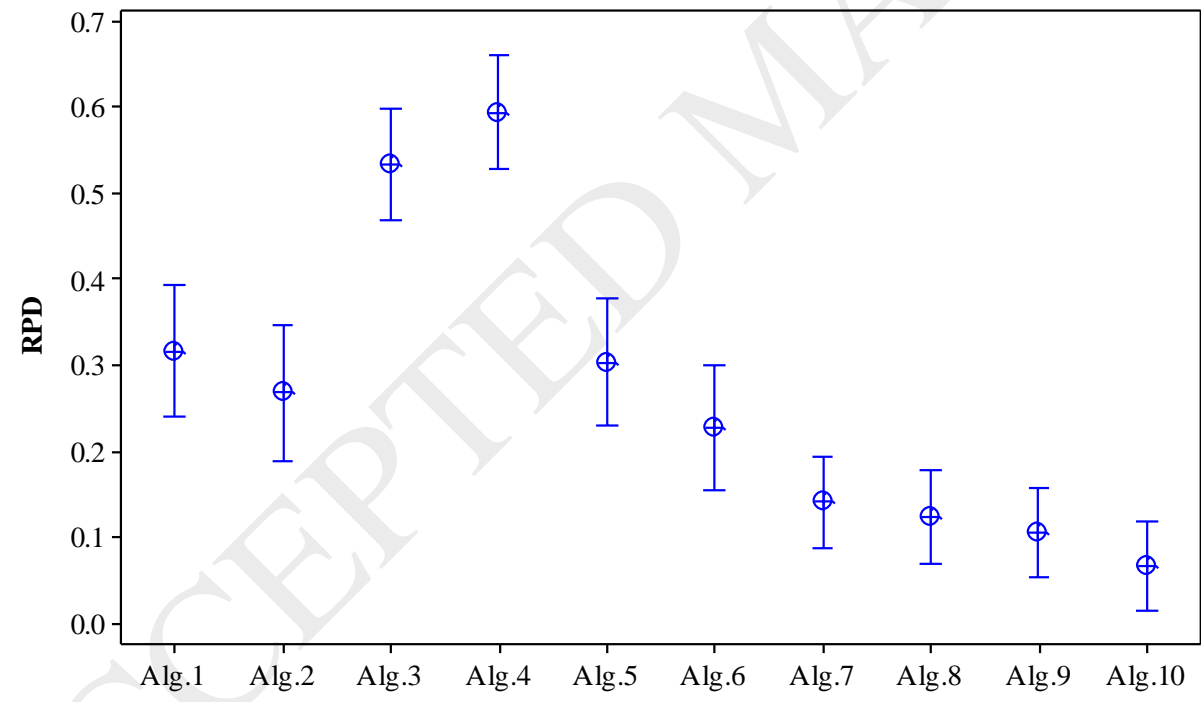

(c) 


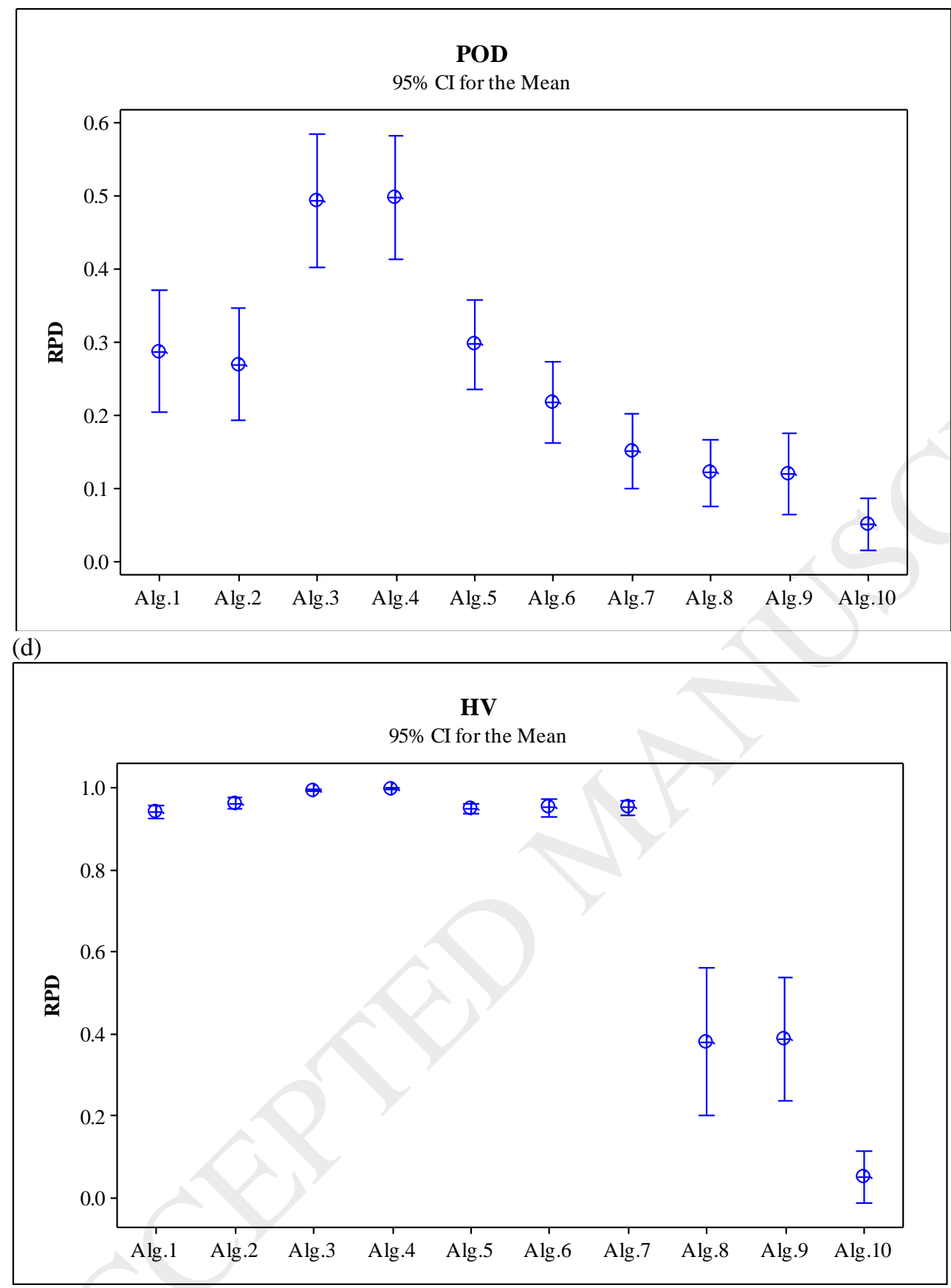

(e)

Fig. 7. Means plot and LSD intervals to specify RPD for evaluation parameter in the medium and large sizes of test problem (i.e. (a) for DM, (b) for SNS, (c) for DEA, (d) for POD and (e) for HV).

To verify the statistical validity of the results, an analysis of variance (ANOVA) has been performed to accurately analyze the results (as seen in Table 12, 13 and 14 based on the RPD). The results demonstrate that there is a clear statistically significant difference between the performances of the algorithms. The means plot and LSD intervals (at the $95 \%$ confidence level) for all methods are shown in Fig. 6 and 7. 
From Fig. 6, the statistical results of metaheuristics are provided for the small sizes of test problems. Based on these computational results, the exact method in all metrics except SNS and HV reaches a better performance. In SNS, RDKAGA (Alg. 10) shows a better behavior (Fig. 6 (b)). Also, RDKAGA reveals a robust performance in comparison of other algorithms in $\mathrm{HV}$ metric (Fig. 6 (e)). Overall, it can be resulted all proposed three hybrid optimizers reach a satisfied output. Among these algorithms, RDKAGA shows the best performance in the small sizes of problem developed.

From Fig. 7, a comprehensive comparison has been considered for the employed metaheuristics based on the results in the medium and large sizes of test problem. In this figure, the algorithms are explored for all of size of problems based on the evaluation metrics. Regarding to the assessment metrics, a mixed performance can be seen for RDKAGA (Alg.10). Based on DM metric (Fig. 7(a)), RDKAGA shows a clear difference between other hybrid metaheuristics and their individual ones. While NSGA-II (Alg. 3) shows the worst behavior, RDKAGA depicts a clear performance and finds a better solution in this item. Additionally, according to SNS metric (Fig. 7(b)), in the first glance, the proposed three novel metaheuristic algorithms show the better values. Although, RDKAGA is better than others, multi-objective of SA (Alg. 4) shows the lowest performance, clearly. Also, based on DEA metric (Fig. 7(c)), some similarities can be seen like two prior evaluation metrics. In this regard, multi-objective of SA and NSGA-II are clearly shows a clear difference and reaches a weak performance in comparison of other metaheuristics. Besides, RDKAGA is better than others in this item. In terms of POD metric (Fig. 7(d)), some similarities results can be concluded. Regarding the most important evaluation metric i.e. HV (Fig. 7(e)), there is a clear difference between the applied metaheuristics (Alg.1 to Alg. 7) and three new hybrid optimizers. Among these hybrid optimizers, RDKAGA shows the best performance in this regard. In conclusion, the results provided show the superiority of the novel hybrid approaches as well as the effectiveness and efficiency of RDKAGA (Alg.10) in practice.

Finally, to compare the solution sets of adopted and proposed metaheuristics in a visual way (qualitatively), the parallel coordinates plot [82] is drawn in Fig. 8 to see the convergences and diversity of solutions found for the multi-objective problem investigated. Due to the large number of case studies, P8 is selected as a sample test problem. In this case, the numbers of nondominated solutions for Alg. 1 to Alg. 10 are 12, 11, 8, 10, 11, 13, 11, 13, 13 and 15, respectively. For instance, S1 to S15 are the set of solutions for Alg. 10. Since the range and unit of each objective function are not the same, the normalized values of solutions have been considered. The positive and negative ideal solutions (the best and the worst values for each objective function) adopted from the exact method are used to normalize the solutions set of metaheuristics [83]. Inspecting the parallel coordinates figures, it is evident that the diversity of the proposed hybrid methods i.e. Alg. 8, 9 and 10 are better than other algorithms. 


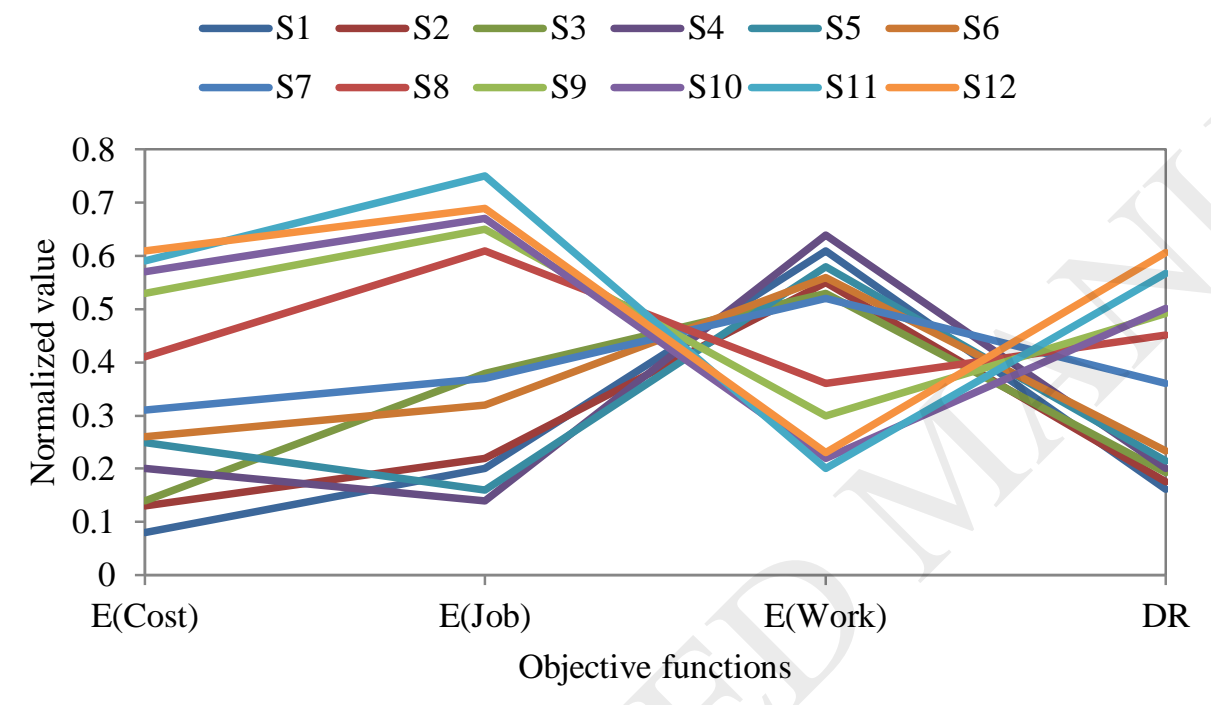

(a) Alg. 1

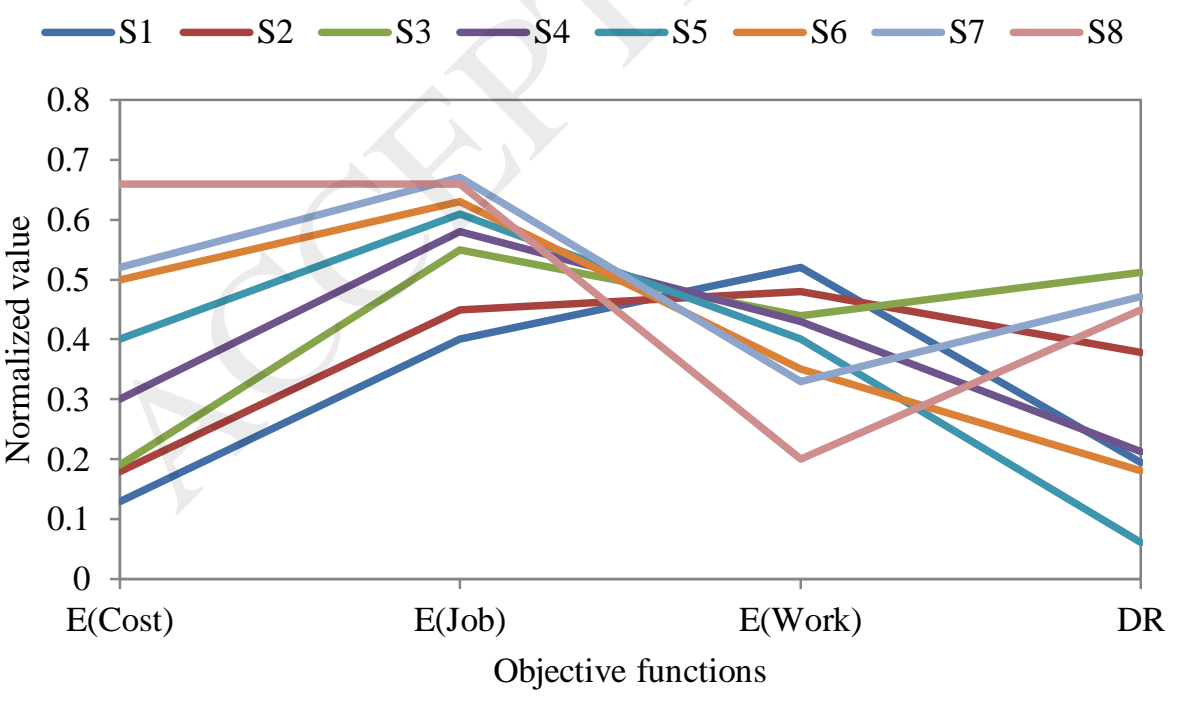

(c) Alg. 3

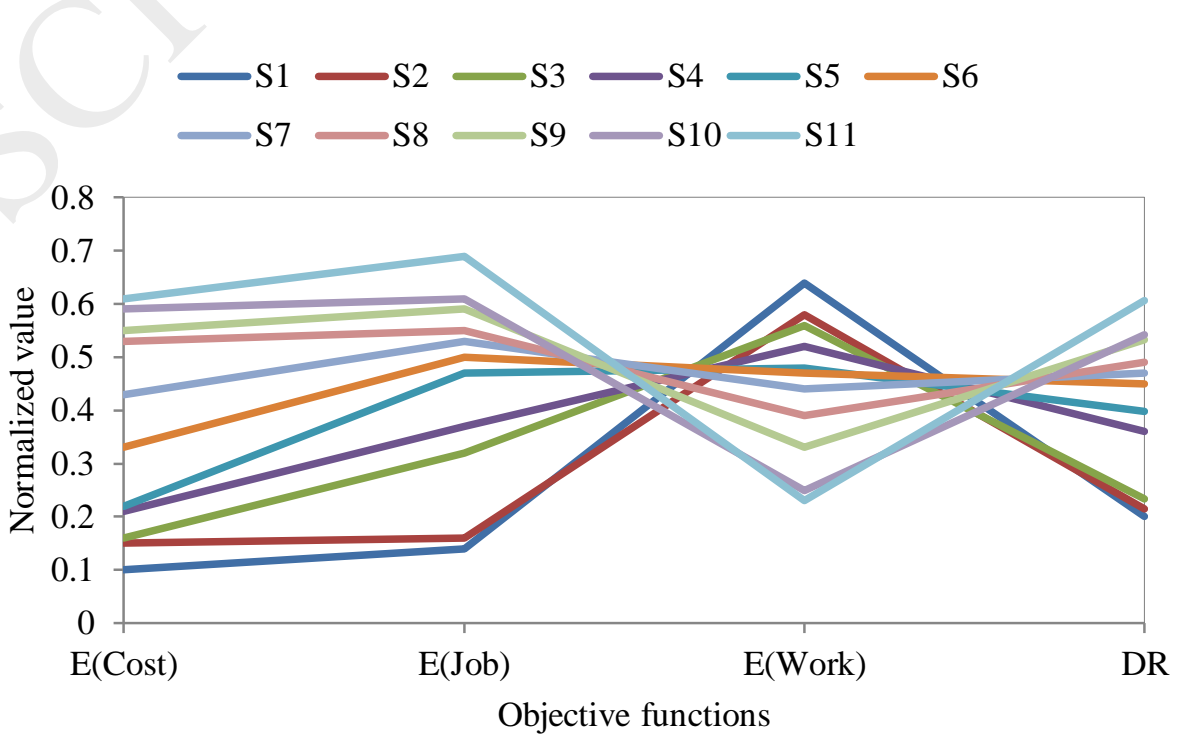

(b) Alg. 2

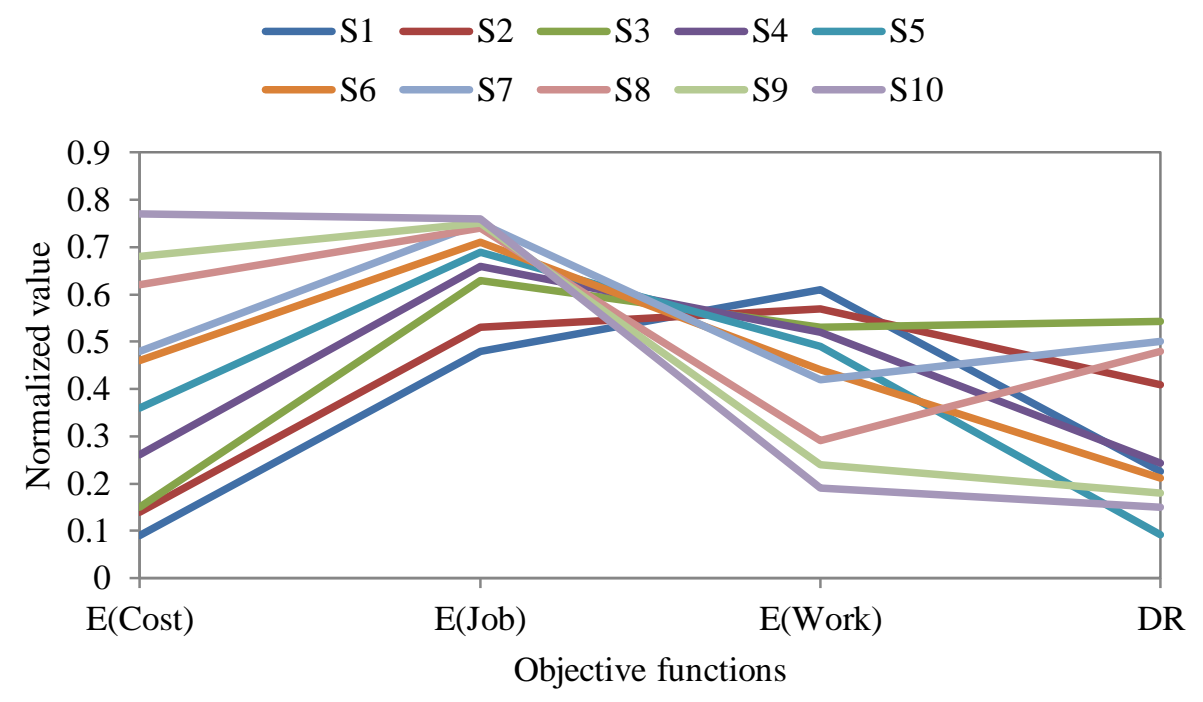

(d) Alg. 4 


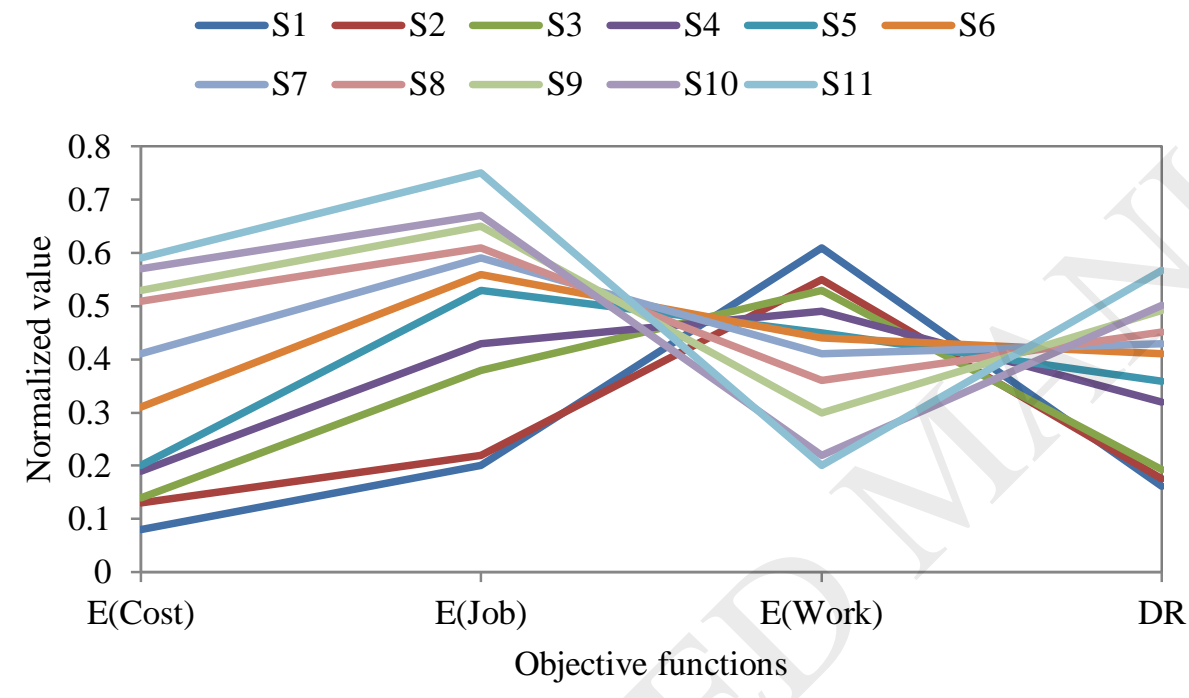

(e) Alg. 5

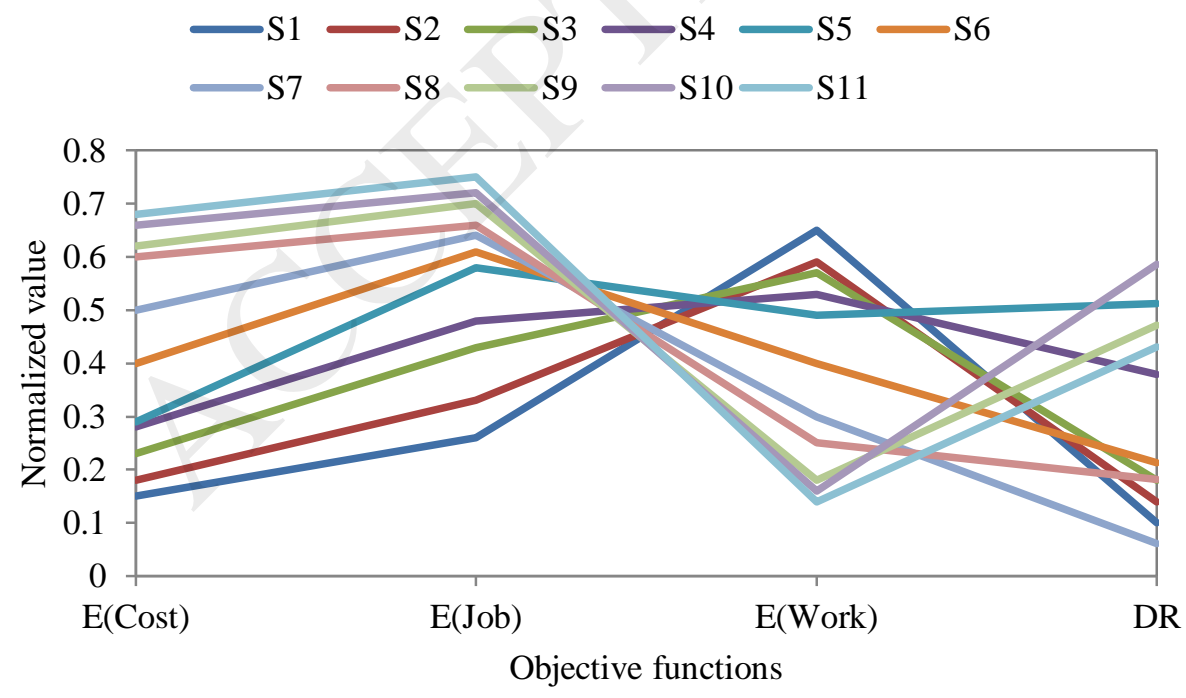

(g) Alg. 7

$$
\begin{array}{r}
-\mathrm{S} 1-\mathrm{S} 2-\mathrm{S} 3-\mathrm{S} 4-\mathrm{S} 5-\mathrm{S} 6-\mathrm{S} 7 \\
-\mathrm{S} 8-\mathrm{S} 9-\mathrm{S} 10-\mathrm{S} 11-\mathrm{S} 12-\mathrm{S} 13
\end{array}
$$

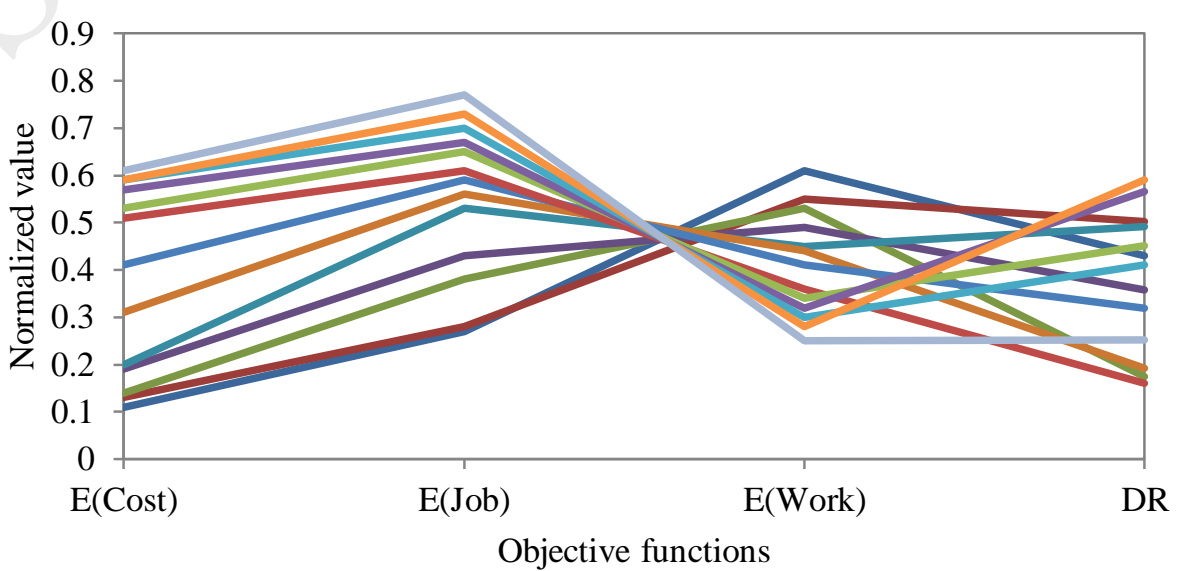

(f) Alg. 6

$$
\begin{array}{r}
-\mathrm{S} 1-\mathrm{S} 2-\mathrm{S} 3-\mathrm{S} 4-\mathrm{S} 5-\mathrm{S} 6-\mathrm{S} 7 \\
\mathrm{~S} 8-\mathrm{S} 9-\mathrm{S} 10-\mathrm{S} 11-\mathrm{S} 12-\mathrm{S} 13
\end{array}
$$

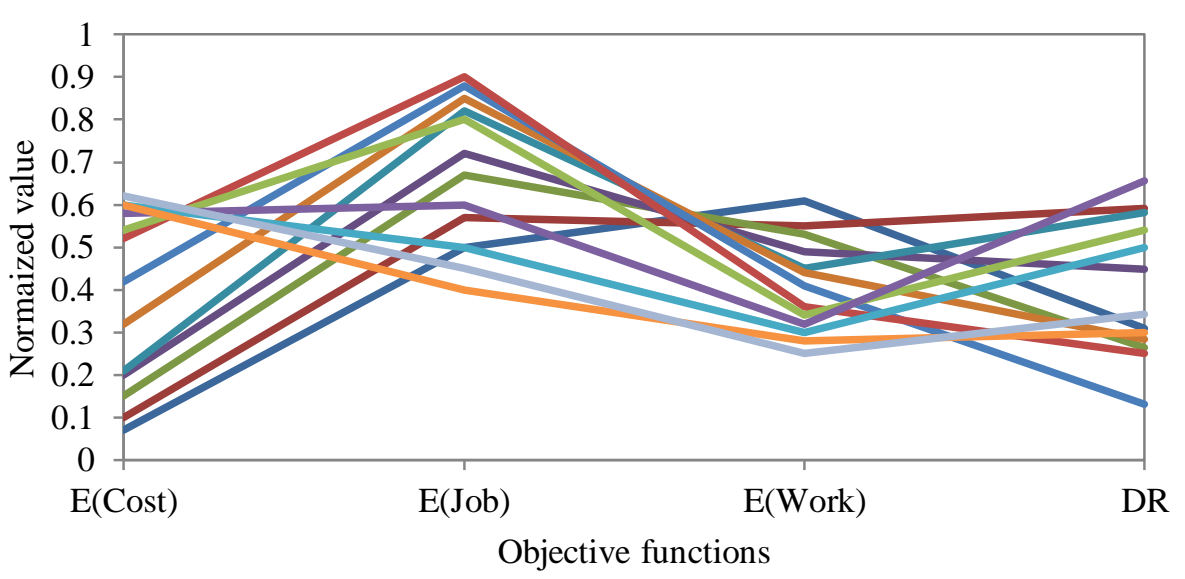

(h) Alg. 8 


$$
-\mathrm{S} 1-\mathrm{S} 2-\mathrm{S} 3-\mathrm{S} 4-\mathrm{S} 5-\mathrm{S} 6-\mathrm{S} 7
$$

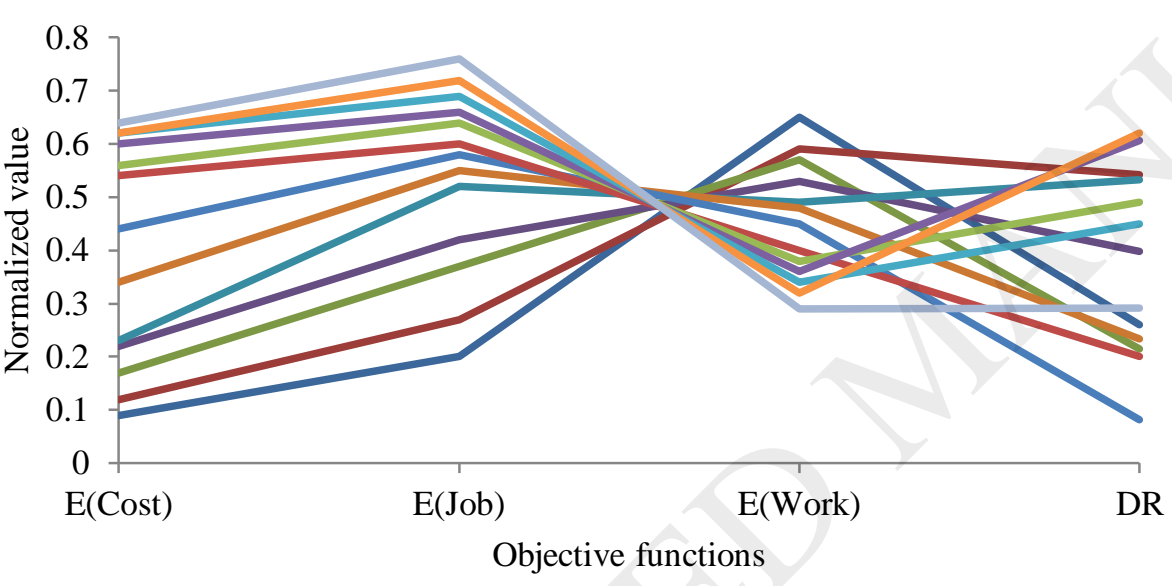

(i) Alg. 9

Fig. 8. The parallel coordinates plot for each metaheuristic in a sample test problem i.e. P8

$$
\begin{array}{r}
\mathrm{S} 1-\mathrm{S} 2-\mathrm{S} 3-\mathrm{S} 4-\mathrm{S} 5-\mathrm{S} 6-\mathrm{S} 7-\mathrm{S} 8 \\
\mathrm{~S} 9-\mathrm{S} 10-\mathrm{S} 11-\mathrm{S} 12-\mathrm{S} 13-\mathrm{S} 14-\mathrm{S} 15
\end{array}
$$

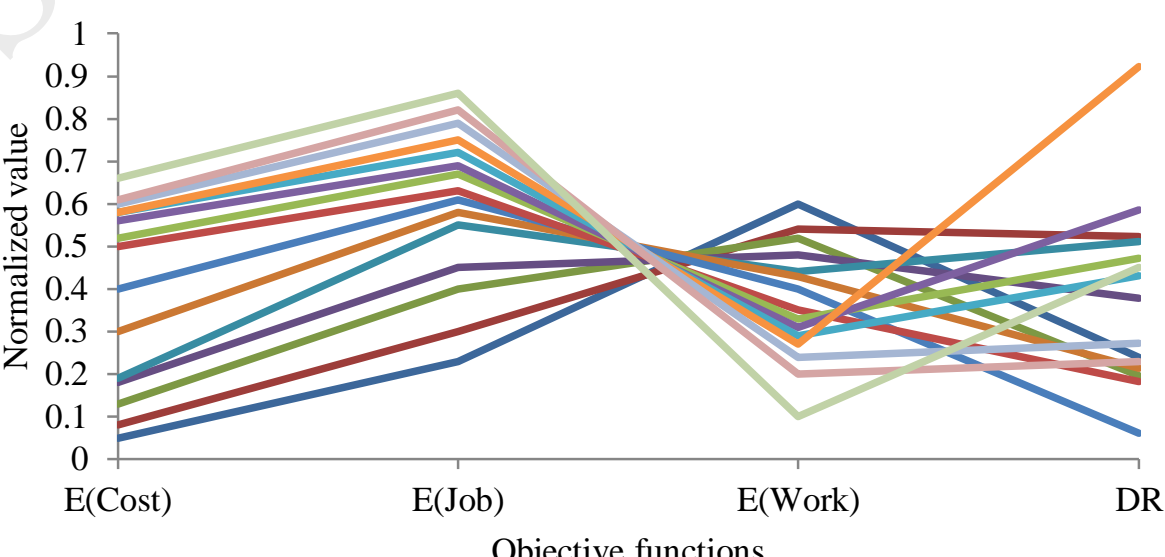

(j) Alg. 10 


\subsection{Sensitivity analyses on the social considerations along with downside risk management}

Here, a real data set adopted from Devika et al., [5] has been utilized to perform a set of sensitivity analyses on the risk management of model proposed. Glass industry is one of the real applications of CLSC developed. Due to page limitation, the details of this real application of model has not been presented and referred to [5]. Regarding the provided sensitivity analyses, the impact of considered risk management on the economic and social objectives has been analyzed.

Regarding the risk management, two phases are set. In the first one, the value of risk and the target of $\varphi$ are assumed as 0 , respectively. Accordingly, the three other objectives are computed. Consequently, by considering the risk management, we calculate the objectives again.

To do these experiments, the best algorithm in this study i.e. RDKAGA is applied. This optimizer is run for 10 times. The best run is saved and presented in Table 15. The nine nondominated solutions are numbered as S1 to S9, accordingly. Note that 10 scenarios have been considered similar to Table 8, as well. Regarding the table provided, each solution has been analyzed by considered risk management methodology.

Table 15

The values of economic and social objectives before and after risk measure in different cases.

\begin{tabular}{|c|c|c|c|c|c|c|c|c|c|c|}
\hline \multirow{2}{*}{$\begin{array}{l}\text { The } \\
\text { number } \\
\text { of } \\
\text { solutions }\end{array}$} & \multicolumn{3}{|c|}{ Before the risk } & \multicolumn{3}{|c|}{ After the risk } & \multirow{2}{*}{$\begin{array}{l}\text { Downside } \\
\operatorname{risk}(\varphi= \\
10 \text { milions } \\
\text { Rial })\end{array}$} & \multirow{2}{*}{$\begin{array}{l}\text { Gap of } \\
\mathrm{E}(\text { Cost })^{*} \\
(\%)\end{array}$} & \multirow{2}{*}{$\begin{array}{l}\text { Gap of } \\
\mathrm{E}(\mathrm{Job})^{*} \\
(\%)\end{array}$} & \multirow{2}{*}{$\begin{array}{l}\text { Gap of } \\
\mathrm{E}(\text { Work) } \\
(\%)\end{array}$} \\
\hline & $\mathrm{E}(\mathrm{Cost})^{*}$ & $\mathrm{E}(\mathrm{Job})^{*}$ & $\mathrm{E}$ (Work)* & $\mathrm{E}(\text { Cost })^{*}$ & $\mathrm{E}(\mathrm{Job})^{*}$ & $\mathrm{E}\left(\right.$ Work) ${ }^{*}$ & & & & \\
\hline S1 & 1.142 & 1.89 & 1.883 & 1.184 & 2.2 & 1.989 & 184.32 & 3.677 & 16.402 & 5.629 \\
\hline $\mathrm{S} 2$ & 1.156 & 1.75 & 2.638 & 1.251 & 2.15 & 2.658 & 235.17 & 8.217 & 22.857 & 0.758 \\
\hline S3 & 1.218 & 1.7 & 3.192 & 1.243 & 2.1 & 3.332 & 256.19 & 2.052 & 23.529 & 4.385 \\
\hline S4 & 1.243 & 1.65 & 3.752 & 1.263 & 2.05 & 3.354 & 243.75 & 1.609 & 24.242 & -10.607 \\
\hline S5 & 1.257 & 1.65 & 4.295 & 1.271 & 2.033 & 4.098 & 251.66 & 1.113 & 23.212 & -4.586 \\
\hline S6 & 1.273 & 1.54 & 4.948 & 1.263 & 1.89 & 4.966 & 274.52 & -0.785 & 22.727 & 0.363 \\
\hline S7 & 1.282 & 1.4 & 5.631 & 1.312 & 1.887 & 5.699 & 238.44 & 2.340 & 34.785 & 1.207 \\
\hline S8 & 1.322 & 1.39 & 6.184 & 1.334 & 1.76 & 6.548 & 262.75 & 0.907 & 26.618 & 5.886 \\
\hline S9 & 1.342 & 1.388 & 6.729 & 1.362 & 1.752 & 7.282 & 286.29 & 1.490 & 26.224 & 8.218 \\
\hline
\end{tabular}

*The values of $\mathrm{E}(\mathrm{Cost})$ are based on the million Rials $\left(10^{6}\right)$ and the expected of social impacts i.e. E(Job) and E(Work) are based on the $10^{4}$

Regarding the risk methodology, the outputs of proposed algorithms regarding the before and after the downside risk, are given in Table 15. In order to emphasize the changes of three economic and social objectives, a metric is presumed by Equation (39) in the following:

Gap $=100 \times \frac{\text { Value after the risk }- \text { Value before the risk }}{\text { Value before the risk }}$ 
From Table 15, the impact of the changes of expected total cost (E(Cost)) which should be minimized, expected job opportunity (E(Job)) which should be maximized and expected work damages (E(Work)) which should be minimized, has been illustrated, satisfactorily. To depict the deviation of the changes of mentioned objective functions, Fig. 9 has been provided, accordingly. Generally, the downside risk model shows an impressive effect on the objective functions. Regarding the expected total cost and work damages as the minimizing objective functions, in some solutions, a decrease can be seen. Overall, except S1 and S2, the downside risk model for expected total cost is successful to control the uncertainty and to achieve a robust solution in this regard. Similarly, regarding the expected work damages, the deviation of changes has been reduced in general. Except S1, S3, S8 and S9, the risk model can control and improve the expected work damages. Finally, regarding the expected job opportunity which should be maximized, the risk model is completely successful to generate a robust answer. In all solutions, an increase is resulted after the risk management. Generally speaking, the considered risk model can help to decision maker to control the uncertainty and to achieve a better candidate solution against uncertainty.

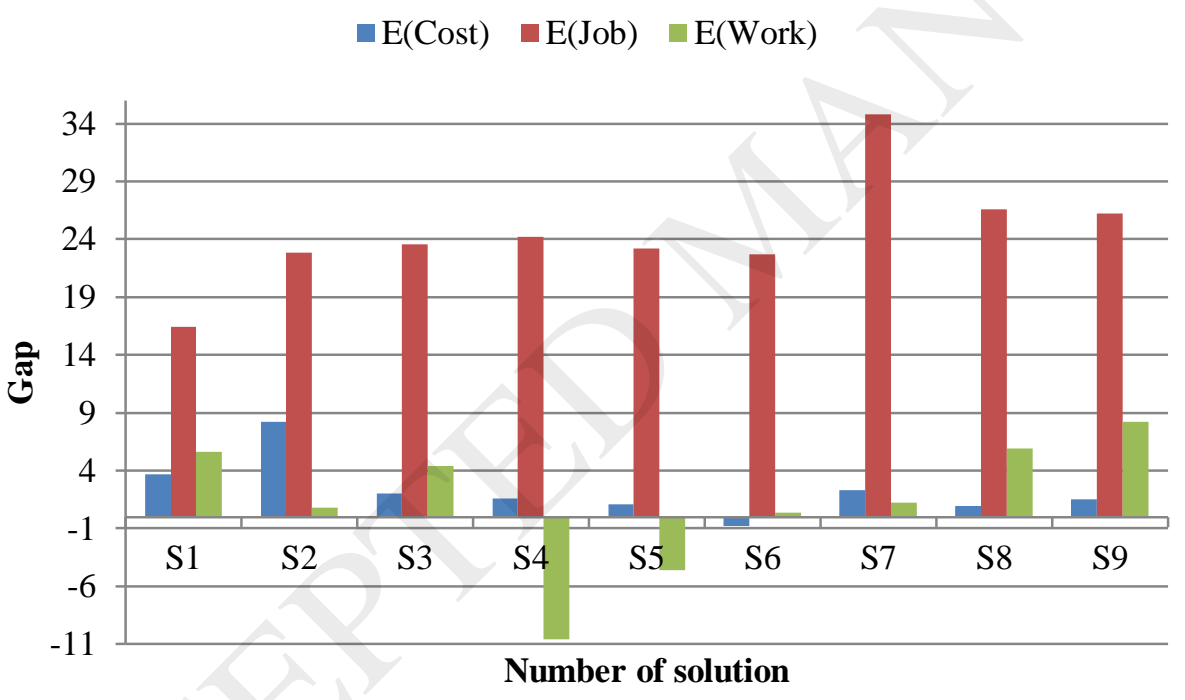

Fig. 9. The Gap behavior of objective functions regarding the downside risk methodology

\section{Conclusion and future works}

In this work, three novel hybrid metaheuristics were applied to a strategically CLSC with four distinguished objectives including the economic and social dimensions along with the downside risk management of model presented. Regarding literature review, a comprehensive survey on the classifications of previous works in SCND was first provided. Then, a number of recent and state of art multi-objective metaheuristic techniques were utilized in this research area. In this regard, NSGA-II, SA, KA and RDA were employed. Consequently, the advantages and disadvantages of all algorithms were analyzed. 
Another contribution of the paper was the development of three new hybridization methods. We also highlighted the need of utilizing the hybridization methods to design an intelligent solver. In order to check the satisfying of metaheuristics results, the $\varepsilon$-constraint method was used. Besides, RSM was applied to adjust the parameters of metaheuristics and better performance of them. In addition, by utilizing five evaluation metrics including DM, SNS, POD, DEA and HV, the effectiveness and efficiency of methods were measured. As a result, a comparative study showed that the RDKAGA algorithm among the other proposed hybrid algorithms outperforms the current algorithms in literature in the problem area investigated. Furthermore, by employing a case study, the performance of RDKAGA and the efficiency of developed formulation had been analyzed. The main managerial insights of the paper can stated as follows:

- The used constraints in our developed model such as capacity constraints are more likely to be efficient in a real world. In this way, adopted decisions by managers should consider an interaction for social aspects and other sustainability dimensions.

- The uncertainty of parameters in the real world is so challenging. This study considered a downside risk model to control the uncertainty. So, estimating suitable values of these parameters by using a proper database is helpful to enhance the performance of downside risk approach as the managerial insights.

- Executive constraints such as the prices of products for in each level are also significant. Also, according to the analyses, it can affect on the other parts of the model and its outputs. Therefore, controlling and setting a suitable decision for these parameters are so valuable for developed closed-loop supply chain network.

- Managers usually need an efficient and quick solution approach to decide a proper decision. So, this study by proposing three novel metaheuristics showed that RDKAGA algorithm is one of most effective and efficiency solution method in the literature to provide a quick and performance solution for the decision-makers of closed-loop supply chain network.

For future works, more comprehensive analyses on our proposed model may be required to be explored. Furthermore, our model can be employed by some other real study cases such as mine or gold industry along with their special characteristics. Generally, there are a set of new directions to expand the mathematical model for our new works. From the economic dimension of CLSC proposed, the model can be added by more real-life constraints such as cross-docking operations and vehicle routing practicing which can be diminished the transportation total cost by utilizing same facility in forward and reverse logistics and can also be abated the capacity of vehicles which is unused all of them by considering a stochastic model. Regarding the social dimensions of proposed model, some other social impacts based on other guidelines can be recommended, as well. Finally, the proposed risk model may be compared with some other risk models to achieve a robust solution against uncertainty. 


\section{References:}

[1] F., Sgarbossa, I., Russo, "A proactive model in sustainable food supply chain: Insight from a case study." International Journal of Production Economics, 183, (2017), 596-606.

[2] A. M. Fathollahi Fard, \& M. Hajiaghaei-Keshteli, M. "A tri-level location-allocation model for forward/ reverse supply chain." Applied Soft Computing, 62, (2018), 328-346.

[3] A. Samadi, N. Mehranfar, A. M. Fathollahi Fard \& M Hajiaghaei-Keshteli, "Heuristic-based metaheuristics to address a sustainable supply chain network design problem." Journal of Industrial and Production Engineering, (2018), 35 (2), 102-117.

[4] A. M. Fathollahi Fard, F. Gholian-Jouybari, M. M. Paydar, \& M. Hajiaghaei-Keshteli, “A Bi-Objective Stochastic Closed-loop Supply Chain Network Design Problem Considering Downside Risk." Industrial Engineering \& Management Systems, 16(3), (2017), 342-362.

[5] K. Devika, A. Jafarian, V. Nourbakhsh, "Designing a sustainable closed-loop supply chain network based on triple bottom line approach: A comparison of metaheuristics hybridization techniques." European Journal of Operation Research, 235, (3), (2014), 594-615.

[6] M., Hajiaghaei-Keshteli, \& A. M., Fathollahi Fard, (2018). Sustainable Closed-loop Supply Chain Network Design with Discount Supposition. Neural Computing and Applications, 1-25.

[7] R. Babazadeh, J. Razmi, M. S. Pishvaee, M. Rabbani, "A sustainable second-generation biodiesel supply chain network design problem under risk." Omega, 66, (2017), 258-277.

[8] C., Arampantzi, I., Minis, I. "A new model for designing sustainable supply chain networks and its application to a global manufacturer." Journal of Cleaner Production, 156, (2017), 276-292.

[9] Ç. Koç, "An evolutionary algorithm for supply chain network design with assembly line balancing." Neural Computing and Applications, 28(11), (2017), 3183-3195.

[10] K. Govindan, P. Paam, A. Abtahi, "A fuzzy multi-objective optimization model for sustainable reverse logistics network design.” Ecological Indicators, 67, (2016), 753-768.

[11] D. L. Spar, L. T. La Mure, "The power of activism: Assessing the impact of NGOs on global business." California Management Review, 45, (3), (2003), 78-101.

[12] K. Govindan, A. Jafarian, V. Nourbakhsh, "Biobjective integrating sustainable order allocation and sustainable supply chain network strategic design with stochastic demand using a novel robust hybrid multi-objective metaheuristic." Computers \& Operations Research, 62, (2015), 112-130.

[13] F. Dehghanian, S. Mansour, "Designing sustainable recovery network of end-of-life products using genetic algorithm." Resources Conservation and Recycling, 53, (10), (2009), 559-570.

[14] V. Jayaraman, H. Pirkul, "Planning and coordination of production and distribution facilities for multiple commodities." European Journal of Operational Research, 133, (2), (2001), 394-408.

[15] M. Pishvaee, K. Kianfar, B. Karimi, Reverse logistics network design using simulated annealing. The International Journal of Advanced Manufacturing Technology, 47, (1), (2010), 269-281.

[16] E.H. Sabri, B.M. Beamon, A multi-objective approach to simultaneous strategic and operational planning in supply chain design, Omega, 28 (2000) 581-598.

[17] M.S. Daskin, L.V. Sriyder, R.T. Berger, Facility location in supply chain design, in: A. Lan gevin, D. Riopel (Eds.), Logistics Systems: Design and Optimization, Kluwer, 2003, pp. 39-65. Chapter 2.

[18] M. Pishvaee, J. Razmi, S. A. Torabi, "Robust possibilistic programming for socially responsible supply chain network design: A new approach." Fuzzy Sets and Systems, 206, (0), (2012a), 1-20.

[19] M. Pishvaee, S. A. Torabi, J. Razmi, "Credibility-based fuzzy mathematical programming model for green logistics design under uncertainty." Computers and Industrial Engineering, 62, (2), (2012b), 624-632.

[20] A. M. Fathollahi Fard, M. Hajiaghaei-Keshteli, "Red Deer Algorithm (RDA); A New Optimization Algorithm Inspired by Red Deers' Mating." $12^{\text {th }}$ International Conference on Industrial Engineering (ICIE 2016), IEEE, Tehran, Iran, (2016), 34-35. 
[21] M. Hajiaghaei-Keshteli, M. Aminnayeri, "Keshtel Algorithm (KA); a new optimization algorithm inspired by Keshtels' feeding." Proceeding in IEEE Conference on Industrial Engineering and Management Systems (2013), 2249-2253.

[22] P. Sasikumar, G. Kannan, "Issues in reverse supply chains, Part I: End-of-life product recovery and inventory management - An overview." International Journal of Sustainable Engineering, 1, (3), (2008a), 154-172.

[23] P. Sasikumar, G. Kannan, "Issues in reverse supply chain, Part II: Reverse distribution issues - an overview." International Journal of Sustainable Engineering, 1, (4), (2008b), 234-249.

[24] P. Sasikumar, G. Kannan, "Issues in reverse supply chain, Part III: Classification and simple analysis." International Journal of Sustainable Engineering, 2(1), (2009), 2-27.

[25] S. Pokharel, A. Mutha, "Perspectives in reverse logistics: A review." Resources, Conservation and Recycling, 53, (4), (2009), 175-182.

[26] P. Yi, M. Huang, L. Guo, T. Shi, "A Retailer Oriented Closed-loop Supply Chain Network Design for End of Life Construction Machinery Remanufacturing.” Journal of Cleaner Production, 124, (2016), 191-203.

[27] D. Kannan, A. Diabat, M. Alrefaei, K. Govindan, G. Yong, "A carbon footprint based reverse logistics network design model." Resources Conservation and Recycling, 67, (2012), 75-79.

[28] S. K. Srivastava, "Network design for reverse logistics." Omega, 36, (4), (2008), 535-548.

[29] Z. Ardalan, S. Karimi, B. Naderi, A. Arshadi Khamseh, "Supply chain networks design with multi-mode demand satisfaction policy." Computers and Industrial Engineering, 96, (2016), 108-117.

[30] M., Zhalechian, R., Tavakkoli-Moghaddam, B., Zahiri, M., Mohammadi, "Sustainable design of a closed-loop location-routing-inventory supply chain network under mixed uncertainty." Transportation Research Part E: Logistics and Transportation Review, 89, (2016), 182-214.

[31] N., Tahirov, P., Hasanov, M. Y., Jaber, "Optimization of closed-loop supply chain of multi-items with returned subassemblies." International Journal of Production Economics, 174, (2016), 1-10.

[32] H., Soleimani, K., Govindan, H., Saghafi, H., Jafari, "Fuzzy multi-objective sustainable and green closed-loop supply chain network design." Computers \& Industrial Engineering, 109, (2017), 191-203.

[33] A. Dasci, V. Verter, “A continuous model for production-distribution system design.” European Journal of Operational Research, 129, (2), (2001), 287-298.

[34] V. Jayaraman, A. Ross, "A simulated annealing methodology to distribution network design and management." European Journal of Operational Research, 144, (3), (2003), 629-645.

[35] P. A. Miranda, R. A. Garrido, "Incorporating inventory control decisions into a strategic distribution network design model with stochastic demand." Transportation Research Part E: Logistics and Transportation Review, 40, 3, (2004), 183-207.

[36] F. Wang, X. Lai, N. Shi, “A multi-objective optimization for green supply chain network design.” Decision Support Systems, 51, (2), (2011a), 262-269.

[37] M. C. Georgiadis, P. Tsiakis, P. Longinidis, M. K. Sofioglou, "Optimal design of supply chain networks under uncertain transient demand variations." Omega, 39, (3), (2011), 254-272.

[38] A. Syarif, Y. Yun, M. Gen, "Study on multi-stage logistic chain network: A spanning tree-based genetic algorithm approach." Computers and Industrial Engineering, 43, (1-2), (2002), 299-314.

[39] S. Elhedhli, R. Merrick, "Green supply chain network design to reduce carbon emissions." Transportation Research Part D: Transport and Environment, 17, (5), (2012), 370-379.

[40] Listeş, O., \& Dekker, R. (2005). A stochastic approach to a case study for product recovery network design. European Journal of Operational Research, 160(1), 268-287.

[41] M. C. Fonseca, Á. García-Sánchez, M. Ortega-Mier, F. Saldanha-da-Gama, "A stochastic bi-objective location model for strategic reverse logistics." Top, 18, (1), (2010), 158-184.

[42] Cruz-Rivera, R., \& Ertel, J. (2009). Reverse logistics network design for the collection of end-of-life vehicles in Mexico. European Journal of Operational Research, 196(3), 930-939.

[43] M. Fleischmann, P. Beullens, J. M. Bloemhof-Ruwaard, L. N. Van Wassenhove, "The impact of product recovery on logistics network design.” Production and Operations Management, 10, (2), (2001), 156-173. 
[44] Demirel, N. Ö., \& Gökçen, H. (2008). A mixed integer programming model for remanufacturing in reverse logistics environment. The International Journal of Advanced Manufacturing Technology, 39(11-12), 11971206.

[45] A. Chaabane, A. Ramudhin, M. Paquet, "Design of sustainable supply chains under the emission trading scheme." International Journal of Production Economics, 135, (1), (2012), 37-49.

[46] H. F. Wang, H. W. Hsu, "A closed-loop logistic model with a spanning-tree based genetic algorithm." Computers and Operations Research, 37, (2), (2010), 376-389.

[47] Ramezani, M., Bashiri, M., \& Tavakkoli-Moghaddam, R. (2013). A new multi-objective stochastic model for a forward/reverse logistic network design with responsiveness and quality level. Applied Mathematical Modelling, 37(1-2), 328-344.

[48] H. Soleimani, G. Kannan, "A Hybrid particle swarm optimization and genetic algorithm for closed-loop supply chain network design in large-scale networks." Applied Mathematical Modeling, 39, (14), (2015), 3990-4012.

[49] M. Zohal, H. Soleimani, "Developing an Ant Colony Approach for Green Closed-Loop Supply Chain Network Design: A Case Study in Gold Industry." Journal of Cleaner Production, 133, (2016), 314-337.

[50] F. Schultmann, M. Zumkeller, O. Rentz, "Modeling reverse logistic tasks within closed-loop supply chains: An example from the automotive industry." European Journal of Operational Research, 171(3), (2006), 10331050.

[51] Y. C. Tsao, J. C. Lu, "A Supply Chain Network Design considering Transportation Cost.” Transportation Research Part E, 48, (2012) 401-414.

[52] H. Soleimani, M. S. Esfahani, K. Govindan, "Incorporating risk measures in closed-loop supply chain network design.” International Journal of Production Research, 52, (6), (2014), 1843-1867.

[53] C. Eckert, J. Gottlieb, "Direct representation and variation operators for the fixed charge transportation problem.” In J. Guervós, P. Adamidis, H.-G. Beyer, H. P. Schwefel, J.-L. Fernández-Villacañas (Eds.), "Parallel problem solving from nature."-PPSN VII (2002), (pp. 77-87), Berlin, Heidelberg: Springer.

[54] J.-B Jo, Y. Li, M. Gen, "Nonlinear fixed charge transportation problem by spanning tree-based genetic algorithm." Computers and Industrial Engineering, 53, (2), (2007), 290-298.

[55] Beno 1t, C., Mazijn, B. (Eds.), 2009. Guidelines for Social Life Cycle Assessment of Products. UNEP.

[56] ISO, 2010. Final Draft International Standard ISO/FDIS 26000:2010(E), Guidance on Social Responsibility.

[57] SAI, 2008. Social Accountability 8000 (SA8000), International Standard. SAI, New York.

[58] H.-W. Hsu, H.-F. Wang, "Modeling of green supply logistics. In H.-F. Wang (Ed.), Web-based green products life cycle management systems: Reverse supply chain utilization." USA: IGI Global Publication (2009), (pp. 268-282).

[59] M. J. Yao, H. W. Hsu, "A new spanning tree-based genetic algorithm for the design of multi-stage supply chain networks with nonlinear transportation costs." Optimization and Engineering, 10, (2), (2009), 219-237.

[60] E. Van Der Laan, M. Salomon, R. Dekker, L.Van Wassenhove, "Inventory control in hybrid systems with remanufacturing." Management Science, 45(5), (1999), 733-747.

[61] S., Saremi, S., Mirjalili, \& A., Lewis, "Grasshopper optimisation algorithm: Theory and application.” Advances in Engineering Software, 105, (2017), 30-47.

[62] S., Mirjalili, A. H., Gandomi, S. Z., Mirjalili, S. Saremi, H., Faris, \& S. M., Mirjalili, "Salp swarm algorithm: a bio-inspired optimizer for engineering design problems." Advances in Engineering Software, 114, (2017), 163-191.

[63] D. H., Wolpert, \& W. G., Macready, (1997). No free lunch theorems for optimization. IEEE transactions on evolutionary computation, 1(1), 67-82.

[64] S., Mirjalili, \& A. H., Gandomi, "Chaotic gravitational constants for the gravitational search algorithm.” Applied Soft Computing, 53, (2017), 407-419.

[65] S. Golmohamadi, R. Tavakkoli-Moghaddam, \& M. Hajiaghaei-Keshteli, "Solving a fuzzy fixed charge solid transportation problem using batch transferring by new approaches in meta-heuristic." Electronic Notes in Discrete Mathematics, 58, (2017), 143-150. 
[66] K. Deb, S. Agrawal, A. Pratap, T. Meyarivan, “A fast elitist non-dominated sorting genetic algorithm for multiobjective optimization: NSGA-II.” In International Conference on Parallel Problem Solving From Nature (pp. 849-858). Springer Berlin Heidelberg, (2000, September).

[67] S. Kirkpatrick, C. D. Gelatto, M. P. Vecchi, “Optimization by simulated annealing." Science, 220, (1983), 671680.

[68] A. Golshahi-Roudbaneh, M. Hajiaghaei-Keshteli, \& M. M. Paydar, "Developing a lower bound and strong heuristics for a truck scheduling problem in a cross-docking center." Knowledge-Based Systems, 129, (2017), $17-38$.

[69] S. Sadeghi-Moghaddam, M. Hajiaghaei-Keshteli, \& M. Mahmoodjanloo, "New approaches in metaheuristics to solve the fixed charge transportation problem in a fuzzy environment." Neural Computing and Applications, (2017), 1-21.

[70] J. Behnamian, S. Fatemi Ghomi, "Hybrid flowshop scheduling with machine and resource-dependent processing times." Applied Mathematical Modelling, 35, (3), (2011), 1107-1123.

[71] G. R. Amin, M. Toloo, "Finding the most efficient DMUs in DEA: An improved integrated model." Computers \& Industrial Engineering, 52, (1), (2007), 71-77.

[72] G. Chen, K. Govindan, M. M. Golias, "A queueing network based multiobjective model to reduce truck emissions at container terminals." Transportation research Part E, 55, (2013), 3-22.

[73] L. While, P. Hingston, L. Barone, S. Huband, A faster algorithm for calculating hypervolume, IEEE Trans. Evol. Comput. 10 (1) (2006) 29-38.

[74] K. Govindan, A. Jafarian, R. Khodaverdi, K. Devika, "Two-echelon multiple-vehicle location-routing problem with time windows for optimization of sustainable supply chain network of perishable food." International Journal of Production Economics, 152, (2014), 9-28.

[75] A., M. Fathollahi Fard, and M. Hajiaghaei-Keshteli. "A bi-objective partial interdiction problem considering different defensive systems with capacity expansion of facilities under imminent attacks." Applied Soft Computing, 68, (2018), 343-359.

[76] R. H. Myers, C. D. Montgomery, C. M. Anderson-Cook. "Response Surface Methodology, Hoboken.” New Jersey: John Wiley \& Sons, Inc 2, (0), (2009), 38.

[77] M. A. Bezerra, R. E. Santelli, E. P. Oliveira, L. S. Villar, L. A. Escaleira, (2008). "Response surface methodology (RSM) as a tool for optimization in analytical chemistry." Talanta, 76, (5), (2008) 965-977.

[78] G. Derringer, R. Suich, "Simultaneous optimization of several response variables." Journal of quality technology, 12, (4), (1980), 214-219.

[79] A. M. Fathollahi-Fard, M., Hajiaghaei-Keshteli, (2018). "A stochastic multi-objective model for a closed-loop supply chain with environmental considerations." Applied Soft Computing, 69, 232-249.

[80] A. M., Fathollahi-Fard, M., Hajiaghaei-Keshteli, \& R., Tavakkoli-Moghaddam, (2018). "The Social Engineering Optimizer (SEO).” Engineering Applications of Artificial Intelligence, 72, 267-293.

[81] N., Sahebjamnia, A. M., Fathollahi-Fard, \& M., Hajiaghaei-Keshteli, (2018). "Sustainable tire closed-loop supply chain network design: Hybrid metaheuristic algorithms for large-scale networks." Journal of Cleaner Production. 196, 273-296.

[82] M. Li, L. Zhen, X. Yao, (2017). "How to Read Many-Objective Solution Sets in Parallel Coordinates." IEEE Computational Intelligence Magazine, 12 (4): 88-100.

[83] A. M. Fathollahi-Fard, M. Hajiaghaei-Keshteli \& S. Mirjalili, (2018). "Hybrid optimizers to solve a tri-level programming model for a tire closed-loop supply chain network design problem." Applied Soft Computing, https://doi.org/10.1016/j.asoc.2018.06.021 


\section{Accepted Manuscript}

Title: Multi-objective stochastic closed-loop supply chain network design with social considerations

Authors: Amir Mohammad Fathollahi-Fard, Mostafa

Hajiaghaei-Keshteli, Seyedali Mirjalili

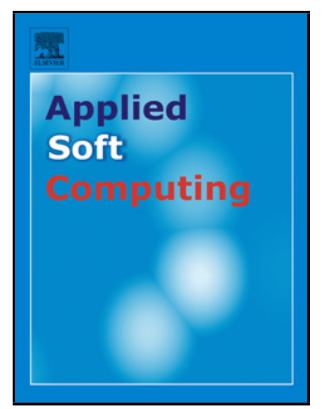

PII:

DOI:

Reference:

To appear in:

Received date:

Revised date:

Accepted date:
S1568-4946(18)30413-7

https://doi.org/10.1016/j.asoc.2018.07.025

ASOC 4993

Applied Soft Computing

23-2-2018

23-6-2018

8-7-2018

Please cite this article as: Fathollahi-Fard AM, Hajiaghaei-Keshteli M, Mirjalili S, Multi-objective stochastic closed-loop supply chain network design with social considerations, Applied Soft Computing Journal (2018), https://doi.org/10.1016/j.asoc.2018.07.025

This is a PDF file of an unedited manuscript that has been accepted for publication. As a service to our customers we are providing this early version of the manuscript. The manuscript will undergo copyediting, typesetting, and review of the resulting proof before it is published in its final form. Please note that during the production process errors may be discovered which could affect the content, and all legal disclaimers that apply to the journal pertain. 